\title{
Hartwig Berger
}

In Verteidigung des ,pueblo" -

Historische Sozialbewegung und heutige Arbeitsemigration in Südspanien

I. Fortschrittsidee und Landgemeinde in der Theorie der Arbeiterbewegung Vorbemerkungen $\mathrm{zu}$ den Teilen II. und III.

II. Das Gesellschaftsbild der andalusischen Agraranarchisten

1. Produktionsverhältnisse und Klassenbewegung

2. Landarbeiterpresse als proletarische Öffentlichkeit

3. Die Ideen des Agraranarchismus

4. Verteidigung der ländlichen Klassenkultur

5. Internationalismus und Persönlichkeitsbegriff der Landarbeiter

III. „Gastarbeiter“ zwischen Landgemeinde und Großstadtleben

1. Die Emigrationsbewegung vom Land

2. Landarbeit und Fabrik

3. Bindungen an das Dorfleben

4. Identitätskrisen und soziale Entfremdung in Westeuropa

5. Großstadtkritik und dörfliche Gemeinschaft

6. Klassensolidarität und Klassenbewußtsein auf dem Land

\section{Fortschrittsidee und Rückgriff auf ländliche Verkehrsformen} in der Theorie der Arbeiterbewegung

Soziale Bewegungen im vorindustriellen Milieu denken sich die befreite Gesellschaft meist als Wiederherstellung alter Zustände, die durch die Eingriffe der herrschenden Klasse in das soziale Leben zerstört oder depraviert worden sind. Im Gegensatz zu dieser rückwärtsgewandten Utopie hat die aufgeklärte Intelligenz der bürgerlichen Gesellschaft einen Begriff sozialen Wandels formuliert, der sich an der Idee gesellschaftlichen Wandels orientiert und die Unzulänglichkeiten der Gegenwart durch konsequente Beseitigung der alten Lebensformen des, ,unwissenden Volks" überwinden will. Nur wenn die Volksklassen (1) aus der überkommenen Welt des Lasters, der Ig-

1 Mit ,Volksklasse“ oder „Volksklassen“ meine ich im folgenden immer alle Schichten der arbeitenden Bevölkerung, soweit sie unter ähnlichen Bedingungen und einer gleichartigen Klassenkultur leben. Für die näher betrachtete Region Andalusiens sind das etwa Landarbeiter, Bau- und (heute) Industrie-Arbeiter, Kleinpächter und Kleinbauern, Handwerker, kleine Händler und Gastwirte. Die Zusammengehörigkeit dieser Schichten wird noch dadurch unterstrichen, daß viele mehrere der genannten Tätigkeitszweige in einem Arbeitsleben, Jahr oder sogar gleichzeitig ausüben. ,,Volksklassen " bestimmen noch heute die soziale Struktur der wenig industrialisierten Landgebiete und Städte Südeuropas. Diese Schichten als ,Proletariat“" zu bezeichnen, ist ebenso irreführend, wie eine Zurechnung der klei- 
noranz, der zeitlosen Muße, der Verkettung des Individuums in sozialen Kollektiven hinausgeführt werden, kann man auf eine entscheidende Verbesserung der Verhältnisse hoffen. Die befreite Gesellschaft gründet auf Emanzipation - sie löst die Abhängigkeit der Volksklassen an ihre naturwüchsigen Traditionen sozialen und kulturellen Lebens, ihre als „Aberglauben“ stigmatisierten Muster geistiger Auseinandersetzung mit der Umwelt, um sie frei und fähig zu machen, ihre sozialen Beziehungen bewußt zu gestalten und ihr Denken über Strukturen und Bewegkräfte der Welt rational zu gliedern. Dem aufgeklärten Begriff gesellșchaftlichen Wandels ist die Verbreitung rückwärtsgewandter Utopien in Volksbewegungen ein Zeichen ihrer Unreife und ihres im Kern reaktionären Charakters.

Die Arbeiterbewegung im frühindustriellen Westeuropa stützte sich, wie die vorindustriellen Umsturzbewegungen, auf ein Bild sozialer Revolution, das Gleichheit, Brüderlichkeit und Gerechtigkeit im alten Leben der Volksklassen wiederherzustellen suchte. Ihre Kapitalismuskritik bildet sie zum Teil durch Idealisierung einer erlebten Vergangenheit. Gegen die neue Wirtschaftsweise, die den Arbeitsprozeß durch abstrakte Zeitrhy thmen, rigide Befehlshierarchien und den Abbau kommunikativer Beziehungen während der Arbeit disziplinierte, die den Lebenstil der Muße, der intensiven Nachbarschaftlichkeit, der Vereinigung in ungehemmt verlebten Gemeinschaftsfesten zu zerstören suchte, machten die Industriearbeiter, Handwerker und Landproletarier im frühkapitalistischen England noch lebensgeschichtliche Erfahrungen kommunalegalitären Zusammenlebens geltend. Die befreite Gesellschaft sollte wesentliche Er rungenschaften der neuen Produktionsweise übernehmen - wie die maschinelle Technologie, die Verallgemeinerung der Schriftkultur und des überlokalen Kommunikationsnetzes - insofern war die Utopie der frühen Arbeiterbewegung progressiv. Gleichzeitig sollte sie Merkmale traditioneller Lebensformen wie die überfamiliäre Solidarität, Gleichheit und Nachbarschaftlichkeit wiederherstellen -- insofern war die Utopie rückwärtsgewandt. Dieser Rückgriff hatte seine materielle Grundlage in der Tatsache, daß große Teile des Industrieproletariats noch in Gemeinwesen mit sozialen Verkehrsregeln und kulturellen Wertmustern aufgewachsen waren, die sich von der Lebenskultur der aufstrebenden bürgerlichen wie der unzeitgemäßen feudalen Klasse deutlich unterschieden. Die lebensgeschichtliche Bindung der frühindustriellen Arbeiter an eine vergleichsweise autonome Volkskultur, bestimmte entscheidend ihre Vorstellungen und Hoffnungen zu einer befreiten Gesellschaft ( 1 a).

nen Bauern und Händler zum „Kleinbürgertum“. Bezeichnenderweise ist in diesen Ländern noch der Ausdruck ,,Volk“ als Klassen- und Kampfbegriff geläufig: ,, el pueblo" , ,,o povo", ,, popolo".

Daneben meint „pueblo“ auch Landgemeinde, die im Mittelmeerraum durchaus Größe und Einwohnerzahl einer Stadt hat. In ihr bildet sich eine gemeinsame Lebensweise und „Kultur" der Volksklasse aus, die in der Regel vom Leben der reichen Klasse deutlich getrennt ist. Auf die Verbindung von Klasse, Landgemeinde und Lebensweise spielt der Titel des Aufsatzes an.

1 a Vgl. dazu W.P. Thompson, The Making of the English Working Class, London 1963, v.a. Kap. 12, ,Community“" Sowie, daran anknüpfend, M. Vester, die Entstehung des Proletariats ais Lemprozeß.

Das Ziel der frühen englischen Arbeiterbewegung, die kapitalistische Produktionsweise schon in ihren Anfängen zu zerstören und rückgreifend auf alte Lebensformen der Volks- 
Die marxistische Theorie sozialer Revolutionen verbindet den Antikapitalismus der frühen Arbeiterbewegung mit dem Fortschrittsbegriff der bürgerlichen Aufklärung. Rückwärtsgewandte Utopien gelten ihr als irreale Verheißungen, hinter denen sich im Kern reaktionäre Handlungsziele verstecken. Die Befreiung von Ausbeutung und Herrschaft schließt eine Wiederbelebung der plebejischen Lebensformen aus, die der Kapitalismus schrittweise eingeschränkt oder zerstört hat. Die historische Destruktivität des Kapitals hat insofern auch eine „zivilisierende Wirkung“, als sie Produktionsweise und soziale Verkehrsformen einer befreiten Zukunftsgesellschaft vorbereitet. Sie ermöglicht eine qualitativ neue Vergesellschaftung der Arbeit und begründet durch die weltweite Verflechtung von Produktion und Verteilung eine Universalisierung der menschlichen Beziehungen: sie sprengt die Fesseln lokal begrenzter Kommunalität und ihrer vorrationalen kulturellen Traditionen, sie erweitert den menschlichen Bedürfnishorizont und schafft durch die Entfaltung der Produktivkräfte die Möglichkeiten, die neuen Bedürfnisse zu befriedigen.

Gegen die rückwärtsgewandten Sozialutopien der vor- wie frühindustriellen Umsturzbewegungen setzt darum der Marxismus die Idee, daß die kapitalistische Produktionsweise selber die realen Voraussetzungen zur endgültigen Beseitigung von Ausbeutung und Herrschaft in der menschlichen Welt schafft. Sie bildet und organisiert nicht nur das Subjekt des Umsturzes, die Arbeiterklasse, sie leitet auch die Umwälzung der Arbeits- und Sozialverhältnisse ein, die mit einer erfolgreichen Sozialrevolution fortgeführt werden. Unverzerrte Vorstellungen über das Leben in der befreiten Gesellschaft können sich darum nur aus der Analyse der gegenwärtig dominierenden sozio-ökonomischen Struktu ren bilden, eine Idealisienung historisch überholter und teilweise zerstörter Lebensformen ist demgegenüber im schlechten Sinn u topisch und ideologieverdächtig.

Marx hat den Utopismus in der Arbeiterbewegung vor allem als intellektuelles Gebilde kritisiert und - z. B. in seinen Schriften gegen Proudhon - mit zum Teil überzeugenden Argumenten zurückgewiesen. Auf die massenwirksame Zielsetzung des Utopismus, nämlich die Idee der Wiederherstellung sozialer Lebensformen der Volksklassen, ist er nicht näher eingegangen. Diese Idee ist aber durchaus unabhängig von den Gesellschaftstheorien Fouriers, Owens und Proudhons.

Später wurde eine Kritik der utopischen Frühsozialisten mehr zur geistesgeschichtlichen Pflichtübung - dafür trat die Auseinandersetzung der Marxisten mit Bewegungen in den Vordergrund, die vorkapitalistische Lebensformen zu erhalten suchten.

klassen eine befreite und gerechte Gesellschaft $z u$ schaffen, war ein Grund für die Verbreitung der verschiedenen Formen des, ,u topischen Sozialismus". Erst nachdem dieses Ziel vorläufig gescheitert war, konnte die marxistische Gesellschaftstheorie (bzw. in England der Trade-Unionismus) Fuß fassen, da sie wenigstens für Westeuropa davon ausging, daß der Kapitalismus notwendiges Durchgangsstadium für eine erfolgreiche proletarische Emanzipationsbewegung ist. Vgl, auch Korschs Andeutungen zu den ,zwei Phasen der Arbeiterbewegung" („Karl Marx“, Frankfurt 1971, S. 181). Die sozialhistorische Untersuchung Thompsons läßt den Schluß zu, daß eine materielle Grundlage der ,utopistischen“ Phase die lebensgeschichtliche Herkunft und Bindung des frühen Industrieproletariats an eine vorkapitalistische Volkskultur war. 
So lehnte Ende des 19. Jahrhunderts die russische Sozialdemokratie auch gegen Marx' Votum den Plan der ,Volkstümler“" ab, ein sozialistisches Rußland auf die Lebens- und Produktionsformen der alten Dorfgemeinde zu stiitzen (2). Unmittelbar nach der Ok tober revolution haben die Bolschewiki vereinzelte kollektivwirtschaftliche Bewegungen der Bauern nicht unterstuitzt (3), gegen die ukrainische Machnowiki sind sie militärisch vorgegangen (4). Als während der Industrialisierung die bäuerlich sozialisierten neuen Arbeiter mit Ansprüchen, Disziplinierungen und Entfremdungen der Fabriktätigkeit nicht zurechtkamen, hat die Partei hieraus erklärbare Verhaltenstendenzen und Widerstände mit Sanktionenwie Lohnkïrzungen, Sonderarbeit, Streichung sozialer Rechte, Entlassung, auch Deportationen in Arbeitslager beantwortet (5). Bereits ab 1918 nimmt Lenin das Konzept einer proletarischen Rätedemokratie mit dem ausdrücklichen Hinweis zurück, die vom Lande stammenden, mit bäuerlichen ,Warenproduzenten "verwandtschaftlich verbundenen Arbeiter seien unsichere Kantonisten, behaftet mit „kleinbürgerlichen Relikten“ (6).

In der Einschätzung von Bauerngesellschaften stimmen die Trotzkisten mit der KPdSU weitgehend überein. Trotzki sah in der bäuerlichen Bewegung nur eine „Morgenröte der bürgerlichen Entwicklung", immerhin hat er ihre revolutionäre Kraft anerkannt (7). Seine Nachfolger sind da eindeutig festgelegt: Die industrielle Arbeiterschaft sei ,,die einzige Kraft zur Verwirklichung des Sozialismus“ - schreibt „International Socialism" - die armen Bauern und, ,lumpenproletarischen "Landarbeiter keine zuverlässigen Bündnispartner. Ihre Ideale sind im Grunde fortschrittsfeindlich und antirevolutionär, ihre familiären und lokalen Bindungen machen sie unfähig zur Selbstorganisation (8), ihre ,ureigensten Lebensbedingungen " verhindern, daß sie „,die Gesellschaft als Ganzes erkennen“, oder das auch nur versuchen. Erstes Ziel einer Revolution müsse daher auf dem Land die Zerschlagung der Bauernschaft als Klasse und Lebensform sein, indem man die Bauern in große Kollektivfarmen zusammenfaßt und die überschüssigen Arbeitskräfte in die städtische Industrie ableitet (9).

Weil marxistische Organisationen aus einem evolutionistischen Geschichtsbe-

2 F. Kramer, Über den Sozialismus in China und Rußland ..., Rotes Forum (Heidelberg) 3, 1970 ; ders., Kollektivwirtschaftliche Ursprünge des Sozialismus in Rußland und China, in Meschkat/Negt, Gesellschaftsstrukturen, Frankfurt 1972

3 F. Kramer, a.a.O.

4 P. Arschinow, Anarchisten im Freiheitskampf - Geschichte der Machnobewegung, neu aufgelegt Zürich 1971. Zur bäuerlichen Selbstorganisation speziell, S. 115 ff.; sowie die Auszüge aus Machnos kaum zugänglichen Memoiren in Hobsbawn, Sozialre bellen, S. $234 \mathrm{ff}$. S. Schwarz, Arbeiterklasse und Arbeiterpolitik in der Sowjetunion, 1953, Kap. 1 I, Deutscher, die sowjetischen Gewerkschaften, Frankfurt (eva).

z. B. in: ,,Die nächsten Aufgaben der Sowjetmacht ${ }^{6 /}$; ,,über linke Kinderei und Kleinbürgerei"; ,Linksradikalismus - eine Kinderkrankheit des Kommunismus".

7 Trotzki, Geschichte der russischen Revolution, Berlin 1967, S. 44 ff., 306 ff., 516 ff. Die zitierte Wendung S. 59.

8 Mit demselben Argument wird auch häufig eine angebliche Passivität von Gastarbeitern ländlicher Herkunft im Klassenkampf erklärt. Z. B. Arbeitersache, Was wir brauchen, müssen wir uns nehmen, trikont, München 1972.

9 N. Harris, Die Rolle der Bauern in der Revolution, International Socialism 41, 1969/70 
griff heraus einen historischen Auftrag der Bourgeoisie zusprachen, haben sie bäuerliche Bewegungen, die sich auf vorkapitalistische Traditionen stützten, oft mißverstanden, alleingelassen und manchmal auch bekämpft. Das zeichnete sich bereits in der Stellung der II. Internationale zur Kolonialfrage ab und setzte sich mit der Politik der Komintern gegenüber Befreiungsbewegungen in kolonialisierten Gebietenfort (10). Im europäischen Raum ist das politische Konzept der damals stalinistischen KP im spanischen Bürgerkrieg das bekannteste Beispiel, speziell ihr Vorgehen gegen Kollektivierungen auf dem Land und den Anarchosyndikalismus des städtischen Proletariats (11).

Diese theoretischen und strategischen Positionen berufen sich auf Gesellschaftsanalysen von Marx und Engels, obwohl gerade Marx' Stellung zu emanzipatorischen Möglichkeiten in Bauerngesellschaften und ländlichen Sozialbewegungen keineswegs eindeu tig ist (12). Dennoch orientiert sich auch Marx unverkennbar am Fortschrittsbegriff der Aufklärung und neigt, wenngleich nicht widerspruchsfrei, dazu, Möglichkeiten und Emanzipationsaussichten von Sozialbewegungen im ländlichen Milieu zu bezweifeln. In dieser Einschätzung stïtzt er sich vor allem auf vier Überlegungen, die in der Stellung marxistischer Organisationen zu Bauerngesellschaften und bäuerlichen Sozialbewegungen wichtige theoretische Rechtfertigungen darstellen. Es handelt sich um:

1) Die Annahme einer soziozentrischen Abgeschlossenheit bäuerlicher Gemeinwesen

2) Die Annahme, daß die Lebensweise in diesen Gemeinwesen die Bildung menschlicher Individualität behindert

3) Die Annahme, daß das historisch-soziale Bedürfnisniveau in vorindustriellen Landkommunen auf dem „Pegel“ elementarer Subsistenzsicherung stagniert, also jede innere Tendenz zur Entfaltung des materiellen gesellschaftlichen Reichtums fehit

4) Die Annahme, daß eine bedeutende Steigerung des technischen Produktionsniveaus ausgeschlossen ist; denn das vor- und antirationale Denken in diesen Gesellschaften steht der vollen Herausbildung technisch-instrumenteller Umweitbeziehungen, wie einer aufgeklärten Selbstverständigung über soziale Prozesse und Strukturen im Weg.

Die folgende Darstellung beschränkt sich auf die Annahmen 1) und 2), da sie direkt auf die hier interessierende Frage bezogen sind: Ob der Rïckgriff auf ländlich-kommunale Verkehrsformen dem Emanzipationsanspruch von Sozialbewegungen Grenzen setzt.

1) Die sozialen Beziehungen in bäuerlich-vorkapitalistischen Gemeinwesen bestimmen sich aus der Gemeinsamkeit der Abstammung und sekundär der gemeinsamen Ortszugehörigkeit. Diese Tatsache begründet zwar eine ausgebildete Kollektivi-

10 vgl. R. Schlesinger, Die Kolonialfrage in der Kommunistischen Internationale, Frankfurt 1970

11 z. B. Broue/Temime, Revolution und Krieg in Spanien, Frankfurt 1968

12 Besonders in den Briefen an Vera Sassulitsch und die "Otetschestwennye Sapiski“, wo Marx die Volkstümler gegen die russischen ,Marxisten“ unterstützt. 
tät im Bewußtsein und Handeln der Bauern - insofern entspricht sie der Leitidee einer vergesellschafteten Lebensweise -, doch bedingt sie gleichzeitig einen extremen Soziozentrismus. Da produktive und soziale Aktivitäten auf die Ortsgruppe beschränkt bleiben, ist die Idee des menschlichen Gattungssubjekts nur schwach oder gar nicht entwickelt; die soziale Solidarität reicht nicht über die Grenzen der Ortsgesellschaft oder des Stammes hinaus; die Beziehungen zu Außengesellschaften stehen unter den Alternativen „Krieg“, ,,Kooperationslosigkeit“ oder „,Warentausch“. Damit wird die Bildung von Klassengesellschaften entweder durch interethnische Utberlagerung, durch Zuweisung an sich gemeinschaftlicher Aufgaben der abgeschlossenen Gemeinwesen an eine äußere Instanz, oder durch innergesellschaftliche Auswirkungen äußeren Warenverkehrs historisch unvermeidlich. Der erste Fall liegt etwa vor, wenn ein fremder Stamm isolierte Gemeinwesen erobert und ihre Bewohner versklavt; den zweiten Fall erörtert Marx in Untersuchungen zur ,asiatischen Produktionsweise“, wenn etwa die Regulierung des Wasserhaushalts von einer Zentralbürokratie übernommen wird; der dritte Fall spielt auf das Problem an, daß sich friedliche Beziehungen zwischen abgeschlossenen Gemeinwesen über das „entsolidarisierte" Verhältnis des Warentausches herstellen, dieser aber in der Ortsgesellschaft Tendenzen zu privaten Besitzformen und sozialer Ungleichheit befördern kann - etwa indem sich eine für die Abwicklung des Handels zuständige Klasse bildet, die ihre Monopolstellung schrittweise zur Ausbeutung der produzierenden Ortsbewohner nutzen kann.

2) In vorindustriellen Bauerngesellschaften kann sich menschliche Individualität nur unzulänglich herausbilden. Die Menschen sind durch die Bande der Blutsverwandtschaft, , die Nabelschnur des natürlichen Gattungszusammenhangs" (MEW 23, 102) verbunden; im Extremfall hängen sie, wie Marx für das indische Gemeinwesen formuliert, ,wie die Bienen in einem Bienenstock" (MEW 23, 354) zusammen und verbleiben in ihrer kollektiven Denkweise so gleichartig und unterschiedslos wie ein ,Herden"- oder „Hammelbewußtsein".

Marx scheint in diesem Urteil von folgender Überlegung geleitet: Die Lebensweise in bäuerlichen Gesellschaften ist, vor allem soweit keine klassenmäßige Differenzierung stattfindet und die Menschen gleiche oder sehr ähnliche Arbeitstätigkeiten verrichten, durch starke Homogenität gekennzeichnet. In den sozialen Handlungsregeln und Bewußtseinsformen der Ortsmitglieder treten wenig Unterschiede auf zumindest nicht in derselben Geschlechts- oder Altersgruppe. Hinzu kommt die Dichte des täglichen Zusammenlebens in der gemeinsamen und kaum arbeitsteiligen Produktion wie im dörflichen Sozialverkehr - sie ermöglicht strenge soziale Selbstkontrolle des Ortskollektivs und wirksame Sanktionen gegen Normbrüche und Verhaltensabweichungen. Marx spricht in diesem Zusammenhang gern von den „Fesseln der Gruppe". Selbst in den Briefentwürfen an Vera Sassulitsch nimmt er eine - wenngleich widersprüchlich: emanzipatorische Funktion der Ackerbaugemeinde an, in der private Bewirtschaftung und getrennte Familienhaushalte ,eine Entwicklung der Persönlichkeit gestatten, die mit den Bedingungen der Urgemeinschaft unvereinbar war" (MEW 19, 388).

Sein Konzept „individueller Persönlichkeit“ orientiert Marx ziemlich eindeutig am philosophischen Subjektbegriff Hegels und knüpft in diesem Punkt an die gei- 
stige Tradition der bürgerlichen Aufklärung an: Individualität bildet sich nur dann heraus, wenn die Regeln gesellschaftlicher Produktion und Sozialverkehrs es zulassen, daß im Prinzip jede der miteinander verkehrenden Personen eine besondere soziale Position mit verschiedenen sozialen Merkmalen einnehmen kann. Sie stellt sich her, wenn in einer Gesellschaft die materiellen Bedingungen dafür gegeben sind, daß sich die Subjekte wechselseitig in ihrer Einzigartigkeit sehen und anerkennen. Da in bäuerlichen Produktionskommunen diese Bedingungen nur begrenzt erfullt sind, ist hier die ,,individuelle Persönlichkeit" nur , unentwickelt" vorhanden. Im Lichte dieser Überlegung neigt Marx dazu, Warenverkehr und privaten Besitzformen eine begrenzt emanzipatorische Funktion zuzusprechen, insofern sie - wenngleich unter En tsolidarisierung der Sozialbeziehungen - die Herausbildung freier und unabhängiger Subjekte gestatten. Die real gesellschaftlichen Arbeits- und Lebensformen der kapitalistischen Industrie schaffen dann die Voraussetzungen dafür, daß unter der proletarisierten Arbeiterschaft neue Formen kollektiven und solidarischen Handelns entstehen können. Sie lassen - im Unterschied zur homogenen Kollektivbildung in Bauerngesellschaften - eine wechselseitige Anerkennung besonderer Individualität zu, bedingt etwa durch die arbeitsteilige Tätigkeit in einem gleichwohl direkt vergesellschaftbaren Produktionszusammenhang.

Daß Industriearbeiter ihre Bindungen an kommunale Verkehrsformen ihrerländlichen Herkunft lösen, ist nach Auffassung vieler Marxisten ein wichtiger Schritt für die Bildung einer Klassenbewegung mit sozialistischer Perspektive. Man kann diese Auffassung angreifen, indem man die zugrundeliegende Einschätzung der begrenzten Emanzipationsmöglichkeiten innerhalb von Landgemeinden kritisiert. Am Beispiel der Kapitalismuskritik und Sozialutopie einer ländlichen Sozialbewegung soll das gleich versucht werden. Man kann aber auch die beiden Bestandteile der Auffassung auf ihre Vereinbarkeit prüfen, also die Frage aufwerfen, ob eine negative Einschätzung ländlich-kommunaler Verkehrsformen nicht möglicherweise der Idee widerspricht, daß eine einheitliche proletarische Klassenbewegung gegen die kapitalistische Produktionsweise herstellbar sein muß. Daß in der Auffassung, die Bildung einer Klassenbewegung erfordere die Ablösung der Industriearbeiter von ländlich-kommunalen Bindungen, Ungereimtheiten stecken, soll jetzt allgemein aufgezeigt werden. Das soll gleichzeitig dazu dienen, die spätere Darstellung einer Emigrationsbewegung vom Lande in das Problem der gesellschaftspolitischen Relevanz oder Fragwürdigkeit „utopischer Rückgriffe" besser einzuordnen.

1) Die Ausbreitung der kapitalistischen Produktion erzwingt eine Erweiterung kooperativer Arbeitsformen in den Produktionseinheiten und ihre weltweite Verflechtung über Großkonzerne und den Weltmarkt. Gleichzeitig vergrößert die Verstädterung das Netz möglicher sozialer Beziehungen außerhalb der Produktion; die Verdichtung der Kommunikationswege, wie die Ausbreitung der Massenmedien, verbindet die Menschen über ihre lokalen Siedlungen hinweg. Daß, wie viele Marxisten annehmen, die Universalisierung gesellschaftlicher Beziehungen im Kapitalismus die Möglichkeiten ihrer Vergesellschaftung verbessert, ist jedoch nicht einsichtig. Denn die Universalisierung setzt sich als Formalisierung und Verkümmerung der direkten 
sozialen Beziehungen der Menschen durch. Der abstrakten Universalisierungentspricht eine wirkliche Vereinzelung in den menschlichen Beziehungen: gemeinsames Handeln wird ebenso erschwert wie eine ihrer Voraussetzungen: die Kommunalisierung von Lebenserfahrungen und ihren Deutungen. Gemeinsamkeit des Handelns wird über formelle soziale Organisationen und unter Ausübung von Herrschaft hergestellt: die Bewußtseinsindustrie ersetzt den Verlust an kommunalisierter Sozialerfahrung durch stereotype Orientierungsmuster, über die sich die Unterdrückten mit den Unterdrückten geistig vereinigen können.

Unter den Wohn- und Lebensbedingungen der modernen Großstadt zerfällt die sozio-kulturelle Einheit der Arbeiterklasse, die noch im Frïhkapitalismus durch einheitliche Lebensweise, Dichte des Zusammenlebens, ausgeprägte Geselligkeit und die informellen Regeln gegenseitiger Hilfe hergestellt war. Soziabilität, Egalitarismus und Solidarität in den informellen Alltagsbeziehungen waren aber die Voraussetzung dafür, daß sich die Mitglieder der arbeitenden Volksschichten zu Klassenbewegungen gegen die Ausbeuterordnung zusammenschlossen und gemeinsame Vorstellungen über die Gestalt einer befreiten Gesellschaft entwickeln konnten. Zum entscheidenden Problem für die Bildung einer Umsturzbewegung wird daher, wie sich direkte Formen sozialen Verkehrs als Bedingung einheitlichen Klassenhandelns wiederherstellen lassen. Auf dieser Wiederherstellung insistieren aber die rückwärtsgewandten Utopien aus der Frïhphase der Arbeiterbewegung. Nach ihrem Konzept bildet sich eine revolutionäre Bewegung nicht mit, sondern gegen die universelle Vergesellschaftung des Kapitalismus.

2) Als historischer Denker hat Marx darauf verwiesen, daß sich das Industrieproletariat aus Kommunen mit vorkapitalistischer Produktionsweise und Sozialverhältnissen rekrutiert. Die Zerstörung überkommener agrarisch-handwerklicher Produktion setzt die Arbeitskräfte für die industrielle Lohnarbeit frei, die verelendeten Bewohner der Kommunen sind zur Abwandenung in Regionen gezwungen, in denen sich der Akkumulationsprozeß des Kapitals konzentriert. In seinen Analysen zur „ursprünglichen Akkumulation" und zur ,industriellen Reservearmee“ betont Marx zusätzlich, daß dieser Prozeß die gesamte historische Entwicklung des Kapitalismus begleitet. Tatsächlich übertrifft gegenwärtig die weltweite Freisetzung von Bewohnern aus vorindustriellen-ländlichen Milieus in ihrem quantitativen Ausmaß den Proletarisienungsprozeß im Frühkapitalismus.

Sozialgeschich tliche Untersuchungen zur Bildung der englischen Arbeiterbewegung zeigen, daß vor allem Industriearbeiter der ersten Generation die befreite Gesellschaft durch rückwärtsgewandte Utopien ausmalen und zu dem entsprechenden Organisations- und Aktionsformen greifen. Ähnliches gilt etwa für die Bewegung de. Anarchosyn dikalismus in Spanien. Man kann also die begründete Vermutung formulieren, daß bei gegenwärtig noch verstärkter Proletarisierung und Abwanderung von Bewohnern ländlicher Kommunen utopische Rückgriffe im Denken der Industriearbeiterschaft lebendig sind. Da sich Verkümmerung und Formalisierung menschlicher Beziehungen in den spätkapitalistischen Wohnsilos noch verschärft, ist ebenfalls zu vermuten, daß Idealisierung lebensgeschichtlich erfahrener Sozialverhältnisse auch und gerade die Erinnerung an nachbarschaftliches Zusammenleben, ausgeprägtes 
Gleichheitsdenken, Autonomie und Solidarität umfassen. Soweit dagegen Marxisten Rückgriffe aufvorkapitalistische Lebensformen entweder ignorieren oder als verschleierte politische Restauration verwerfen, stellen sie sich - so die Konsequenz der Vermutung - neben das Bewußtsein einer breiten Schicht der Arbeiterschaft. Programme und politische Praxis marxistischer Organisationen zielen in dieser Hinsicht an Interessen und Vorstellungen wichtiger Teile des Proletariats vorbei. Vielfältige Erfahrungen der Art, daß die organisierte Arbeiterbewegung vor allem von Lohnabhängigen mit proletarischer Familientradition und städtischer Sozialisation getragen wird, während Arbeiter ländlicher Herkunft zunächst abseits bleiben, weisen in diese Richtung.

Eine Gesellschaftstheorie wird zu einer wirksamen Waffe im Klassenkampf, wenn sie das Wirklichkeits- und Selbstverständnis unterdrückter Volksschichten repräsentiert, rechtfertigt und weiter entfaltet. Dazu muß sie Bedürfnisse und Lebenserfahrungen der Unterdrückten aufgreifen und theoretisch verarbeiten. Soweit die Akkulturation der Lohnabhängigen in die spätkapitalistischen Sozialverhältnisse nicht bruchlos gelingt, gehört dazu auch das Interesse, die Verarmung und die Verdinglichung sozialer Beziehungen zu durchbrechen. Diesem Interesse kommen vermutlich die lebensgeschichtlichen Erfahrungen des Teils der Arbeiterklasse entgegen, die aus Gemeinwesen mit weitgehend vorkapitalistischen Formen sozialen Verkehrs stammen.

Ob das wirklich der Fall ist, und wie sich diese Erfahrungen zu einem Bild über die gegenwärtige und Vorstellungen zu einer besseren Gesellschaft formen, soll jetzt an einem empirischen Beispiel untersucht werden.

Diese Untersuchung gliedert sich in einen historischen und einen aktuellen Teil. Beide sind darüber vereinigt, daß die Arbeiter, deren Kapitalismusk ritik dargestellt wird, aus derselben Region stammen: nämlich einer Provinz in Andalusien. Der historische Teil der Darstellung handelt über die agraranarchistische Sozialbewegung Andalusiens. An schriftlichen Selbstzeugnissen dieser Bewegung wird deutlich, wie eine emanzipatorisch gerichtete Sozialutopie auf Lebensformen der ländlichen Volksklassen zurückgreift. Gleichzeitig läßt sich gegen die Annahme vieler Marxisten zeigen, daß die Stützung der Klassenbewegung auf Ortsgesellschaften weder ihren Emanzipationsanspruch soziozentrisch beschränkt, noch eine Anerkennung individueller Persönlichkeit innerhalb homogener Sozialbeziehung behindert.

Die andalusische Sozialbewegung wurde durch die faschistische Militärdiktatur in den 30er Jahren zerschlagen, dieselbe Region bildet heute ein zentrales Rekrutierungsfeld von Lohnarbeitern für das Industriekapital in Spanien und Westeuropa. Viele der andalusischen Arbeiter, die heute in der nordspanischen und westeuropäischen Industrie ihr Brot verdienen, sind Töchter, Söhne, Enkel oder Urenkel der Landproletarier, die vor Jahrzehnten für eine weltweite kommunistische Gesellschaft kämpften. An Verlaufsformen und Selbstdeutungen dieser Wanderungsbewegung, die wir in einigen andalusischen Dörfern untersucht haben, wird deutlich, wie Industriearbeiter der ersten Generation großstädtisches Alltagsleben vërmittelt über ihre Erfahrungen mit Sozialbeziehungen in ländlichen Gemeinwesen wahrnehmen, deuten 
und bewerten. Dabei stellt sich derselbe Zusammenhang von - in diesem Fall: potentieller - Sozialutopie und Idealisierung ländlicher Verkehrsformen heraus, der gegen den Fortschrittsbegriff der Aufklärung ausgespielt und am Agraranarchismus exemplarisch aufgewiesen wurde. Die Wahrnehmungen westeuropäischen Großstadtlebens durch südspanische Emigranten enthalten einen wichtigen Aspekt der Kritik an kapitalistischer Vergesellschaftung. Ob diese Sichtweise bei Industriearbeitern ländlicher Herkunft allgemein anzutreffen ist, läßt sich im Rahmen einer Fallstudie natïrlich nur vermuten.

Der folgende Bericht stützt sich im historischen Teil auf schriftliche Selbstzeugnisse andalusischer Landarbeiter, im aktuellen Teil auf Untersuchungen einiger Studenten der FU im Gebiet. Dokumentarische Unterlage ist die regionale Landarbeiterpresse aus der Zeit der II. spanischen Republik, soweit sie im Amsterdamer Institut für Sozialgeschichte noch zugänglich ist, in zweiter Linie Sekundärliteratur. Die Sozialuntersuchung wurde, bei einer breiter angelegten Thematik (13), 1973 und später als „beteiligte Beobachtung" durchgeführt. Wir haben jeweils mehrere Monate in einem Dorf gelebt und dabei versucht, das Alltagsleben der Arbeiterfamilien, Kleinproduzenten und Kleinhändler, ihre Arbeitsverhältnisse und Klassenbeziehungen $_{3}$ die Strukturen der Ausbeutung und politischen Unterdrückung, die Probleme der Emigranten nach Westeuropa oder in die nordspanische Industrie kennenzulernen. Aus methodenkritischen Erwägungen haben wir keine standardisierbaren Erhebungen gemacht. Eigene Teilnahme und Freundschaften mit Ortsbewohnern waren unsere wichtigsten ,Methoden“. Unsere Kenntnisse und Erfahrungen verdanken wir daher informellen Gesprächen über die Problemkreise Arbeit, Ortsleben und Emigration, täglichen Beobachtungen und Lebensberichten.

Um Mißdeutungen der Verteidigung „,utopischer Rückgriffe" vorzubeugen, stelle ich klar: Eine Sozialbewegung, die auf dörfliche Verkehrsformen zurückgreift, vertritt nicht notwendig emanzipatorische Ziele, dieser Rückgriff allein macht sie aber erst recht nicht reaktionär. Wie gleich am Agraranarchismus des südspanischen Andalusien zu zeigen, kann gerade eine soziale Bewegung, die an Gleichheitsregeln, Gemeinschaftlichkeit und Gegenseitigkeit im Leben ländlicher Volksklassen anknüpft, klare und wirklichkeitsbezogene Vorstellungen über die anzustrebende Gesellschaft entwikkeln und dabei sehr bewußt gegen jede Form der Klassenherrschaft gerichtet sein.

Dagegen haben die süditalienischen Bauern und Landarbeiter, obwohl sie untervergleichbaren ökonomischen Bedingungen wie die andalusische Volksklasse lebten (ausgeprägter Großgrundbesitz, Auflösung des Gemeindelandes als wichtige Subsistenzquelle im 19. Jahrhundert, allerdings relativ mehr Kleinpachten) keine mit dem siidspanischen Agraranarchismus an Militanz und emanzipatorischer Perspektive vergleichbare Widerstandsbewegung hervorgebracht. Nach der nationalen Einigung Italiens verteidigten die süditalienischen Bauern die bourbonische Reaktion und später gelang es den linken Organisationen lange Zeit nicht, die katholische Ideologie der Demut und Unterwerfung auf dem Land zu durchbrechen. Mögliche Gründe dafür kann natürlich nur eine gründliche sozialhistorische Untersuchung ermitteln. Den-

dazu wird die Gruppe im Herbst 1977 einen ausführlichen Sozialbericht veröffentlichen. 
noch liegt die Vermutung nahe, daß die weniger ausgebildete Dorfsolidarität in Süditalien und die stärkere Familienzentrierung der bäuerlichen Schichten für den Pazifismus der ländlichen Volksklasse eine nicht unbeträch tliche Rolle spielt (Banfields These des ,amoralischen Familismus“, auf die wir uns hier stützen, ist allerdings mit Vorsicht zu genießen. Vgl. Banfield, The Moral Basis of a Backward Society, N.Y. 1965). Indirekt in diese Richtung weist eine Dorfuntersuchung in Kalabiren, 1962, damals vor allem zur überseeischen Emigration (Lopreato, Peasants no more, San Francisco 1967). Der Autor bemerkt, daß die zuriickkehrenden Emigranten ihre Ersparnisse sehr häufig zur demonstrativen Abgrenzung gegen die zurückgebliebenen ärmeren Familien verwenden. Diese schnelle Auflösung des Gleichheitsbewußtseins weist offenbar auf eine relative Schwäche der örtlichen Klassensolidarität hin. In andalusischen pueblos machten wir zur Stellung zurückgekehrter Emigranten andere Erfahrungen. Zwar integrieren sie sich nicht alle in das Dorfleben, Ansätze zu demonstrativem Konsum, die das Gleichheitsbewußtsein der Familien verletzen, konnten wir dagegen nicht feststellen. Offenbar ist hier die örtliche Klassensolidarität stärker verankert.

Ob eine bäuerliche Sozialbewegung eine emanzipatorische oder reaktionäre Richtung nimmt, läßt sich natürlich nicht allgemein voraussagen. Die Stärke ländlich-kommunaler Verkehrsformen ist hier ein Faktor, wie wir exemplarisch zeigen wollten. Ein anderer ist die Herausbildung antagonistischer Klassenverhältnisse, die in Andalusien so weit ging, daß die herrschende Klasse aus den pueblo ausgegrenzt war und dort die arbeitende Klasse eine reale soziokulturelle Lebenseinheit bildete. Umgekehrt verlief die Entwicklung im nordspanischen Navarra, wo Gemeineigentum und Gemeinbewirtschaftung bis in die 60er Jahre dieses Jahrhunderts eine wichtige Rolle spielen und wo die Dorfsolidarität ebenfalls ausgebildet war, allerdings - das ist hier entscheidend - im Rahmen einer nicht antagonistisch zugespitzten Klassendifferenzierung . Die Sozialbewegung der Bauern Navarras war darum reaktionär. Sie zielte auf die Wiederherstellung vorkapitalistischer Zustände unter Einfluß monarchisch und klerikal legitimierter Herrschaftsverhältnisse. Ihre politische Organisation und Ideologie war der ,Karlismus", der sich im spanischen Klassenkrieg eng mit dem Faschismus verbündete. Heute allerdings stehen die Nachkommen der karlistischen Bauern Navarras an vorderster Front der Klassenauseinandersetzungen, nämlich in der neu erreich teten Industriezone um Pamplona, deren Arbeiter fast ausschließlich aus den Dörfern Navarras kommen. Entscheidend war sicher der lebensgeschichtliche Bruch von autonomer Land- zu fremdbestimmter und entfremdeter Industriearbeit. Der VerlaufderStreikauseinandersetzungen in Pamplona 1973, die in einem regelrechten (unbewaffneten) Volksaufstand gipfel ten, läßt vermuten, daß die erste Industriearbeitergeneration Navarras Formen der alten Dorfsolidarität in proletarische Klassensolidarität, typischerweise unter Einschluß der kleinbürgerlichen Schichten, transformiert hat.

Bei ausgeprägtem Klassenantagonismus wird der Rückgriff auf dörfliche Verkehrsformen zu einer Waffe im Kampf gegen die kapitalistischen Verhältnisse. Überdeckt dagegen die Dorfsolidarität die Klassendifferenzierung, ist die Sozialbewegung für die Reaktion instrumentalisierbar. In diese Richtung weisen auch die unterschiedli- 
chen Sozialverhältnisse in Nordportugal, wo in z. T. noch gemeinbewirtschafteten Landgegenden die restaurativen Kräfte starke Unterstützung finden, und in Südportugal, dessen Landbewohner den revolutionären Prozeß aktiv vorantreiben.

\section{Das Gesellschaftsbild der andalusischen Agraranarchisten}

\section{Produktionsverhältnisse und Klassenbewegung}

Seit dem römischen Imperium dominiert in der andalusischen Landwirtschaft der Latifundienbesitz. Das ändert sich auch nicht nach der Eroberung durch die kastilischen Könige, als die Güter den Militäroffizieren und dem christlichen Grenzadel übergeben werden. Die Feudalherren bewohnten palastähnliche Gutshöfe, an die sich die Gebäude ihrer unmittelbaren Vasallen anschlossen. Die Mehrheit der Pächter, kleinen Bauern, Handwerker und Tagelöhner lebte dagegen auf engem Raum in befestigten ,pueblos", die mit einer Stadt die große Einwohnerzahl und ein vielfältiges Gewerbe, mit einem Dorf den Vorrang der landwirtschaftlichen Produktion gemein hatten.

Produziert wurde unter einer Mischung von feudaler Guts- und Grundherrschaft und parzelliertem Gemeineigentum. Die Latifundien waren über die Ausfuhr von Weizen, Wein und Olivenöl früh in die Marktproduktion integriert, bewirtschaftet wurden sie durch erbuntertäniges Gesinde, Pächter und Tagelöhner aus den pueblos.

Vor allem die Tagelöhner stützten sich auf das Land der pueblos als weitere Subsistenzquelle. Jedes Jahr teilten die ortsansässigen Familien den kultivierbaren Teil des Gemeindelandes (14) durch Losentscheid unter sich auf. Im Unterschied zu Nordspanien wird für Andalusien eine „urkommunistische“ Gemeinbewirtschaftung nie erwähnt. Die trockenen Böden waren mit geringer Ochsenkraft und der Arbeit eines Bauernhaushalts zu pflügen. Damit blieb - im Unterschied etwa zur germanischen Produktionsweise - die Kooperativarbeit der Bauern begrenzt, andererseits konnte sich aber auch nicht über ein Monopol an Ochsengespannen innerbäuerliche Abhängigkeit und Ausbeutung herausbilden (15). Das breiträumige Brachland, die Weiden und Wälder schließlich standen allen Familien zur Nutzung offen.

Die Verbindung eines stark marktorientierten Feudalbesitzes mit kleinbäuerlich-kommunaler Subsistenzwirtschaft erhielt sich in Andalusien bis 1800 . Von seltenen Erhebungen wie dem großen Hungeraufstand von Cordoba 1652, Judenpogromen, die wohl gegen die vordringende Tauschwirtschaft zielten und dem bäuerlichen Sozialbanditismus abgesehen, haben die andalusischen Volksklassen weder das System

14 zum Gemeineigentum in Spanien informiert am besten: Joaquin Costa, Colectivismo Agrario en Espana, Madrid 1898 (im Ibero-Amer. Institut W-Berlin) wie die meiste angegebene spanische Literatur Eric Wolf, Peasants, Prentice Hall 1966, S. $30 \mathrm{ff}$. 
der Ausbeutung noch seine Auswïchse bekämpft. Noch zu Beginn des 19. Jahrhunderts vertreibt die bäuerliche Guerilla im Bund mit den adligen und klerikalen Grundherren die antifeudalen französischen Invasoren.

Ein massenhafter Widerstand der andalusischen Tagelöhner, Handwerker und kleinen Bauern beginnt, als sie die Folgen einer kapitalistischen Transformation der ländlichen Produktionsverhältnisse zu spüren bekommen. Nach dem vorübergehenden Machtantritt einer liberalen Bourgeoisie 1812, die sich in der Eigentumsfrage immer mit den alten herrschenden Klassen verbündet hat, werden die „,Rechtsgrundlagen" dieser Transformation gelegt (16). Drei Maßnahmen verschlechterten entscheidend die Lage der arbeitenden Landbevölkerung:

Einmal wurde ein Teil der Kleinpachten auf dem Adelsland abgeschafft, die Verträge für die verbleibenden Pächter verschlechtert. Viele proletarisierte Kleinpächter mußten sich nun als Landarbeiter mit Gelegenheitslohn durchschlagen. Ähnlich war die Entwicklung auf dem Kirchenland, das der spanische Staat jetzt an den Landadel und vor allem an eine aufstrebende Agrarbourgeoisie verkaufte. Besonders die zum lokalen Klerus gehörenden Landstücke waren vorher an kleine Pächter vergeben, die jetzt zum Teil ihre Bewirtschaftungsrechte verloren. Die Mitwirkung des Klerus bei diesen Enteignungsmaßnahmen ist ein wichtiger historischer Grund für den heftigen Antiklerikalismus der Sozialbewegung, während noch wenige Jahrzehnte zuvor Priester die Guerilla gegen Napoleon anfiihrten. Von jetzt ab galt die Kirche - ihrem Selbstverständnis durchaus angemessen - als Pfeiler der Klassenherrschaft. Volksaufstände begannen oft mit der Zerstörung der Ortskirchen und die überzeugten Anarchisten mieden von der Hochzeit bis zur Beerdigung religiöse Zeremonien wie die Pest. In der Arbeiterpresse gibt es empörte Abhandlungen über Vesuche der Priester, verstorbene Arbeiter christlich zu beerdigen. Nach dem Sturz der Monarchie 1931 wurden in manchen Orten Prozessionen als offene Provokation der Arbeiter angesehen und entsprechend beantwortet.

Die einschneidendste Maßnahme war der Verkauf des Gemeindelandes, das überwiegend dem großen Grundbesitz zufiel. Zunächst wurden die „,baldios“, unbebautes Land, das aus Wäldern, Weide und Wildwuchs bestand, zu Privateigentum „umdefiniert". Bisher nutzten Bauern und landlose Familien gemeinsam die baldios zu verschiedenen Zwecken: Als Viehtrift und zur Beschaffung von Viehfutter, zum Sammeln von Wildgemüse, Materialien für den Hausbau, von Brennholz, zur Jagd auf wilde Tiere. Der Landadel übte über die baldios nur jurisdiktionelle Gewalt aus, z.B. war er für die Schlichtung von Streitfällen zuständig. Die formalen Rechtansprüche nutzte er während der desamortisacion dazu, die baldios in seinen Privatbesitz zu übernehmen. Versuche der Gemeinden, diese Aneignungen auf dem „,Rechtweg“ $\mathrm{zu}$ bekämpfen, schlugen samt und sonders fehl. Wenn die Gerichte nicht schon von Familienangehörigen der reichen Landbesitzer direkt gebildet waren, erkaufte man ihr

Leider stützen sich die Untersuchungen zur Änderung der ländlichen Eigentumsverhältnisse im Spanien des 19. Jahrhundert fast nur auf bürgerlich gefilterte Dokumente, kaum auf lokalgeschichtliche Studien, überhaupt nicht auf die historischen Erfahrungen der armen Landbevölkerung. Am nützlichsten ist: Antonio Miguel Bernal, La propriedad de la tierra y las luchas agrarias Andaluzas, Sevilla 1974. 
Urteil. Typisch ist ein Fall aus Moron (Sevilla) - später eine Bastion des Anarchosyndikalismus. Dort klagte die Gemeinde gegen die Vereinnahmung der baldios durch den Herzog von Osuna. Der Richter, der zu entscheiden hatte, gehörte zu einer Familie, die weite Landstriche des Herzogs in Großpacht bewirtschaftete. Der Ausgang des Rech tsstreits war damit klar.

Das Gemeindeeigentum im engeren Sinn gliederte sich von alters her in das „Munizipaleigentum“ und das ,zum Ortsbewohner gehörige Land“. Mit dem erstgenannten bestritt die Gemeinde ihre Steuern und öffentlichen Ausgaben, das zweite wurde unentgeltlich und periodisch an die landlosen Familien zu gleichen Teilen verlost. Um seine Zahlungsbilanz zu verbessern, leitet der spanische Staat in zweifacher Hinsicht eine Auflösung des Gemeindelandes ein. Zum einen wird das „Nachbarland“ schrittweise zu Munizipalland verwandelt und dieses zu einem Pachtzins versteigert, den nur Großbauern entrich ten können. Dieser Prozeß hat schon vor 1800 eingesetzt. Mit den Flurbereinigungen des 19. Jahrhunderts wird dann das Gemeindeland überhaupt verkauft, wobei der hauptsächliche Nutznießer die ortsansässige Bourgeoisie ist, die das Land zu Vorzugspreisen erwirbt, während den subsistent wirtschaftenden Kleinbauern und Landproletariern jede überschüssige Pesete zum Erwerb fehlte. Zum Teil spielten sich himmelschreiende Episoden ab. Das Rathaus von Arcos (Cardiz) verschleuderte einen großen Teil des Nachbarlandes, um einen luxuriös ausgestatteten Ortsplatz zu errichten, auf dem fortab die hungernden Tagelöhner, statt das verkaufte Land zu bearbeiten, auf Arbeitsgelegenheiten warten konnten.

Eine quantitative Schätzung der Enteignungsmaßnahmen ist kaum möglich, da es kaum überlokale statistische Unterlagen gibt und da die Angaben, auf denen sie beruhen, meist das Resultat interessierter Fälschung durch die Besitzenden sein dürfte. (Nicht zufällig beginnen die ersten Volkserhebungen ab 1840 meist mit der Verbrennung der örtlichen Rathausakten.) Für den Ort Guillena stellte man fest, daß um $176546 \%$ - also fast die Hälfte des Landes - aus baldios bestand und $20 \%$ als Nachbarland der Gemeinde gehörten. Weniger als 100 Jahre später befinden sich diese Ländereien zum größten Teil in den Händen der senoritos. Die Zahlen aus Guillena stimmen mit der Auskunft eines Experten der Staatsverwaltung 1768 überein, daß mindestens $2 / 3$ des andalusischen Territoriums Gemeinbesitz oder ungenutztes - also allgemein zugängliches - Land sei (17).

Herstellung kapitalistischer Agrarverhältnisse in Andalusien bedeutete also, daß die Lohnarbeit auf den Latifundien anstelle langfristiger Parzellierung in Kleinpachten ausgeweitet wird, die unbebauten Landstriche als Privatbesitz den Latifundien zugeschlagen und die wich tige Erwerbsquelle des Gemeineigentums den Bewohnern der Agrostädte geraubt wird. Bis heute ist die Erinnerung an die Enteignungsmaßnahmen der herrschenden Klasse in der armen Landbevölkerung lebendig geblieben (18).

Die Klassenbewegung der Landarbeiter und Kleinproduzenten ist ihre unmittelbare

17 J. Costas, a.a.O.

18 im August 1976 gab es in Algodonales (Cadiz) eine Demonstration mit 6.000 Teilnehmern. Man forderte, daß alte Nutzungsrechte am Land der Gemeinde zurückgegeben werden sollten! 
bare Antwort auf Proletarisierung und Expropriation. Zeitlich entsteht sie genau mit der Auflösung des Gemeindelandes und diese Erfahrung bestimmt auch das zentrale gesellschaftspolitische Ziel der Bewegung: ,reparto" nannte man die jährliche Verteilung des Nachbarlandes unter die landlosen Ortsbewohner: „,reparto “ ist von nun an eine Parole, mit der die Bewegung die Aufteilung des kapitalistischen Eigentums unter alle arbeitenden Landbewohner fordert.

Über größere Klassenaktionen andalusischer Landarbeiter (19) wird zuerst 1840 berichtet (20). Die Landarbeiter des Dorfes Casabermeja bei Malaga besetzen 5 große Güter, die sie sofort aufteilen und kultivieren. Sie emennen aus ihrer Mitte einen Bürgermeister und nehmen die Ortsgeschäfte selbst in die Hand. Einige Orte der Umgebung folgen ihrem Beispiel, erst nach Monaten zerschlägt eine militärische Expedition die Lokalrevolutionen.

In den 50er Jahren häufen sich Berichte über ,,Tumulte " in den Dörfern und Agrostädten, die alle um die Forderungen „Brot“, „Arbeit“ und „Land" kreisen. In El Arahal (Sevilla) und anderen Orten zünden Aktionsgruppen die verhaßten Rathausarchive an, die den Landraub der Reichen legalisieren. Immer wieder gibt es spontane Enteignungs- und Sabotage-Maßnahmen gegen Großgrundbesitzer, gelegentlich besetzen Arbeiter Ländereien, werden aber von der 1844 gegründeten Zivilgarde schnell vertrieben. Selten kommt es zu einer bewaffneten Volkserhebung wie der von Loja (Granada), an der 10000 bis 20000 Bauern unter Führung des Tierarztes Perez del Alamo teilgenommen haben sollen (21). Die Arbeiterbewegung ist in dieser ihrer ,,rebellischen Phase" (22) über lokale Absprachen hinaus nicht organisiert, ihre Aktio-

19 Zur andalusischen Sozialbewegung stütze ich mich hauptsächlich auf:

Juan Diaz del Moral, Historia de las agitaciones campesinas Andaluzas, Madrid 1967 (zuerst: 1929). Eine hervorragende Darstellung der Landarbeiterbewegung in der Provinz Cordoba, geschrieben von einem halb sympathisierenden bürgerlichen Zeitgenossen und Augenzeugen.

Bernaldo de Quiros, El espartaquismo agrario Andaluz, zuerst Madrid 1912, neu: Anales de Sociologia 1968/9, IV.

Clara E. Lida, Anarquismo y revolucion en la Espana del XIX siglo, Madrid 1972

Antonio M. Calero, Movimientos sociales en Andalucia, Madrid 1976

20 Bernaldo de Quiros, a.a.O.

21 derselbe hat über diese Ereignisse interessante Memoiren geschrieben: Perez del Alamo, Apuntes sobre dos revoluciones Andaluzas, neu aufg. Madrid 1971

22 Hobsbawm hat in seiner Studie, Sozialrebellen“" (Neuwied 1962) den andalusischen Anarchismus als eine typisch millenarische Bewegung beschrieben, für die eine Revolution weniger Klassenkampf und mehr Heilserwartung war. Seine Einschätzung stützt er stark auf eigene Studien in und zum Ort Casas Viejas (Cadiz), dessen Einwohner 1933 einen blutig unterdrückten Aufstand gemacht haben.

In einem Nachbarort berichteten mir ältere Arbeiter, der Aufstand sei unter 4 - 5 pueblos abgesprochen gewesen und er sollte eine gleichzeitige revolutionäre Bewegung in Katalonien unterstützen. Weil sich die anderen Orte nicht an die Absprache hielten, schlugen die Arbeiter von Casas Viejas isoliert los.

Nach Gesprächen in Casas Viejas halte ich das rückblickende Urteil dortiger Bewohner für weniger zuverlässig. Mindestens gegenüber Fremden läuft es zu stark nach dem Schema „damals waren die Leute dumm und kulturlos" ab, das als offizielles Geschichtsbild eingetrichtert wird. Nach diesem indoktrinierten Schema mag dann leicht ein gescheiterter revolutionärer Plan als naive Verrücktheit verharmlost und abgewiesen werden. 
nen knüpfen deutlich an Traditionen des Sozialbanditismus an, die aber zu direkten Massenaktionen ausgeweitet werden. Soweit sie in politische Machtkämpfe eingreift, ist die Arbeiterbewegung durch Geheimbünde der antiroyalisitschen Intelligenz gesteuert, eine eigenständige Ideologie und organisierte Klassenkampfstrategie bildet sie noch nicht aus.

Eine autonome und organisierte proletarische Sozialbewegung bildet sich in Andalusien sehr rasch mit und unmittelbar nach der bürgerlichen spanischen Revolution 1868 - 1872. Mit ihren Versprechungen auf soziale Gerechtigkeit haben die republikanisch-föderalistisch gesinnten Teile der Bourgeoisie in den Städten und Dörfern die Handwerker, Landarbeiter und kleine Pächter mobilisieren können. Deren Militanz verhalf ihr zur politischen Macht, die sie sofort gegen die radikalen Forderungen der Volksklassen einsetzte. Schnell arrangiert sie sich mit der politischen Reaktion, als diese militärisch das Übergewicht erringt. ,Feigheit" und „Verrat" sind die Schlüsselerfahrungen, mit denen fortab die andalusische Sozialbewegung jede Verbindung zur bürgerlichen Politik und Ideologie abbricht. In ihrer konsequenten Klassenautonomie übertrifft sie jede west- und zentraleuropäische Arbeiterorganisation. Erst Jahrzehnte später wird sich ihr sozialistischer Flügel den Republikanern begrenzt annähern.

Binnen weniger Jahre werden über 100 örtliche Sektionen der anarchistischen Internationale gegrïndet. In praktisch jedem Ort der Feldregionen um Sevilla und Cordoba, der Provinz Cadiz, in Malaga und den Bergdörfern um Ronda ist die Internationale vertreten. Die nach Berufszweigen gegliederten Sektionen erfassen zu etwa gleichen Teilen die Landarbeiter, wie die Manufakturarbeiter und Handwerker. Oft wurden Landarbeiter nur deshalb nicht Mitglied, weil sie als ärmste Schicht die Beiträge nicht zahlen konnten (23). Die Sektionen werden vom Staatsapparat, der die Aktionen der „Mano Negra" zum Vorwand nimmt, massiv unterdrückt. Der bloße Verdacht eines Großgrundbesitzers oder Polizisten reichte, um einen Landarbeiter ins Gefängnis zu werfen. In Jerez de la Frontera (Cadiz) soll es im März 18833.000 politisch-soziale Gefangene gegeben haben (24). Dennoch vertreten 1882, auf dem Kongreß der spanischen Sektion der Internationale in Sevilla, die andalusischen Delegierten fast 40.000 Mitglieder.

Die politischen Ziele der Landarbeiterbewegung orientierten sich überwiegend am Anarcho-Kommunismus - ,jeder nach seinen Kräften, jeder nach seinen Bedürfnissen ". Eine Entlohnung nach Leistung war den Tagelöhnern nicht plausibel, die gegen die Einfuihrung des Akkords kämpften und denen jeder über den elementaren

23 Das berichten etwa Arbeiter aus Medina Sidonia (Cadiz) 1872 an die AIT (span. Sekt. d. Intern.): G. Brey/J. Maurice, Casas Viejas: reformisme et anarchisme en Andalousie. In: Mouvement social 1973, S. 102.

Aufschlußreich ist die Zusammensetzung der Sektion der AIT in Sanlucar 1872, verglichen mit den Löhnen:

230 Weinarbeiter, die 10 reales Tagelohn erhalten

28 Schuster mit dto. 10 reales

106 Landarbeiter mit 2 reales (Frauen nur 1 real)

(nach Espoir, 26.1.1975, Organ der CNT in Frankreich)

Clara E. Lida, La Mano Negra, Madrid 1972, S. 9 
Lebensunterhalt hinausgehender Luxus fremd war. Noch 1936 haben viele andalusische Landorte in der republikanischen Zone Produktion und Verteilung nach anarcho-kommunistischen Prinzipien geregelt (25).

Neben vereinzelten Aufständen wie der Besetzung von Jerez 1892 waren die Mittel des Klassenkampfs zunächst Sabotage, Zerstörungen, nächtliche Enteignungskationen gegen den großen Grundbesitz. Diese unter dem Namen "Mano Negar" (Schwarze Hand) bekanntgewordenen Aktionen muß man verstehen als Folge der enormen Schwierigkeiten, die ökonomischen Kampfmittel der Industrie auf die Bedingungen ländlicher Gelegenheitsarbeit zu übertragen (26).

Mit der organisierten ökonomischen Klassenaktion beginnt die dritte Phase der andalusischen Landarbeiterbewegung. Den ersten großen Streik führten die Weizenschnitter 1883 in der Feldregion von Jerez durch (27). In den ersten Jahrens des 20. Jahrhundert breitet sich die Kampfform des Streiks über ganz Andalusien aus. Die Forderungen zielen konkret auf Verbesserung der Lohn- und Arbeitsbedingungen, nicht selten kommt es zu revolutionären Generalstreiks, die die Arbeiterzentren meist auf Absprache und in der Erwartung ausrufen, daß er sich auf weitere

25 Vgl. z. B. Borkenau, The Spanish Cockpit, zuerst London 1937, über Castro del Rio (Cordoba).

Ein Arbeiter aus Ronda la Vieja (Malaga) schreibt über die Tage der Freiheit, die dieser Ort im Sommer 1936 durchlebte:

„Wenige Stunden waren wir frei, da fand schon die erste allgemeine Volksversammlung statt. ... Einmütig entschied man sich für die vollständige Kollektivierung der Reichtümer ... Die kleinen Pächter auf den Gütern waren die ersten, die dem Kollektiv alles anboten, was sie besaßen: Tiere, Ackergeräte, Saatkorn, Land, überhaupt alles, was dem gemeinsamen Interesse dienen könnte. ...

Um ein annäherndes Bild des Reichtums zu geben, den man vergesellschaftete, möchte ich sagen, daß man allein an Arbeitstieren 200 Gespanne zählte. Die erste Arbeit des Kollektivs war die Ernte. ... Nie wurden die Erntearbeiten so schnell und gründlich durchgefïhrt wie dieses Jahr.

Auf allgemeinen Versammlungen wurden nach dem Urteil aller Regelungen für die Arbeit festgelegt. ... Ebenso benannte man Delegierte für die Sektoren: Männer, denen man vertrauen konnte und die sich auskannten. Jeden Abend versammelten sie sich, um Bilanz zu ziehen und festzulegen, was am nächsten Tag zu tun sei....

Das Geld wurde abgeschafft. ... Stattdessen nahm jeder, was er brauchte, wenn die Artikel nicht knapp waren. Wenn es sie nicht reichlich gab, verteilte man zu gleichen Teilen. Zur gleichen Zeit stellte man mit benachbarten Kollektiven ein System gegenseitigen Austauschs her, das jedem (Kollektiv) ermöglichte, gerade oder knapp selber durchzukommen. Wir können versichern, daß es zu keiner Zeit Mißbrauch oder Unordnung gab, weder in der Verteilung noch im Verbrauch."

So berich tet Antonio Guerrero in der ,C.N.T.“, am 14.2. und 21.2.1954

26 Darauf weist Clara E. Lida hin. A.a.O. Dieselben Mittel hat auch die unter dem Namen „Captain Swing“ bekanntgewordenen englische Landarbeiterbewegung angewendet: E.J. Hobsbawm/Georg Rude, Captain Swing 1969.

Noch heute wehren sich die andalusischen Landarbeiter gelegentlich durch Sabotage gegen die großen Grundbesitzer. Als im Sommer 1975 in vielen Länderen um Jerez die senoritos das Sammeln von Schnecken und Flech tgräsern untersagten - Arbeiten, von denen viele Familien in dieser Zeit leben -, wurden den schlimmsten Ausbeutem nächtlich Felder angezündet.

27 Bernaldo de Quiros, a.a.O. 
Ortschaften und Provinzen ausdehnt. Am Generalstreik nimmt die arbeitende Bevölkerung eines pueblo geschlossen teil, bis hin zu den Kindermädchen der Bürgerfamilien. Weitere Aktionsformen der Bewegungen sind Volksdemonstrationen und Boykott. Der Boykott - eine oft und wirksam angewendete Waffe - richtet sich gegen besonders massive Fälle von Ausbeutung und Unterdrückung, niemand darf beim boykottierten Kapitalisten arbeiten, Streikbrecher werden von den Ortsläden oder diese von der übrigen Arbeiterschaft boykottiert. Demonstrationen finden hauptsächlich während der arbeitslosen Monate statt, um die Kommunalverwaltungen zur Vergabe von Gemeinschaftsarbeiten zu zwingen.

Höhepunkte der Landarbeiterbewegung sind das „bolschewistische Triennium“ 1918 bis 1920 und die Jahre der II. spanischen Republik 1931 - 1936, als die Frage einer Umgestaltung der ländlichen Eigentumsverhältnisse besonders aktuell wird. Ab Frühjahr 1918 reagieren die Landarbeiter auf die Kunde von der erfolgreichen russischen Revolution überall mit Generalstreiks und anderen Aktionen. Ab 1931 soll die Mobilisierung auf dem Land den (nicht eingehaltenen) Versprechungen der bürgerlich-sozialistischen Regierung nach Landverteilung Nachdruck geben. Nach dem Sieg der Volksfront in den Februarwahlen 1936 beginnen in einigen Gebieten die Arbeiter damit, Latifundien zu besetzen und selbst zu kultivieren. Der mit Klerus, Finanzkapital und Grundbesitz arrangierte Militäraufstand ab Juli 1936 bereitet dem in Andalusien schnell ein Ende. In einem beispiellosen Terror zerschlägt die Konterrevolution alle Arbeiterorganisationen (28).

Politisch-ideologisch hat sich die ländliche Sozialbewegung Andalusiens nach

28 Nach Schätzungen wurde in der Provinz Cordoba jeder 10. Landarbeiter ermordet. (J. Martinez, La Estabilidad del Latifundismo, S. 142).

In Moron (Sevilla), das sich eine Woche gegen eine militärische Übermacht verteidigte, haben die Faschisten - nach Angaben eines zu ihnen gehörigen Augenzeugen - 3.000 Menschen umgebracht, ebenso in Jerez. In Sevilla sollen von 250.000 Einwohnern 20.000 ermordet worden sein, in Granada 10.000 (nach A. Lorenzo, Los anarquistas espanoles y el poder, Paris 1972, S. 159).

Der Terror der Besitzenden und die nachfolgende Unterdrückung durch die Franco-Diktatur ist der Hauptgrund dafür, daß sich bis heute die Arbeiterschaft in den meisten ländlichen Gegenden Andalusiens ruhig verhält (mit wichtigen Ausnahmen!) . . . In diesem Sinn trug mir ein alter Landarbeiter ausdrücklich auf, meinen politischen Freunden in Deutschland zu berichten: „1936 hat man uns allen die Köpfe abgeschnitten: Den Toten, weil man sie umgebracht hat; den Lebenden, weil sie sahen was geschah".

Niederlage und Terror der Faschisten haben bei der arbeitenden Bevölkerung Andalusiens - den Älteren wie den damals Geborenen und Aufwachsenden - eine tiefsitzende Furcht und Zurückhaltung davor hinterlassen, ,sich in politische Dinge einzumischen“. Erst in den letzten Jahren gibt es deutliche Anzeichen, für eine neue soziale Bewegung in den Landorten. In den ersten Monaten 1976 gab es große Streiks der Landarbeiter in den Provinzen Cordoba und Sevilla, sowie der - großenteils auf dem Lande lebenden Bauarbeiter von Cadiz und teilweise auch Cordoba, Jaen und Sevilla. Über die jahrelange Sonderrolle der Weinarbeiter bei Jerez wird noch zu berichten sein (in III.6.).

Im übrigen ist nicht zu übersehen, daß die roten Arbeiterstädte von Barcelona wie Tarrasa, Bajo Llobregat, Hospitalet heute hauptsächlich von Einwandern aus dem Süden bewohnt werden. Aktionen auf dem Land werden fast immer über die Arbeiterkommissionen organisiert. Mit ziemlicher Sicherheit wird die Kommunistische Partei (P.C.E.) heute unter den Landarbeitern den größten Rückhalt haben. 
1900 in der anarchosyndikalistischen C.N.T. oder der sozialistischen Gewerkschaft U.G.T. und der sozialistischen Partei organisiert. In den Kerngebieten der Bewegung hatten die Sozialisten erst seit der II. Republik größeren Zulauf, als die Hoffnungen auf eine staatliche Agrarreform zunahmen. Die Führer der Sozialisten waren fast immer bürgerliche Intellektuelle (Anwälte, Lehrer, Ärzte), oder ausgebildete Facharbeiter der größeren Städte. Auf dem Land stützte sich die U.G.T. hauptsächlich auf kleine Bauern, Pächter, und ,yunteros“ (landlose Arbeiter mit Zugtiergespannen). Die C.N.T. dagegen war eine reine Arbeiterorganisation. Ein sachkundiger Zeitgenosse kennt nicht einen Professionellen, der sie aktiv unterstützt hätte (29). Auf dem Land waren hauptsächlich die Tagelöhner und viele Handwerker Mitglied der C.N.T. Die schwerpunktmäßige Zuordnung U.G.T. und C.N.T. zu verschiedenen Schichten der arbeitenden Klasse wird aber stark durch lokale Besonderheiten überlagert. In den kleinen und mittleren pueblos, aber auch in größeren Agrostädten, haben sich die Volksklassen fast immer in einem Syndikat vereinigt (30).

\section{Landarbeiterpresse als proletarische Öffentlichkeit}

Die anarcho-syndikalistische Bewegung der Landarbeiter war streng elitär aufgebaut - es gab weder Funktionäre, noch Privilegien. Die Sprecher, die „obreros conscientes", hatten den anderen Arbeitern höchstens die Fähigkeit voraus, lesen und schreiben zu können, eine besondere Rednergabe und vor allem Mut gegen die Repressionen der herrschenden Klasse zu zeigen. Ein dürftiges Gehalt bezog nur der Redakteur der regionalen Zeitschrift, da er wegen der vielen Korrekturen, Postsendungen, Abrechnungen, Botengänge und anderer Dinge keiner weiteren Arbeit nachgehen konnte. Da die konsequent syndikalistische Bewegung nie Kandidaten für Rathaus und überlokale Parlamente aufstellte, war ein indirekter sozialer Aufstieg einzelner Repräsentanten und ihre mögliche Entfremdung von der Bewegung praktisch ausgeschlossen. Inhaber eines mit staatlicher Herrschaft irgendwie verbundenen Amtes und Zugehörigkeit zur C.N.T. schlossen sich aus. Das änderte sich für den nordspanischen Anarchosyndikalismus erst 1936, als die CNT Delegierte in die republikanischen Regierungsorgane entsandte.

Horizontaler Aufbau und proletarischer Charakter der Gewerkschaft rechtfertigen es, ihre sozialrevolutionären Ideen und Ziele als originären Ausdruck der Vorstellungen zu sehen, die sich spontan unter dem Landproletariat über die Klassengesellschaft und den Kommunismus gebildet hatten. Die Arbeiteröffentlichkeit der andalusischen Landorte beruhte in erster Linie auf mündlicher Kommunikation. Die Arbeiterpresse war in diese unmittelbare Öffentlichkeit eng integriert. Zum einen

29 zur sozialen Rekrutierung von C.N.T. und U.G.T. v.a.: Juan Diaz del Moral, a.a.O. Gut unterrichtet dazu auch Manuel Cortes, ein Sozialist aus Mijas (Malaga), in seinen Lebenserinnerungen: R. Frazer, Im Versteck, Hamburg 1972

30 Nach Dokumenten über Zentren der UGT 1888 - 1923 und der CNT 1919 gab es in dieser Zeit in 252 Orten Syndikate. Nur in 19 dieser Orte waren sowohl UGT wie CNT vertreten. (nach Antonio Calero, a.a.O.) 
hatten die Zeitschriften vorwiegend regionale Bindung und Verbreitung, wobei allerdings die extreme Armut der Landarbeiter und die Repressionen der herrschenden Klasse bewirkten, daß sie in der Regel nur für wenige Jahre oder gar Monate erschienen. Typisch ist wohl das Beispiel der Zeitschrift „La Voz del Campesino“, „,Die Stimme des Bauern", die von der Landarbeiterföderation der Gegend um Cadiz herausgegeben wurde.

Seit dem Sturz der Monarchie, 1931, wurde sie in Jerez de la Frontera zusammengestellt und gedruckt, einer großen Stadt, deren Bevölkerung hauptsächlich von Landarbeit und Weinverarbeitung lebte. Sie erschien zweimal im Monat bei einer Auflage von vielleicht 5 - 6.000 Exemplaren und wurde zum größeren Teil in den 20 Orten der comarca gelesen, in denen die regionale Föderation ihre Zentren hatte. Gleichzeitig war ihre Verbreitung über feste Abonnenten in anderen Orten ein wichtiges Mittel, auch dort die Gründung eines Zentrums voranzutreiben. Die Artikel und Berichte in der "Stimme des Bauern“ stammten meist aus den Orten der comarca. Daneben veröffentlichte sie Schreiben der Arbeiterzentren aus anderen spanischen Regionen, Artikel aus der anarchistischen Presse Madrids und vor allem Barcelonas, Zirkulare der A.I.T. aus Berlin und Berichte der Arbeiterbewegung aus anderen Ländern, wie der syndikalistischen Bewegung im Alentejo oder aus einem Streik der kubanischen Tabakarbeiter. Vorrang hatten aber immer die regional und lokal bezogenen und verfaßten Artikel.

Zum anderen wurden die Artikel dieser Zeitschriften in Gruppen verlesen und gemeinsam diskutiert. Dies war schon deshalb notwendig, weil die meisten Landarbeiter überhaupt nicht oder nur mit Mühe das Alphabet beherrschten. Nach Berichten von Diaz del Moral, der als Rechtsanwalt in einem cordobesischen Landort lebte, ließen sich viele Arbeiter solange Artikel von ihren lesekundigen Genossen vortragen, bis sie sie auswendig beherrschten. Die Beiträge wurden von Arbeitern, die der Bewegung angehörten, verfaßt. Wahrscheinlich gingen ihrer Niederschrift intensive Diskussionen auf den Landgehöften und in den Orten voraus. Die Aufgabe der Redaktion - aber auch der Redakteur war Artikelschreiber - beschränkte sich darauf, die Beiträge grammatisch und orthographisch zu korrigieren. Oft ergriffen Arbeiter zum, wie sie sagten ,ersten Mal in ihrem Leben die Feder" (und wahrscheinlich auch zum letzten Mal), um Elend, Ausbeutung und Korruptheit der Bourgeoisie anzuklagen, zur Vereinigung aller Arbeiter im Kampf aufzurufen und um die Idee einer freien und menschlichen Gesellschaft auszumalen. In ihrem rhetorischen und breit ausmalenden Stil sind diese Artikel oft deutlich der Versuch, eine flammende mündliche Agitation in die tote Schriftsprache zu übersetzen und für einelau teund gemeinsame Lektüre wieder aktualisierbar zu machen. Vielfach beginnen die Beiträge mit konkreten Wahmehmungen und Erfahrungen, die allen Lesern zugänglich und einsichtig sind und leiten dadurch allgemeinere Urteile über Klassengesellschaft und libertären Kommunismus ein. Z. B.: „Ich steige auf einen Berg und sehe die fruchtbaren Landstriche meiner Heimat, wie sie veröden und ungenutzt daliegen ..." - schrittweise werden dann die Gründe der Verödung in Ökonomie und Moral der herrschenden Klasse entwickelt. Oder: ,ich kann nicht schreiben, denn ich mußte schon als Kind die Schweine des Landjunkers Domecq hüten, damit dieser seine Kinder auf gute 
Schulen schicken konnte ..." - aus seiner verallgemeinerbaren persönlichen Situation stellt dann der Schreiber die allgemeine Lage der Landarbeiter in einer kapitalistischen Ökonomie dar.

Trotz des Regionalismus der Arbeiterpresse, der Herkunft der Artikel, ihrer engen Integration in einen mündlichen Kommunikations- und Erfahrungszusammenhang blieb man sich der Grenzen bewußt, die eine schriftliche Kommunikation für eine politische Arbeiteröffentlichkeit hat. So schreibt ein Militanter an „La Voz del Campesino": „Man theoretisiert viel vom hohen Podest herunter und in Zeitschriften, und vergißt dabei die öffentlichen Plätze, wo Tag für Tag Arbeiter dahinsiechen, weil sie nichts zu essen haben. Dort muß die revolutionäre Agitation gemacht werden!" Und ein Arbeiter aus Jerez leitet seine Streitschrift gegen den Akkord selbstkritisch mit den Worten ein: „Genossen. Die Feder zu ergreifen heißt, einen Schritt in die Anomalie zu tun. Die aber verbreitet sich höchst unklug in den Reihen des organisierten Proletariats“. Andererseits war sich die anarchosyndikalistische Bewegung über die großen Möglichkeiten einer Presseöffentlichkeit im klaren, die darin liegt, daß die politischen Diskussionen der einzelnen pueblos und Regionen verallgemeinerbar und koordinierbar werden.

Die agraranarchistischen Zeitschriften Andalusiens geben, so sollte jetzt deutlich sein, ein stark angenähertes Bild der Vorstellungen, die die Landarbeiter, Kleinbauern und Handwerker der Region über die kapitalistische Gesellschaft und Wege wie Ziele einer Sozialrevolution hatten. Die folgende Skizze stuitzt sich vor allem auf Artikel der Zeitschrift „La Voz del Campesino“ aus dem Jahre 1932 (31).

\section{Die Ideen des Agraranarchismus}

„Das Land denen, die es bearbeiten!“ war der Titelspruch von „La Voz del Campesino“, oder wie ein Sprecher der Bewegung formulierte: „Befreien wir das Land, dann wird der Mensch befreit sein! Das ist der einmïtige Ruf, den die Parias der Äcker Spaniens und der ganzen Welt erheben." Damals wie heute befindet sich das andalusische Land hauptsächlich in den Händen weniger reicher Großgrundbesitzer, die Mehrheit der Landbevölkenung ist von ihren gelegentlichen Arbeitsangeboten abhängig, die niedrigen Löhne - der Durchschnitt lag 1932 bei 6 pts. knapp über der Hungergrenze - reichen nicht, um die Familie über die arbeitslosen Monate ohne Hunger und krasses Elend durchzubringen (32). Eine dünne Schicht von Kleinbauern und Kleinpäch tern lebt unter kaum besseren Bedingungen, da die Landjunker auch

31 Vom Juli 1932 bis Januar 1933 ist diese Zeitschrift, wie andere Dokumente der anarchistischen und syndikalistischen Presse Spaniens, im „Institut für Internationale Sozialgeschichte Amsterdam zugänglich. „La Voz del Campesino“ erschien 14täglich.

Wenn nicht anders vermerkt, zitiere ich im folgenden Aussagen, Wendungen, Überlegungen und Bilder immer aus dieser Zeitschrift.

32 Antonio Calero Amor, in Historia del movimiento obrero en Granada 1909 - 1923, Madrid 1973, berechnet die Ausgaben einer 4köpfigen Familie, nur für Nahrungsmittel im Jahr 1915 auf 118 pts. monatlich, also 4 pts. pro Tag. (Angenommen ist allerdings täglicher Fleischkonsum, den sich andalusische Arbeiterfamilien bis heute nicht leisten können). 
den Verkauf agrarischer Produkte monopolisieren und durch hohe Pachtzahlungen die Kleinproduzenten in Abhängigkeit und Verschuldung halten. Noch heute besagt ein geläufiger Spruch der Dorfbewohner, $d a ß$,vier oder fünf rancheros das ganze Land der Gemarkung gehört".

In den Augen der Landarbeiter gab (und gibt) es für das Eigentum der ,senoritos" - wie man die Agrarkapitalisten in abwertender Anlehnung an das feudale ,senor" schimpft - keine Legitimation. Wie wir gesehen haben, war hier der Raub des Gemeindelandes die historische Schlüsselerfahrung, wie auch die Forderung nach „reparto“, nach Aufteilung des Landes, an Traditionen des Gemeindeeigentums anknüpfte. ,,reparto“ bedeutete den Anarchisten jedoch nicht, daß man die alten Verhältnisse wiederherstellen will, sondern zielte auf deren Universalisierung und Transformation. Sie ist universalisiert, insofern sie das gesamte bebaute wie unbebaute Land umgreift und sich im Rahmen einer weltweiten Bewegung der Arbeiter - ,der Sklaven der ganzen Welt" -- gegen Privateigentum und Ausbeutung versteht. Sie ist transformiert, insofern die Idee der parzellierten Privatbewirtschaftung abgelöst wird von der Forderung auf kollektive Bodenbebauung. Die Sprecher der anarchosyndikalistischen Bewegung vertraten einhellig die Auffassung, daß gemeinsamer Besitz und Bewirtschaftung ein elementares Naturrecht aller Menschen ist und daß jeder private Eigentumsanspruch die anderen Menschen dieses Rechts beraubt.

Die gemeinsame Bewirtschaftung wird in „La Voz delCampesino"auszweiGründen befürwortet: Zum einen garantiert sie eine Ertragssteigerung und damit die Subsistenz aller, da sie die breite Anwendung maschineller Produktionsmethoden zuläßt. Vor allem aber zersetzt der parzellierte Anbau die Solidarität und Gemeinschaftlichkeit der Menschen, ohne die eine gesellschaftliche Emanzipation nicht durchgesetzt und verteidigt werden kann. So resümiert ein Artikel zur Agrarreform: „Wir sind entschieden gegen eine Parzellierung der Ländereien, denn dieses System der Kultivierung führt moralisch gesehen zu Resultaten, die pessimistisch stimmen. Es macht den Bauem menschenscheu, ungesellig und unsolidarisch mit den anderen Arbeitern, denn der ausschließliche Besitz an Land belebt bei ihm einen am Rande vorhandenen Egoismus und kann ihn zu einem Hindemis für den ökonomischen und sozialen Fortschritt verwandeln. Dieses System ist antiökonomisch und rïckschrittlich - darum auch vertreten es die Eigentümer und Regierenden."

Hobsbawm bemerkt zutreffend, daß die andalusischen braceros und Kleinproduzenten mit dem Kommunismus nicht eine Gesellschaft allgemeinen Reichtums, sondern des ,gerechten Miteinanderteilens der Härten und Bürden des Lebens" herstellen wöllten (S. 109). Die empörende Ungerech tigkeit der Klassengesellschaft stellen die schreibenden Arbeiter immer wieder an der Tatsache dar, daß die Mütter ihre Kinder hungrig zu Bett schicken müssen, während die Reichen in Luxus schwelgen. Nahrung, Wohnung und Kleidung für alle war das materielle Ziel des Agraranarchismus, Konsumansprüche, die darüber hinausgingen, wurden als Nachahmung des Le-

Bis 1932 stiegen die Lebenshaltungskosten um ca. $50 \%$ (der Herstellungspreis von Zeitschriften erhöhte sich um $70 \%$ ), außerdem sind die Familien im Schnitt zahlreicher als A.C. annimmt, vor allem mußten auch die Alten, die keine Rente bezogen, ernährt werden. Schließlich gingen die Familien in den vielen arbeitslosen Monaten völlig leer aus. 
bensstils der herrschenden Klasse verurteilt. Die elementare Bedürfnisorientierung dominierte so sehr im Denken der andalusischen Arbeiter, daß der kapitalistische Akkumulations, , trieb“ ihnen schlicht unverständlich blieb. Man deu tet ihn als krankhafte, da unmäßig gewordene Freßgier, die sich bis zum Hineinschaufeln von Geld in den fetten Wanst steigern kann. Noch heute gilt der ,dicke Bauch“ als das soziale Merkmal des Kapitalisten, und die Akkumulation als nutzloses Anhäufen von Geld auf eine Bank, wo es dann mit den Jahren vermodert. Erklärbar ist das kapitalistische Verhalten neben der unmäßigen Freßgier der Reichen aus ihrem grenzenlosen Egoismus und ihrem Bestreben, sich zu Herren über die anderen Menschen aufzuschwingen.

Die elementare Bedürfnisorientierung schloß - im Gegensatz zu der von vielen Marxisten vertretenen Annahme - eine Entwicklung der Produktionsmethoden nicht aus, sondern ein. Dem lag die bittere Erfahrung zugrunde, daß die Kapitalisten die Landwirtschaft vernachlässigen (33). Auf weiten Landstrichen bauen die senoritos nichts an, fruchtbaren Boden reservieren sie fir Jagd oder Viehzucht und rauben so den braceros Arbeit und Brot. Ein schreibender Arbeiter schildert diese elende Situation für seine unmittelbare Heimat: Das Land wurde eingezäunt und verödet oder wird zur Viehhaltung genutzt. Eine Handvoll Treiber reicht zur Bewachung aus, die Häuser der verstreuten Landsiedlungen verfallen, da ihre Bewohner mangels Arbeit sie verlassen mußten. Sie bevölkern jetzt als Schuhputzer und Bettler die Straßen einer größeren Stadt oder sind irgendwohin in den Norden gewandert. Schuld an der Verwüstung ist ein großer Landbesitzer, „ein Monster, das nach Reichtum hungert“. Erst wenn die soziale Revolution ihn vertreibt, werden die Menschen zurïckkehren und das Land bebauen können. Dann wird wieder Leben in diese Öde einkehren.

Der Agraranarchismus wollte die verfügbaren Produktionstechniken für alle Menschen in gleicher Weise nutzen. Jeder sollte nach seinen Kräften zum allgemeinen Wohl beitragen, jeder sollte nach seinen elementaren Bedürfnissen am Verbrauch des Gesamtprodukts teilhaben. Niemand, der nicht krank, alt oder ein Kind ist, sollte von der Verpflichtung zur (körperlichen) Arbeit entbunden sein. Das Geld, das die sozialen Beziehungen korrumpiert, wird ebenso abgeschafft wie jede Form staatlicher Herrschaft, die freien Dorfkommunen regeln ihre Angelegenheiten durch Volksversammlungen, an denen alle erwachsenen Ortsbewohner teilnehmen, und durch Komitees, die aus den Versammlungen gebildet und abgewählt werden.

33 ,Die capitalistas säen nicht aus. Sie zäunen das Land ein, treiben Vieh auf die Weide und stellen zwei, drei Männer ein, der Rest bleibt ohne Arbeit. Oder sie lassen das Land verkommen und nutzen es für Herrenjagden, zu denen sie aus Madrid oder Sevilla anreisen, uns aber verbieten sie die Jagd, die wir im Winter dringend zum Essen brauchen. Wenn ihnen die Löhne zu hoch sind, pflügen sie die Felder einfach um oder werfen die Früchte den Schweinen vor." So äußern sich auch gegenwärtig andalusische Arbeiter zur Landfrage. Bestimmend ist die Erfahrung, daß die Kapitalisten die Fruchtbarkeit des Bodens nicht nutzen. Die Umwälzung der Eigentumsverhältnisse ist für die Arbeiter unlösbar mit einer Steigerung der landwirtschaftlichen Erträge verbunden. Deutlich wurde das jüngst im portugiesischen Alentejo, dem ,Bruderland“ Andalusiens, wo die reichen Grundbesitzer das Land noch mehr vernachlässigt haben. Die Kooperativbewegung der Landarbeiter ist hier Landnahme im sozialen wie natürlichen Sinn: Enteignung der Latifundien und Kultivierung des bisher ungenutzten Landes. 
Im Widerspruch zu den ,Söhnen von Karl Marx“ lehnten die schreibenden Arbeiter jede proletarische Diktatur ab - ,, was wir für uns nicht wollen, das wollen wir für niemand". Die Bildung politischer Zentralorgane führe unvermeidlich in eine neue Klassengesellschaft, eine neue Despotie über die arbeitende Bevölkerung. Niemand hat das Recht, sich zum „Vormund" oder „Blindenführer" des Volks aufzuspielen. Teilweise griff man darum sogar die Existenz der F.A.I., einer geheimen Organisation anarchistischer Militanter an, die in den 20er Jahren zusätzlich zur syndikalistischen Bewegung der C.N.T. gegründet wurde. Auch durften die freien Kommunen keine Zwangsvereinigung sein - sie müssen durch ihr Beispiel die noch Abseitsstehenden praktisch überzeugen. So würden sich über kurz oder lang alle Menschen ihr anschliessen, ,,denn es ist unmöglich, ein Leben als Einzelgänger zu führen“. Ist soziale Gleichheit im Rahmen kollektiver Produktion und Sozialorganisation einmal hergestellt, so verwandelt sich auch die Arbeit aus einer Last zu einer wesentlichen Lebensverwirklichung. ,Wenn wir alle gemeinsam arbeiten und es außer der gesamten Menschheit keine Herren mehr gibt, stellt sich die Arbeit nicht mehr als Last oder als Pflicht dar, sondern im Gegenteil als ein Vergnügen, dem wir mit Leichtigkeit und Freude nachgehen, denn wir wissen, daß wir es für das eigene Wohl und für die gesamte Menschheit tun.“

\section{Verteidigung der ländlichen Klassenkultur}

Die andalusischen Arbeiter orientierten ihre Ideen zur vergesellschafteten Produktion an der historischen Erfahrung der Gemeinbewirtschaftung, die sie aber universalisierten und transofrmierten. In dieser Hinsicht basierte ihre Sozialutopie ziemlich eindeutig auf „utopischen Rückgriffen “. Gleichzeitig wollten sie die Lebens- und Verkehrsformen der Volksklassen in den Landkommunen defensiv gegen die zersetzenden bürgerlichen Einflüsse erhalten und ihre Merkmale der Gegenseitigkeit und Gleichheit wiederbeleben. Anhand der schriftlichen Selbstzeugnisse soll das jetzt erläutert werden.

Nach dem blutig unterdrückten Versuch der Bewohner von Casas Viejas, Januar 1933, in ihrem Ort den libertären Kommunismus zu errichten, schreibt die nationale Tageszeitung der C.N.T.: „Die allgemeine Erhebung wird auf den Landdörfern ihren Anfang nehmen. Sie wird nicht in den großen Städten beginnen, sondern in Orten wie Casas Viejas. Diese Bewegung wird ein reinigendes Feuer über das Land und die Städte ganz Spaniensentzünden.Casas Viejassteht dafürals Symbol."(CNT, 15.2.1933) Wenige Monate zuvor verkündet ein Militanter aus der Nähe dieses Orts: „Die Revolution hat keinen politischen Charakter, die Umwälzung kommt nicht aus den höheren Sphären der Politk. Die Revolution ist eine wesentliche und natürliche Eigenschaft der Landorte, die darauf drängen, sich zu befreien - und sie ist das im weitesten und ganzen Sinn des Worts."

Dieser pathetischen Einschätzung lagen zwei Überlegungen zugrunde. Einmal, daß die Landarbeiter, Pächter und Kleinbauem einer verglichen zum städtischen Prole tariat extremeren Ausbeutung unterworfen sind. Sie erhalten den geringsten Lohn, 
müssen die härteste Arbeit leisten und ihre Familien leiden dennoch Hunger, da die Männer das halbe Jahr ohne Arbeit sind. Die Landproletarier sahen sich selbst am Rande der Gesellschaft, als ,,die Fußmatte, auf die alle Privilegierten treten“; gleichzeitig aber, weil sie für die elementare Subsistenz aller sorgten, als die eigentlich produktive Klasse in dieser Gesellschaft. Diese Verbindung von sozialer Randstellung und doch die Gesellschaft tragende Produktivität ihrer Tätigkeit begründete, nach der Selbstdeutung des Landproletariats, seine revolutionäre Kraft.

Die zweite unter den Landarbeitern geläufige Überlegung bezog sich auf die relative Intaktheit solidarischer und egalitärer Normen im sozialen Leben der Arbeiterschaft, vor allem der ländlichen Gebiete. Die klassenlose Gesellschaft soll „Liebe, Briiderlichkeit, Harmonie und Wahrhaftigkeit" unter allen Menschen herstellen, und sie knüpft dazu an die existierenden sozialen Beziehungen im „pueblo" an, wie man in Spanien die Landgemeinde nennt. Während die bürgerliche Klasse ein degeneriertes und verworfenes Leben fuihrt und ihre moralische Korruption bereits Teile der Stadtbevölkerung erfaßt, bewahrt vor allem die bäuerliche Klasse die ,ursprüngliche Reinheit" sozialen Zusammenlebens.

Die Gemeinschaftlichkeit und Gegenseitigkeit des pueblo wird durch die Bourgeoisie bedroht, die sich als unmenschlichster Endpunkt einer jahrtausendalten Klassenherrschaft wie Drohnen im sozialen Mechanismus festgesetzt hat. Es ist daher nur konsequent, wenn die andalusischen Landarbeiter eine Theorie oder besser: eine Legende der externen Entstehung von Klassenherrschaft vertraten: Ein Teil der Menschheit habe in friedlicher Gemeinbewirtschaftung Ackerbau und Viehzucht getrieben, ein kleinerer Teil setzte das Leben als Räuber und Jäger fort, die Art ihrer Tätigkeit machte sie zu grausamen und wilden Menschen. „Eines Tages“ überfielen die wilden Stämme die kultiviert und herrschaftsfrei lebenden Bauern und Hirten, mach ten sich zu ihren Herren und führten das Eigentum an Land und Produktionsmitteln ein. „Damit entstanden die Klassen und der Klassenhaß. " Dieser Ursprungsmy thos findet seine historische Anwendung in der Auffassung, daß sich Landadel und Agrarbourgeoisie ihren Besitz durch Raub und Betrug angeeignet haben. Und sie schlägt sich in einem noch heute verbreiteten Bild vom Klassengegensatz nieder, das die Trennungslinie sozialgeographisch fixiert zwischen der ortsansässigen Arbeiterschaft und der außerhalb der proletarischen Klassengemeinde verbleibenden Bourgeoisie und des staatlichen Herrschaftsapparats. Den pueblo bilden die dort wohnenden Arbeiter, er ist Gemeinwesen und Volksklasse in einem.

Die agraranarchistische Bewegung stützte sich auf eine noch gegenwärtig vorhandene Lebenseinheit der Arbeiterklasse in den großen Wohngebilden des pueblo. Diese Einheit wurde durch den Syndikalismus verstärkt. Die örtlichen Arbeiterzentren waren gleichzeitig sozialer Mittelpunkt der arbeitenden Bevölkerung. Sie organisierten nicht nur den Klassenkampf, sondern fungierten auch als Vereinigungen zur gegenseitigen Hilfe. Einen wichtigen Stellenwert hatte dabei die Unterstïtzung der Familien, deren Ernährer verhaftet und ins Gefängnis gesteckt worden waren. Einen beträchtlichen Teil der publizistischen Aktivität des „La Voz del Cámpesino“" nehmen die Aufrufe zur materiellen Solidarität mit den Familien politischer Gefangener und die Veröffentlichung von Sammlungen ein. Die Centros Obreros bemühten 
sich auch, die Lebensmoral der Arbeiterschaft zu stärken und sie bekämpften etwa das Glïcksspiel und den Alkoholgenuß, ,der den Menschen erniedrigt, den Streit nährt und Frieden und gegenseitigen Respekt unter den Menschen zerstört". In den Zentren bestand strenges Trink- und Spielverbot, das überzeugte Anarchisten auch auch sonst befolgten. Schließlich lag ein Schwerpunkt der Zentren in den enseñanzas, der kulturellen Erziehung, die - im Gegensatz zu den Sozialisten - streng von den, in andalusischen Dörfern kaum vorhandenen, staatlichen und religiösen Ausbildungsinstitutionen getrennt wurde. Die Anarchisten haben nie den Bau von Staatsschulen gefordert, sondern ihre eigenen gegründet. Unter enseñanzas verstand man zunächst die Verbreitung der Ideen und der Wissenschaften, wobei man sich ausschließlich auf Arbeiterliteratur stützte. Vor allem aber bemühten sich die Zentren um die Errichtung von ,escuelas racionalistas", Schulen, die nach dem Vorhild des 1909 ermordeten Katalanen Francisco Ferrer die Unterweisung in Lesen, Schreibenund Rechnen mit einer Aufklärung der libertären Ideen verbanden.

Die Centros Obreros verstanden sich als Keimzellen der freien Kommunen in einer kommunistischen Gesellschaft. Oft fielen im pueblo ihre Mitglieder mit der Volksklasse zusammen. Diaz del Moral erhielt um 1920, als er in der cordobesischen Ebene nach der Zahl der im pueblo organisiserten Arbeiter fragte, immer wieder zur Antwort „,man muß sie nicht zählen, es sind alle“ (S. 293). Als 1932 Mitglieder der jungen kommunistischen Partei in der Gegend um Cadiz unter der Parole der Arbeiter-Einheitsfront auftreten, kommt es auf der Arbeiterversammlung eines kleineren Ortes von etwa 2000 Bewohnern zu einer langen Diskussion. In diesem Ort liegen die Klassenverhältnisse klar. Eine Klasse teilt Reichtum und Macht unter sich, abseits und im Kampf gegen sie steht die andere Klasse ohne Freiheit und ohne Brot. Ein Arbeiter vertritt auf der Versammlung den (autoritären) Kommunismus. Ihm wird vor allem mit dem Hinweis geantwortet, daß die Einheitsfrontidee in diesem Ort völlig unsinnig sei. Es habe hier nie Spaltungen gegeben, die man überwinden müsse. „In allem sind wir immer einen gemeinsamen Weg gegangen." Dieser Hinweis soll sogar den Kommunisten wieder bekehrt haben.

Allerdings ist der Bericht nicht verallgemeinerbar. Seit Ausnufung der Republik 1931, als die Hoffnung bestand, auf legalem Weg die bestehenden Eigentumsverhältnisse zu ändern, spaltete sich die Arbeiterschaft in vielen Orten in eine anarchosyndikalistische und eine sozialistische Bewegung. Auf gesamtspanischer Ebene war diese Spaltung, mit ihren Konflikten und Auseinandersetzungen, ein Grund für die historische Niederlage der Arbeiterbewegung. Darum unter anderem setzt sich die neue Bewegung in den Comisiones Obreras die Erhaltung der Klasseneinheit als vorrangiges Ziel, wobei sie in der Bewertung von Autonomie und Unabhängigkeit an die syndikalistische Tradition anknüpft, ohne die anarchistischen Ideen zu übernehmen.

Dem andalusischen Agraranarchismus war der Gedanke völlig fremd, daß die kapitalistischen Produktionsverhältnisse irgendeine Basis für emanzipatorische Veränderungen der sozialen Verkehrsformen abgeben könnten. In dieser Hinsicht war er im Urteil von Theoretikern eines linearen Fortschritts durchaus konservativ. Die Frage ist nur, ob nicht dieser Standpunkt borniert ist, insofern er hinter die historischen Möglichkeiten konkreter Alltagssolidarität in einer befreiten Gesellschaft zu- 
rückfällt, die zumindest damals in der Volksklasse der spanischen pueblos noch bestanden hat.

Der Rückgriff des Agraranarchismus auf alte Formen der Dorfsolidarität findet sich etwa in naturrechtlichen Überlegungen:

Im staatsfreien Gesellschaftszustand, den die Anarchisten sofort errichten wollten, ist jede formelle Gesetzgebung abgeschafft. Die historische und täglich wiederholte Erfahrung bestätigte den Tagelöhnern und Kleinproduzenten Andalusiens, daß Gesetze nur dazu dienen, Ausbeutung und Unterdrïckung des Volks aufrechtzuerhalten und zu verschärfen. Die ,Legalisierung“ der Eigentumsverhältnisse im 19. Jahrhundert vertrieb sie von den Ländereien, die sie meist in Parzellen bewirtschaftet hatten. Die Rechtstitel der Agrarbourgeoisie waren gefälscht oder gekauft, die Richter bestochen oder sonstwie mit den Landräubem verbunden. Zur Verteidigung des, ,legalisierten Eigentums" wurde ab 1944 in jeden Ort eine bewaffnete Streitmacht gesetzt, die guardia civil; von den Arbeiterfamilien im pueblo wurde sie noch mehr gehaßt als gefürchtet. Brenan schreibt, daß jeder guardia civil ein „Rekrutienungsoffizier" für die anarchistische Bewegung war (34). Noch heute sagen selbst politisch eher konforme Ortsbewohner, daß die guardia nur die Interessen der Kapitalisten verteidigt.

Nach Auffassung eines schreibenden Arbeiters, der sicher eine allgemein verbreitete Meinung wiedergibt, hat die herrschende Klasse mit ihren Gesetzen aus dem sozialen Leben eine „Maschine von höchster Kompliziertheit“ gemacht, die wegen der offenkundigen Ungerechtigkeiten, die sie stützt, zutiefst unverständlich ist. Eine gerechte Gesellschaft muß zu der Einfachheit des Lebens zurückkehren, wie sie vor der Entstehung von Klassen und sozialer Herrschaft bestanden hat. Diese Rückkehr stellt soziale Harmonie und Gerechtigkeit her, die von Natur aus den sozialen Verkehr der Menschen bestimmen. „Das Leben kann einfach sein, wenn wir es im Schoß der Natur suchen. Die Natur sollte unsere einzige Regierung sein. Die Regierung der Menschen bedeutet Bosheit und die Ambition zu herrschen." Der Schreiber zitiert einen in der regionalen Bewegung verbreiteten Spruch: „Alle Menschen sind im Grunde genommen Anarchisten, denn die Anarchie ist das Symbol des Lebens. Anarchie ist das Leben."

Das bürgerliche Konzept des Naturrechts und des Naturzustands stellt diesen als die Ordnungslosigkeit ungeselliger Privatproduzenten dar, es projiziert die Normen ökonomisch-sozialer Beziehungen der besitzenden Klasse auf die staatsfreie Lebensweise der Menschen. Das agraranarchistische Konzept des Naturrechts stellt diesen als harmonisches Zusammenleben kollektiver Produzenten ohne soziale Unterschiede und in gegenseitigen Solidaritätsverpflichtungen dar. Es verallgemeinert Verkehrsformen der Volksklassen im pueblo, die sich gegen die kapitalistischen Einflüsse erhalten haben, auf die staatsfreie Lebensweise der Menschen. Diese Lebensweise ist gerecht, da sie keine sozialen Unterschiede zuläßt, sie ist wahr (im Sinn von wahrhaftig), da es in ihr Heuchelei und Lüge, den Bruch zwischen Privatsphäre und gesellschaftlichen Beziehungen, nicht gibt, sie ist brüderlich, da sie die Familiensolidarität

34 G. Brenan, The Spanish Labyrinth. An Account of the Social and Political Background of the Spanish Civil War, Cambridge 1971, S. 156 
auf die gesamte Menschheit ausdehnt, und sie ist einfach und durchschaubar, da nicht komplizierte Gesetze, sondern eine jedermann zugängliche und einsichtige Sozialmoral das tägliche Miteinander regelt. Die Naturgesetze sind die ungeschriebenen sozialen Normen, nach denen sich die Bewohner des pueblo zumindest teilweise richten. „Die Solidarität, die wir fordern - so ein Aufruf - ist Teil unseres eigenen Lebens", nicht nur eine abstrakte Norm für die Zukunft.

Die Orientierung der andalusischen Sozialbewegung an sozialen Verkehrsformen der Volksklassen wird auch negativ deutlich am Bild, das sie zur Lebensweise der herrschenden Klasse zeichnet. In der spanischen Arbeiterbewegung spielte die Kritik an der bürgerlichen Lebensmoral eine wichtige Rolle. Brenan schildert, wie 1936, als die Arbeiter das Zentrum Malagas anzünden, ein alter Anarchist auf die brennende Stadt herabschaut. (Im Zentrum befinden sich die großen Kirchen, die Geschäfte der Reichen, die Villen der señoritos.) „Ja - sagt er - sie brennen es nieder. Und ich sage dir, kein Stein wird auf dem anderen bleiben - nein, nicht eine Pflanze, nicht einmal Kohl wird hier wachsen, damit keine Verruchtheit mehr in der Welt ist" (S. 189).

Die bürgerliche Lebensmoral wird entschieden bekämpft, weil sie die Lebensweise der arbeitenden Klassen beeinflußt und zersetzt. Die schreibenden Arbeiter gehen häufig auf die korrumpierende, die Sitten verderbende Wirkung der Klassengesellschaft und ihrer dominierenden Moral ein. Als Beispiel führen sie an, daß der Hunger viele Frauen zu Prostituierten, ,ihre Liebe käuflich macht", oder daß sich Arbeiter durch relative Privilegien bestechen lassen und von der Klassensolidarität lossagen. Typisch sind Aussagen wie: ,Die gegenwärtige Gesellschaft hat alles, was an Gesundem, Edlem und Gerechtigkeitssinn in den menschlichen Gefühlen geblieben ist, verdorben und sie verdirbt es weiter." Dennoch hat sich eine gerechte und brïderliche Lebensmoral in den arbeitenden Klassen teilweise erhalten. Damit der Zersetzungsprozeß nicht weiter fortschreitet, muß die Revolution möglichst schnell stattfinden: „Nur eine Klasse bewahrt ihre alte seelische Reinheit. Es ist die Arbeiterklasse. Gleichwohl ist sie anfällig für das Eindringen des ekligen Virus, der noch immer unsere sozialen und ökonomischen Geschicke bestimmt. Daher müssen wir uns mit der Verteidigung beeilen, bevor wir in seine (des Virus) Fänge geraten." (35)

Zersetzend auf das Leben der arbeitenden Klassen wirkt sich vor allem der Warenverkehr aus. Ständig weisen die schreibenden Arbeiter auf seine verhängnisvollen Folgen hin. „Kein Zweifel, der Erfinder des Geldes hat dadurch den Menschen entwertet und einem Paperfetzen und einem Metall- oder Silberstück Wert gegeben." „Er ist verantwortlich, daß der Mensch sein persönliches ,Ich“ verlor, seine Unabhängigkeit: daß er zum Gegenstand wurde!“” „Mit diesem Paperfetzen und Metall-

35 Biologisierende Metaphern und Gesellschaftsbilder dürfen natürlich nicht unabhängig von ihrer politischen Funktion beurteilt werden. So hat der spanische Faschismus wenig später die Arbeiterbewegung als Krankheitsherd im Leben der Nation physisch auszurotten versucht. Für die biologisierenden Metaphern der andalusischen Sozialbewegung ist festzuhalten, daß sie immer soziale Verhältnisse darstellen sollen. So ist der ,,eklige Virus" die bürgerliche Lebensweise, nicht der einzelne Bürger. Auch muß beachtet werden, daß ein groBer Teil der biologisierenden Gesellschaftsbilder der Bewegung an lebendige bäuerliche Arbeits- und Naturerfahrungen anknüpft. 
oder Silberstücke haben, ich wiederhole, die Männer und Frauen das heiligste, das ach tbarste, das würdevollste und ehrenwerteste verloren, was das menschliche Wesen besitzen kann: Die Würde, die Redlichkeit, die Achtung - in einem Wort: die erhebende Moralität.“ „(Die Urheber des Geldes haben nichts Nützliches getan, nein,) sie waren einzig und allein Störer der gemeinschaftlichen und individuellen Ruhe, sie haben die geistige Erhabenheit des menschlichen Wesens verkrüppelt."

„Ruhe“", „Würde" und „Ach tung" sprechen wichtige Merkmale sozialer Verkehrsformen unter den arbeitenden Volksklassen an. „,Ruhe" bedeutet, wie noch heute im Alltagsgebrauch des andalusischen pueblos ersichtlich (vgl. unten), daß die Sozialbeziehungen und ihre Regeln durchschaubar sind (= Einfachheit des Lebens) und die Menschen gemeinschaftlich und hilfsbereit miteinander verkehren. An der Lohnarbeit wird neben ihrem ausbeuterischen Charakter immer herausgestellt, daß sie Würde und Achtung des Arbeiters vernichtet. Der Aspekt der formellen Freiheit und Gleichheit des Arbeitsvertrags verschwindet für die andalusischen Landarbeiter völlig hinter der Tatsache der sozialen Ungleichheit, der Herrschaftsgewalt des Kapitalisten und der Entwürdigung des Menschen zum Handelsobjekt.

Als Bewegung gehört der Agraranarchismus heute der Vergangenheit an. Wenn seine Ideen geschildert wurden, so nicht in der Annahme, daß sie noch gegenwärtig das Denken des andalusischen Volks bestimmen. Etwa wird heute die Forderung nach kollektiver Landverteilung stark überlagert von der Forderung, Fabriken auf dem Land zu errichten. Auch würde sich nach der Erweiterung staatlicher Funktionen und der Einführung minimaler sozialstaatlicher Sicherungen in den Landorten nicht mehr die Auffassung durchsetzen, daß der Staat sofort beseitigt werden kann. Und sicher würde eine erfolgreiche sozilrevolutionäre Bewegung nicht das Geld abschaffen, wie es noch 1936 in Castro del Rio, Ronda la Vieja und anderen Orten in der republikanischen Zone geschah (vgl. Anm. 25).

$\mathrm{Da}$ aber die Ideen ziemlich direkt an die sozialen Verhältnisse im pueblo und die alltäglichen Sozialerfahrungen des Volks anknüpfen, dürften sie das Denken andalusischer Arbeiter in vielfältiger Weise weiter bestimmen - nur eben nicht als anarchistische Ideologie. Für die, vorpolitisch bleibende, Kritik am Großstadtleben werden wir das später zeigen (Teil III). Der Terror der Faschisten, die alle greifbaren Sprecher der Bewegung erschossen und jede öffentliche Diskussion gesellschaftspolitischer Themen rigoros unterdruickten, hat jedoch dafür gesorgt, daß es eine öffentliche Überlieferung der Ideen nicht gibt. Dennoch ist die Tradition vor allem bei den Alteren nicht einfach verschwunden. Als Beispiel bringen wir Auszüge aus einem $\mathrm{Ge}-$ spräch mit einem gut 60 -jährigen Alten im Jahr 1973. Sie sollen gleichzeitig verdeutlichen, wie die Orientierung am pueblo als sozialer Gemeinschaft in eine Erklärung kapitalistischer Bereicherungssucht eingeht. Der Alte sieht den Grund dafür im Egoismus der Reichen, $d$.h. wörtlich ihrem Bestreben, sich vom Volk abzusondern und einen eigenen Lebenskreis $\mathrm{zu}$ bilden. Umgekehrt gewendet heißt das wohl, daß das gemeinschaftliche Leben verstärkt werden muß, um in der ,anderen Welt des allgemeinen Glücks" neue soziale Ungleichheit zu verhindern. Der Alte stammt aus einem Ort bei Jerez, in dem bis 1936 die C.N.T. praktisch die gesamte Arbeiterschaft organisiert hatte. Er arbeitet heute auf dem Bau, obwohl er einige Hektar Land besitzt, 
die er aber verpachtet hat. Der Grund? „Auf dem Bau kann ich den ganzen Tag mit meinen Kollegen reden, als kleiner Bauer wäre ich den ganzen Tag allein."

„Das Geld ist die Quelle aller miseria und darum ist es falsch zu meinen, man könne durch Geld glücklich werden. Die Reichen wollen immer mehr Geld, weil sie Egoisten sind. Sie wollen allein sein, sie sind hinter dem Geld her, um sich von anderen Menschen absondern zu können. Sie wollen das Geld, weil sie Einzelgänger sind und sie schnüren darum den anderen Menschen die Hälse zu. Sie töten, um sich zu bereichern, sie lassen verhungern; wer sich ihnen in den Weg stellt, den werfen sie ins Gefängnis oder bringen ihn um. Aber auch die Reichen werden nicht glïcklich. Das Glück gibt es nur in einer anderen Welt, einer Welt ohne Gefängnisse, ohne Geld, ohne Hunger, wo die Menschen alle gleich sind. In dieser Welt wird sich die Lage für alle verbessern. Die Reichen aber setzen alles daran, diese Welt zu verhindern, denn sie sind Egoisten und sie haben keine Liebe. Sie haben alle Macht, das Militär, die Polizei, die Gefängnisse, und doch werden sie diese Welt nicht verhindern können. Die Welt des Glücks, der Liebe und der Gleichheit wird kommen - das ist ganz sicher."

\section{Internationalismus und Persönlichkeitsbegriff der Landarbeiter}

In der marxistischen Diskussion überwiegt - so hatten wir anfangs festgehalten - die Skepsis gegenüber den emanzipatorischen Perspektiven bäuerlicher Sozialbewegungen vor allem dann, wenn sie sich auf dörfliche Lebensformen stützen, die sie gegen die Einflüsse der kapitalistischen Produktionsweise wiederherzustellen suchen. Diese Skepsis stiitzt sich unter anderm auf die Annahme, daß die dörfliche Lebensweise und die an sie anschließende Sozialbewegung soziozentrisch beschränkt bleibt und daß ihr, da sie die Entfaltung einer freien Individualität behindert, eine wesentliche Voraussetzung befreiter Vergesellschaftung abgeht. Wir wollen die Stichhaltigkeit dieser Annahmen am Fall des andalusischen Agraranarchismus prüfen.

1) Der Vorwurf des Soziozentrismus ist für die andalusische Arbeiterbewegung insofern relevant, als sie die kommunistische Gesellschaft in Form der Assoziation autonomer und selbstverwalteter Kommunen propagierte. Deformiert sich eine solche Vergesellschaftung zwangsläufig zu einem Antagonismus lokalbornierter Gemeinwesen, oder garantieren, wie die syndikalistische Sozialbewegung umgekehrt annahm, das Gemeinschaftsleben und die Gleichkeit in überschaubaren Kleingesellschaften gerade ein solidarisches Verhältnis der freien Kommunen? Theoretisch ist diese Frage sicher nicht entscheidbar. Was Ideengehalt und Strategie des Agraranarchismus in Spanien betrifft, so fällt jedoch, im Vergleich etwa zur sozialistischen Bewegung in derselben Region, ihre stark internationalistische Orientierung auf. Typisch sind ÄuBerungen wie die folgende des Arbeiterzentrums von Arcos 1932: „Wir, die Lohnabhängigen, die ewigen Sklaven, kennen weder Vaterland, noch Grenzen, wir sind Kosmopoliten. Wenn es ein Opfer der kapitalistischen Tyrannei gibt, möge es auch auf der anderen Seite des Erdballs leben, so betrachten wir es als unseren Bruder."

Internationalistische Orientierung und starke regionale wie lokale Autonomie der Bewegung waren in den Augen der Agraranarchisten kein Widerspruch. Die schrei- 
benden Arbeiter der Zeitschrift „La Autonomia“, die ab 1883 einige Jahre in Sevilla erschien, mach ten diese Verbindung zu einem regelrechten Leitthema. Ein sehr großer Teil der Artikel besteht aus Aufrufen, örtliche Arbeiterzentren zu bilden bzw. sich schon bestehenden Zentren anzuschließen. Die Aufrufe sind eingebettet entweder in allgemeine Darstellungen von Ausbeutung, Versklavung und der befreiten Gesellschaft, oder in Berichte über konkrete örtliche Arbeits- und Lebensbedingungen. Sie sind immer adressiert an die Arbeiter einer Berufsbranche, manchmal auch an ,die Arbeiter“ oder „, die Frauen“, und zwar einmal der ganzen Welt, zum anderen aus dem Ort des Artikelschreibers. Typisch sind Überschriften wie: „An alle Schuster im allgemeinen und im besonderen an die aus Montilla“. Internationalismus heißt, die Einheit der Arbeiterschaft am Ort voranzutreiben und diese Einheit hat nur dann Wert, wenn sie sich als Teil der weltweiten proletarischen Bewegung versteht. Es fasziniert in seiner Naivität, wenn die Frauen aus Sanlucar, einem größeren Küstenort in der Provins Cadiz, 1973 der weltweiten Bewegung mitzuteilen haben: „Die Sektion der Frauen von Sanlucar sendet einen brüderlicen Gruß an alle Arbeiter und Arbeiterinnen der Welt und teilt mit, daß sie in Kürze ein Manifest veröffentlichen wird."

Die Orientierung an der weltweiten Bewegung bekundet sich besonders eindrucksvoll im ",trienio bolchevista“" 1918 - 1920, al's vor allem die Dörfer und Agrostädte der Feld-und Olivenregion südlich von Cordoba mehrfach und geschlossen den Generalstreik ausriefen und für kurze Zeit Landarbeit und Ortsleben völlig paralysierten. Zeitweise konnten die Centros Obreros eine wirkliche Gegenmacht zum Rathaus im Ort begründen. Die Klassenkämpfe dieser Jahre sind eindeutig veranlaßt durch die Berichte von der russischen Oktoberrevolution. Sie gab den Landarbeitern das Signal, daß die Stunde der weltweiten Erhebung gegen den Kapitalismus gekommen war. Diaz del Moral berichtet, daß neben den Aktionen der Arbeiterbewegung in Deutschland und Ungarn vor allem Rußland und der Sturz der dortigen Bourgeoisie für Jahre behrrschendes Gesprächsthema war. „,Jede Unterhaltung führte unweigerlich in das Thema ,Rußland“" Und zwar bezogen auf konkrete Erfahrungen: Wenn man über die Aussaat sprach, stellte einer sofort die Frage: Wie sät man in Rußland aus? Regnet es dort viel, wieviel produziert man dort auf einer fanega Land? Immer wieder erkundigte man sich wo Rußland liegt, wieviel Tage man dorthin zu laufen hat...(36). Die Oktoberrevolution bewies den Tagelöhnern und Kleinproduzenten, daß es möglich war, die Bourgeoisie zu besiegen und sie gab mit der revolutionären Landnahme ein Beispiel für das eigene Ziel der „reparto“.

Ernsthafter ist der Einwand einer möglichen soziozentrischen Beschränktheit, wenn er auf die anarchistische Idee weitgehend selbstgenügsamer Dorfökonomie anspielt, die nur begrenzt in wechselseitigem Warentausch stehen. Die Volksklassen der andalusischen pueblos waren bis weit in dieses Jahrhundert imstande, ihre Reproduktion weitgehend autark zu sichern. Das Land, das kaum mit Maschinen bearbeitet wurde, lieferte alle Nahrungsmittel. Kleidung, Schuhzeug und den größten Teil des Hausrats stellten die Handwerker und Frauen im Ort her; die Baumaterialien der Häuser konnten aus Wäldern, Flußniederungen und Steinbrüchen beschafft werden; eine moderne medizinische Versorguing war, soweit überhaupt am Ort, für die arbei-

J. Diaz del Moral, a.a.O. 
tende Bevölkerung unerschwinglich, man griff auf überlieferte Heilmethoden und die Kenntnisse der Hebammen und curanderos (,Quacksalber") zurück. Der Staatsapparat schließlich erfüllte für die Armen keine nützlichen Aufgaben (wie Schulen, Versicherungen, Arbeitsbeschaffung), er trat rein als Organ der Unterdrückung und zusätzlichen Ausbeutung auf.

Unter solchen Umständen ist der Emanzipationsgedanke freier und autonomer Kommunen einleuchtend und naheliegend. Er bringt zunächst nicht eine Lokalborniertheit der Sozialbewegung zum Ausdruck, sondern den historischen Stand von Wirtschaftsweise, Reproduktionsniveau der Volksklasse und staatlicher Organisation. Insofern trifft der Soziozentrismusvorwurf den Agraranarchismus überhaupt nicht. Auch scheint die Annahme, das Denken und Handeln der arbeitenden Dorfbewohner sei lokalborniert (37), zumindest für die andalusischen Verhältnisse des 19. und 20. Jahrhunderts problematisch. Das System der Gelegenheitsarbeit zwang die Landarbeiter zu großer regionaler Mobilität. $\mathrm{Zu}$ den großen Erntearbeiten wie Weizen und Oliven kamen Männer und manchmal ganze Familien aus weitab gelegenen Orten. Große Kontigente der Weizenschnitter in der Feldregion von Jerez stammten immer aus dem Bergland um Ronda (Malaga) und dem südportugiesischen Alentejo. Ältere Arbeiter um Jerez betonen heute durchweg, man sei gut mit diesen „Gastarbeitern“ augekommen. Mit Sicherheit haben die Aktivisten der Bewegung das Zusammentreffen aus verschiedenen Gebieten zur Agitation und zu Absprachen genutzt. Umgekehrt zogen im Winter viele Familien aus der Feldregion in die Bergwälder, um dort von der Köhlerei zu leben. Diese Mobilität führte natürlich zu häufigem Ortswechsel, Heiraten in andere Dörfer usw.

In der mir zugänglichen Landarbeiterpresse Andalusiens habe ich Anzeichen lokalbornierten Denkens nicht gefunden. Im Gegenteil polemisiert „La Voz des Campesino“ heftig gegen das von der Republik geplante ,ley del termino“, wonach nur Arbeiter aus derselben Gemarkung für Landarbeit geworben werden dürfen. Mindestens in dieser Zeit fordert die „Förderation der Landarbeiter“ das Recht auf Arbeit in allen Gemarkungen. Auch rückblickend äußern sich heute alte Landarbeiter aus der Feldregion, die an sich durch das Gesetz bevorzugt wurden, eher abfällig zum ,ley del termino“.

2) Die zweite Annahme, die die Skepsis vieler Marxisten gegen bäuerliche Sozialbewegungen stützt, betrifft die „Fesseln der Gruppenbeziehungen“ die in Landgemeinden mit stark kommunalen Lebensformen eine Entfaltung menschlicher Individualität verhindern sollen. Traditionell waren die Sozialbeziehungen unter den Volksklas-

37 So noch der englische Sozialanthropologe J.A. Pitt-Rivers in seiner auf Feldforschungen beruhenden Studie The People of the Sierra, London 1954 (neuaufg. 1971).

Gegen alle Legenden dörflicher Abgeschlossenheit und Idyllik möchte ich nochmals betonen, daß in diesem Aufsatz unter "Idealisierung des pueblo bzw. ländlicher Gemeinwesen" die Verteidigung einer sozialen Lebensweise und Klassenkultur verstanden wird, die sich vor allem bei der arbeitenden Bevölkerung in Landkommunen findet. Dabei können diese Landkommunen durchaus städtische Dimensionen haben, entscheidend sind die Dominanz landwirtschaftlicher Produktion, eine Homogenität im Lebensstil der Volksklassen, eine sozial offene Wohnweise der Familien. 
sen andalusischer pueblos sehr dicht. Die Familien wohnten in kleinen Häusern, die in der Regel aus einer Küche und einem Schlafraum bestanden und ohne Zwischenraum an den Dorfstraßen aneinandergereiht waren. Die Straßen waren der hauptsächliche Aufenthaltsort der Familie, die Frauen verrichteten wichtige Tätigkeiten gemeinsam, z. B. das Waschen an den wenigen Dorfbrunnen. Teilweise waren die Familien in kleinen Mietshäusern mit einem Obergeschoß zusammengepfercht, deren Wohnungen alle auf einen gemeinsamen Innenhof führten. Erst seit den 60er Jahren löst sich dieser enge Wohnzusammenhang teilweise dadurch auf, daß die Familien weiter Wand an Wand - Häuschen mit gesondertem Innenhof bauen können.

Traditionell lebte nur die dïnne Mittelschicht der Orte in relativ separierten Häusem. Die Agrarkapitalisten gehörten in der Regel nicht zum pueblo, sondern wohnten in Luxuspalästen der großen Provinzstädte. Der ständige soziale Zusammenhang wurde für die Landproletarier auch nicht im Arbeitsprozeß durchbrochen. Landarbeit fand fast durchweg in sog. cuadrillas statt, Arbeitsgruppen von überschaubarer Größe, und war außerdem durch einfache Kooperation, also geringe arbeitsteilige Differenzierung in der Gruppe gekennzeichnet. Eine Ausnahme waren die Kleinbauern auf eigne Rechnung, die z. T. auch außerhalb des Ortes lebten und die Kleinpächter. Individualisierung im Arbeitsprozeß gibt es in nennenswertem Maß erst seit den 50iger Jahren durch die Mechanisierung, also durch Einführung von Traktoren, die in Gebieten mit intensiver Feldbewirtschaftung einem relevanten Teil der Landproletarier Arbeit geben (einer um das Vielfache höheren Zahl allerdings Arbeit rauben).

Die dichten Sozialbeziehungen in Arbeit und Alltagsleben erschwerten zweifellos eine Privatisierung der im Ort ansässigen Personen und Familien. Eine abgesonderte Individualität konnte (und kann) sich nur unter Brüskierung des ständigen $\mathrm{Zu}$ sammenlebens herausbilden. Andererseits blockiert der kollektive Lebenszusammenhang nicht die Anerkennung von Individualität, soweit sie sich nicht gegen die gemeinsame Lebensweise stellt. Nach unseren Beobachtungen zur gegenwärtigen Sozialstruktur andalusischer Landorte ermöglicht gerade das intensive Gemeinschaftsleben, daß sich die Ortsnachbarn über ihre persönlichen Besonderheiten bzw. ihre an die Person geknüpfte Stellung im Ort identifizieren. Nur verläuft die Differenzierung der Individualitäten sozusagen horizontal, sie sprengt nicht die Gleichheit in den Sozialbeziehungen der Volksklasse. Weder begründet die persönliche Stellung eine soziale Dominanz, noch schlagen sich Unterschiede der ökonomischen Stellung im alltäglichen Sozialverkehr nieder. In der Anerkennung persönlicher Besonderheit wird entweder die Klassendifferenz durch vorgetäuschte Gleichheit überdeckt, oder es wird die soziale Interaktion zwischen besitzender und arbeitender Klasse, „,en Reichen“ und, ,den Armen" weitgehend vermieden. Noch heute dominiert der zweite Weg, obwohl der erste im letzen Jahrzehnt langsam zuzunehmen scheint.

Diese relativ abstrakten Feststellungen zum Persönlichkeitsbegriff sollen am gegenwärtigen Leben der ländlichen Volksklasse etwas erläutert werden. Daß hinter die persönliche Indentifikation die Anerkennung über unpersönliche Funktionen oder Rollen zurïcktritt, schlägt sich etwa in der Art der Namensgebung nieder. Man redet sich im pueblo durchweg mit Vornamen an. Da die meisten Namen eine große Verbreitung haben, individualisieren sie natürlich nur im direkten Gespräch. Besonderers 
in Unterhaltungen über Dritte bedient man sich daher der „apodos" - durch ,Spitz* name " sehr unzulänglich übersetzt. Jeder Ortsbewohner trägt mindestens einen apodo, der im Gegensatz zum staatlichen Familiennamen allgemein bekannt ist. Die apodos werden aufgrund bestimmter Persönlichkeitsmerkmale oder wegen besonderer Vorfälle geprägt, in die der Träger verwickelt war. Zum Teil werden sie über Generationen in der Familie vererbt, die betreffende Person trägt dann oft einen weiteren apodo, der genuin auf sie zugeschnitten ist. Nie beziehen sich die apodos auf einen sozialen Status, eine berufliche Funktion oder sonstige allgemeine soziale Eigenschaften, es sei denn, Status oder Funktion sind nur einmalig im pueblo vertreten.

Wie weit sich dieses Prinzip der persönlichen Identifikation auch auf Mitglieder der herrschenden Klasse erstreckt, können wir schwer beurteilen. Gesprächsweise bezieht man sich auf sie meist über den unpersönlichen Status, also etwa „el alcalde“ (der Bürgermeister), „el cura" (der Priester), ,el señorito de los Arquillos "=Name eines Gutshofes). Noch heute wird vielfach gesagt, daß ,los ricos y los que mandan“, die Reichen und die Herrschenden, überhaupt nicht zum pueblo gehören. Sie grenzen sich aus dem Alltagsleben des Ortes aus, oder sie werden aus den Verkehrskreisen der arbeitenden Bevölkerung ausgegrenzt. Doch trifft diese Feststellung heute nicht mehr generell zu. Durch den zunehmenden innerdörflichen Warenverkehr, den vor allem die Überweisungen der Emigranten angeregt haben (Hausbau, Anschaffung vonHausrat), hat sich eine Art "neuer Mittelklasse" herausgebildet, die im Ortsleben eine Zwischenstellung einnimmt.

Teilweise setzt sie sich deutlich von der ortsansässigen Arbeiterschaft ab und liiert sich mit der traditionell herrschenden Klasse, teilweise bleibt sie in das Alltagsleben der Volksklasse integriert. Nur wird dann, begünstigt durch Familien- und Freundschaftsbeziehungen, der Klassenunterschied durch vorgetäuschte Gleichheit in der direkten Interaktion verdeckt. Diese Überdeckung gelingt weniger im Verkehr mit den Argarkapitalisten, soweit diese im Ort ansässig sind. Die señoritos neigen, soweit sie mit den Arbeitern ,,alltäglich“ zusammenkommen, stark dazu, durch gewollte Witzigkeit und Jovialität den großen Mann zu markieren, wobei dieses Verhalten viele Arbeiter offensichtlich peinlich berührt - eine Reaktion, die den señorito im Sozialverkehr wiederum deutlich verunsichert.

Insgesamt läßt sich festhalten, daß die persönliche Individualität im andalusischen pueblo voll anerkannt wird, wobei sich vor allem für die Jahrzehnte offener Klassenkämpfe diese Anerkennung auf́ die Angehörigen der Volksklasse beschränkte. In der agraranarchistischen - sicher auch der sozialistischen - Sozialbewegung spielte die Anerkennung persönlicher Individualität eine wichtige Rolle. Die obreros conscientes, die bewußten Asbeiter, überzeugten hauptsächlich durch ihr persönliches Beispiel der Lebensfuihrung. Außerdem fällt auf, daß in Berichten über Volksreden der obreros conscientes die Darstellung ihrer persönlichen Eigenischaften und Verhaltenszüge einen ziemlichen Raum einnimmt. Der Inhalt der Ideen wird von der Person, die sie vertritt, nicht getrennt, sie erhält durch Persönlichkeit und Verhalten des obrero consciente erst wirkliche Uberzeugungskraft. ,Pino lebt sehr puritanisch und war kräftig wie nur wenige. Er zeigte eine hohe und breite Stim, feurige Augen und einen schönen schwarzen Bart. (Seine Prinzipien verwirklichte er in der eigenen 
Lebensführung). Und in seinen autorisierten und überzeugenden Worten glänzte die Wahrheit und Gerechtigkeit der proletarischen Bestrebungen. In den Orten der Provinz Malaga blieb die Wirkung seiner Propaganda unbesiegbar."

So beschreibt ein Drucker aus Madrid einen andalusischen Militanten Ende des 19. Jahrhunderts (38).

Abschließend sei vor historischen Nostalgien gewarnt: Die bedeutendste Klassenorganisation in Andalusien war die C.N.T. nur bis 1936. Heute spielt sie kaum mehr eine Rolle. Nach allen unseren Informationen hat heute die Kommunistische Partei (P.C.E.) unter den politisch bewußten Arbeitern den stärksten Rückhalt. Lange Zeit war sie die einzig nennenswerte Kraft im antifaschistischen Widerstand. Und wenn in den letzten Jahren Landarbeiter organisiert gekämpft haben, bildeten sie „Arbeiterkommissionen“ (CCOO). An die CCOO knüpfen sich in Spanien heute die Hoffnungen auf eine einheitliche und starke Arbeiterbewegung.

\section{Andalusische Arbeitsemigration: Bindung an das Dorfleben und die Erfahrung westeuropäischen Großstad tlebens}

Der andalusische Agraranarchismus wollte, wie jede ländliche Sozialbewegung, die gesellschaftlichen Verhältnisse am Ort ändern. Solange die Hoffnung auf eine große historische Wende für das internationale Proletariat noch bestand und die Aktivitäten zu ihrer Herbeiführung andauerten, blieben auch die ärmsten Familien im pueblo. Teilweise, scheint es, galt die Abwanderung als Klassenverrat. So ist Andalusien, obwohl nach dem Lebensstandard eine der ärmsten Regionen Spaniens, um die Jahrhundertwende an der damals dominierenden transozeanischen Emigration nur geringfügig beteiligt (39). Auch nach Katalonien, das damals als industrialisiertes Gebiet viele Landarbeiter aus anderen Provinzen anzog, gingen die Andalusier kaum. Nach dem militärischen Sieg des Faschismus in Spanien änderte sich wegen der nationalen Autarkiepolitik und wegen der Stagnation der spanischen Industrie diese Situation zunächst nicht. Die Verelendung der Landbevölkenung spitzte sich weiter zu - nach übereinstimmenden Berichten aus den Dörfern gelten die Jahre nach dem Krieg als die schlimmste Hungerzeit, die das andalusische Landproletriat erlebt hat. Gleichzeitig macht der Terrorismus der Bourgeoisie die Hoffnungen auf eine soziale Veränderung vorläufig zunichte. Die Guerillabewegung in den andalusischen Berggegenden, die an Traditionen des Sozialbanditismus anknüpfte, wurde um 1950 zerschlagen.

\section{Die Emigrationsbewegung vom Land}

Im historischen Kontext des Scheiterns der ländlichen Sozialbewegung steht die Ab-

39 Deutlich belegen das etwa die Statistiken in: La Emigracion Espanola transoceanica 1911 -1915, Madrid 1916 
wanderung vom Land, die in Andalusien mit der zunehmenden Industrialisierung Spaniens einsetzt und ab 1959 mit der Arbeitsemigration nach Westeuropa ihre Fortsetzung findet. Die Vororte Barcelonas sind heute Wohnsiedlungen, deren Bewohner fast durchweg aus südspanischen Gebieten stammen. Von 1960 bis 1973 haben, die Saisonemigranten auf das französische Land abgerechnet, vielleicht eine halbe Million Andalusier in Westeuropa gearbeitet, meist Landarbeiter und auf Lohnarbeit angewiesene Kleinbauern.

Aus der Sicht der kleineren Landorte ist die Abwanderung noch massiver. Für viele pueblos zwischen 2,5 und 5.000 Einwohnern können wir ziemlich gesichert schätzen, daß zwischen 30 und $50 \%$ aller arbeitsfähigen Männer aus dem Landproletariat, dem Kleinhandel, Handwerker und aus „Arbeiterbauern“ - Familien mindestens $1 \mathrm{x}$ in der westeuropäischen Industrie gearbeitet hat. Rechnet man die Saisonemigranten in die französiche Landwirtschaft dazu, die von wenigen Wochen bis zu einem halben Jahr dauern kann, kommt man auf 50 - 70 \% aller Arbeiter. Die Auslandsemigration stellt also eine zentrale Realität im Lebensalltag der Arbeiterfamilien dar. Da außerdem die Emigration die Agrarkapitalisten zu deutlichen Lohnerhöhungen seit 1960 gezwungen hat, wird klar, daß erst sie den Arbeiterfamilien übehaupt eine menschenwürdige Existenz sichert. Niemandem ist die lebenswichtige Bedeutung der Emigration klarer als den Emigranten und den im Dorf verbleibenden Arbeitern, die ja selbst in ihrer Mehrheit vor Jahren im Ausland waren. „Gäbe es keine Emigration, dann würden wir noch in demselben Elend leben wie vor 15 Jahren." Da die andauernde Krise des Kapitalismus viele zur Rückkehr zwingt und Anwerbebeschränkungen wie Anwerbestop einer neuerlichen Abwanderung Riegel vorschieben, spitzt sich gegenwärtig die ökonomisch Situation auf dem andalusischen Land ungemein zu (40). Gleichzeitig stagnieren spanische Industrie und Bauwirtschaft und die fortschreitende Mechanisierung der Landwirtschaft raubt den Dorfbewohnern weiter Arbeitsplätze. Bereits 1974 war der Stop der Emigration ein politisch brisantes Gesprächsthema. „Was passiert, wenn es in Westeuropa keine Arbeit mehr gibt und alle Emigranten zurückmüssen?" Die meisten wichen der Frage aus oder sagten, es sei gefährlich darüber zu reden. Andere erklärten bündig: ,Wenn das passiert, dann gibt es hier Krieg, dann gibt es Revolution“.

Für unsere Fragestellung ist das Verhältnis der innerspanischen zur europäischen Emigration von Interesse. Beide stehen, was die Zukunftsperspektive der Emigranten betrifft, ihrer Gesamttendenz nach in einem Gegensatz. Während die Abwanderung in eine spanische Industriezone fast immer endgültig ist und darum auch meist im Familienverband vollzogen wird, ist die Arbeit im Ausland eine überwiegend provisorische Migration. In der Regel ist sie mit der Absicht verbunden, in den ländlichen Heimatort zurückzukehren. Typisch ist die Auslandsemigration von Familienvätern oder unverheirateten Männern, die ihrer Familie einen Verbleib im Ort sichern wollen:

Diese Existenzsicherung besteht zunächst darin, das Allernotwendigste zu dekken, also Essen, Kleidung und Wohnung, was sich im allgemeinen Ausspruch nieder-

40 Über die Lage von Herbst 1975 - Frühjahr 1976 berichtet näher die Portugal-Spanien Zeitschrift, Nr. 5, Juni 1976. 
schlägt: „Wir emigrieren, um der Familie zu essen zu geben“. Teilweise werden die Auslandsersparnisse auch zum Kauf dauerhafter Konsum- und Gebrauchsgüter wie Kühlschrank, Wäscheschleuder, Möbel, Fernseher, Bad und Toilette verwendet. Im Gegensatz zu unter westdeutschen Linken kursierenden Thesen von einer „kleinbürgerlichen Zukunftsperspektive" bereiten andalusische - wie überhaupt spanische Arbeiteremigranten nur sehr selten eine Existenz als Händler oder Kleinproduzent im Heimatort vor, noch weniger in einer spanischen Großstadt. In einigen Gebieten kaufen Emigranten winzige Landstïcke, um nach der Rückkehr eine minimale Subsistenzgrundlage für die Familie zu haben. Der Warenhandel, der sich besonders durch Überweisungen der Emigranten stark ausbreiten konnte, wird hauptsächlich von reicheren Handwerkern oder ehemaligen Besitzbauern getragen, die nie zu emigrieren brauch ten. Er ist außerdem von einer raschen Besitzkonzentration begleitet. Ehemalige Emigranten findet man ,im Geschäft" der Dörfer kaum. Sehr wenige eröffnen eine Bar, sind über ihre Tätigkeit aber derart mit der Arbeiteröffentlichkeit verbunden, daß sie sich kaum von den proletarischen Familien absetzen. Eher noch dürften viele kleine Gastwirte Wortführer einer möglichen neuen Arbeiterbewegung in Andalusien sein.

Sehr verbreitet ist unter Emigranten der Wunsch, den Kindern durch ihre Opfer dasselbe elende Lebensschicksal zu ersparen. „Ich emigriere, damit meine Kinder eine Schule besuchen und später einen Beruf erlernen können“. Dieses Ziel ist aber angesichts der katastrophalen Schulsituation in Spanien, die Arbeiterkinder noch weit mehr benachteiltigt als in der BRD, kaum zu erreichen. Selbst Emigranten können die kostspielige weiterführende Schul- und Berufsausbildung höchstens dann finanzieren, wenn ihren Kindern ein staatliches Stipendium gewährt wird. Und das ist nur selten der Fall.

Obwohl die erhoffte Ausbildung die Kinder dazu zwingen würde, das heimatliche Dorf zu verlassen, überwiegt bei den Emigranten eindeutig die Perspektive der Riickkehr. Ihre Häufigkeit variiert jedoch mit der besonderen „Arbeitsmarktlage“ im Ortsumkreis. Läßt diese ein Auskommen nach dem sozial geltenden Reproduktionsminimum erwarten, sind eindeutig die Emigranten in der Überzahl, die den Auslandsaufenthalt zum Ortsverbleib nutzen wollen, und das etwa durch den Bau eines Hauses und größere Anschaffungen an Hausrat beabsichtigen. So wurden in einem Ort innerhalb von 10 Jahren, ungefähr 200 Häuser von Emigranten errichtet, die vorher mit ihren Familien in Mietshäusern zusammengepfercht waren.Die Einwohnerzahl nahm, nach def Ortsstatistik, von 1960 - 1972 von etwa 3.200 auf $3.600 \mathrm{zu}$, das natürliche Bevölkerungswachstum in der Region eingerechnet, zogen demnach $10 \%$ in andere Regionen Spaniens. Dieser vorwiegend von Landproletariern bewohnte Ort lag in einem fruchtbaren Gebiet mit relativ günstigen Arbeitsmöglichkeiten, was für Andalusien 6 bis höchstens 8 Monate Lohnarbeit im Jahr bedeutet. Außerdem fand ein Teil der Arbeiter als Pendler in einer nicht übermäßig entfernten Industriezone Beschäftigung.

In Orten mit permanenter, nicht nur saisonal begrenzter Arbeitslosigkeit, zögert die Auslandsemigration eher eine endguiltige Entscheidung über den Ortswegzug hinaus, oder man bereitet diesen gezielt vor, indem man Geld für den Kauf einer 
Stadtwohnung anlegt (ohne diese Anlage müßte die in Spanien abwartenden Familien in elenden städtischen Slumvierteln hausen). So verringerte sich in einem Ort, der solche miserablen Arbeitsbedingungen aufwies, die Bewohnerschaft von 3.800 1960 auf 2.6001970 , was einem realen Schwund von $75 \%$ entspricht. Hier zerstörte die kapitalistische Ökonomie den Arbeiterfamilien weitgehend die minimale Voraussetzung dazu, die Bedingung an den Heimatort aufrechtzuerhalten.

Die zurückgekehrten und im Urlaub weilenden Arbeiter äußern sich über die Emigration oft sehr positiv und in idealisierenden Schilderungen, wenn sie nicht was häufiger vorkommt - sich überhaupt ausschweigen. In aller Regel teilen sie auch ihren Kollegen die extremen Entfremdungen des Auslandsaufenthalts nicht mit - die sexuellen Entsagungen, die harten Arbeitsbedingungen, der Lohnbetrug, die völlige Isolierung, die Diskrimination, die Schikanen mit der Bürokratie und ihren undurchschaubaren Auflagen. Andalusische Emigranten in Europa beklagen sich oft, daß darüber ihre erfahrenen Kollegen am Ort nicht gesprochen haben. Dieses Verhalten des Verschweigens oder der Idealisierung spiegelt aber mehr eine Verdrängung und Kompensation traumatischer Lebenserfahrungen wider. Nach einer Stichprobe, die wir in einem Ort aus verschiedenen Gesprächen mit Emigranten zusammengestellt haben, hielt jeder sechste weniger als ein Jahr im Ausland durch, einige ergriffen schon nach ein paar Wochen die Flucht. Hier sind diejenigen nicht eingerechnet, die ihren Auslandsaufenthalt mehrfach unterbrochen haben und sich nach einiger Zeit neu anwerben ließen.

Das Gesamtbild von der Emigrationszeit, das unabhängig von dem immer als besser hingestellten individuellen Schicksal gezeichnet wird, ist eindeutig düster. Die Emigration ins Ausland gilt allgemein als „Opfer" oder gar „Martyrium“, sie verbindes sich mit den Bildern von Krankheit und Tod. „Mädchen, wie gern wïrde ich heute Nacht vor dein Fenster kommen und singen. Aber ich habe Angst vor deinem Vater, mehr als vor dem Tod. Dein Vater wünscht, daß ich nach Deutschland gehe und für immer dort bleibe“ - so lautet der Text einer beliebten „copla“, Liedersprüche, die in Andalusien viel gesungen werden. Die Angst bezieht sich auf die Gefahr, die Bindung an den Heimatort zu verlieren. Landarbeiter schreiben gemeinsam mit fortschrittlichen Landlehrern ein Theaterstück, mit dem Thema des verlorenen Sohnes in Deutschland, der spät und krank zurückkehrt, als seine Mutter vor Trennungsschmerz gestorben ist. „Verfluchte Emigration, die unsere Männer so verändert. Schwalben mit starken Flügeln, die eines Tages losfliegen und lange Zeit in der Luft bleiben, ohne auf die Erde zu kommen. Müde vom Flug und mit gebrochenen Flügeln kommen sie zurück, auf der Suche nach dem Nest, das sie verlassen haben und jetzt kalt und leer vorfinden."

\section{Landarbeit und Fabrik}

Was hält so viele Landarbeiter und Kleinproduzenten Andalusiens davon ab, ihren Heimatort für immer zu verlassen und statt desssen das Martyrium der jahrelangen Emigration, getrennt von Familie und Freunden, in Kauf zu nehmen? Die höheren 
Löhne sind allein keine ausreichende Erklärung, da die wenigen Ersparnisse nach der geplanten Rückkehr in den pueblo schnell aufgebraucht sein werden, und da die Gründung einer kleinbürgerlichen Existenz von den meisten län dlichen Emigranten nicht ernsthaft erwogen wird. Auf keinen Fall übt die Landarbeit nach der Rückkehr irgendeine Anziehungskraft aus. Landarbeit beurteilt man einhellig als härter denn Fabrikarbeit. Zwar spiegelt dieses Urteil auch das Selbstbewußtsein der Landproletarier - so gelten die schwieligen Hände als vereinigendes Klassensymbol, das die Arbeiterschaft von den reichen Nichtstuern, den parasitären „Brotschluckern" mit „dicken Bäuchen“" abgrenzt; dennoch artikuliert es vor allem eine Ablehnung der Landarbeit. ,Niemand hier würde noch auf die Felder gehen, wenn er eine andere Arbeit fände" - so ein ehemaliger Landarbeiter, jetzt Klempner im Ort.

Abgelehnt wird die Landarbeit aus drei Gründen: wegen des geringen Lohns, der hohen physichen Kraftverausgabung, der langen Perioden der Arbeitslosigkeit. ,Wir schuften uns auf den Feldern ab und verdienen dabei ein Stück Scheiße". Im Sommer arbeitet man in extremer Hitze, im Winter bei Regen und auf verschlammtem Boden, die Arbeit ist anstrengend und wird meistens im Akkord verrichtet. Die Arbeitsgeschwindigkeit, etwa der körperlich schweren Zuckerrübenernte, liegt höher als das gegenwärtige Durchschnittstempo industrieller Bandarbeit. Aber selbst der Akkordlohn reicht den Familien nicht, die arbeitslose Zeit zu überbrücken. ,,Hier findest du für einen Monat Arbeit und die folgenden zwei sitzt du im Ort herum und verdienst keine Pesete". Selbst in Orten mit intensiv bewirtschaftetem Umland kann ein Landarbeiter ohne feste Stelle mit höchstens 6 Monaten Tageslohnarbeit im Jahr rechnen.

Die Ablehnung der Landarbeit hat auch historische Dimensionen. Generationenlange Erfahrung des Hungers und des Elends, der Arbeitslosigkeit, der endlosen Tage während der Stoßzeiten, „wo wir von morgens 4 bis abends 9, 10 auf den Feldern waren", der Kasernierung in den Gutshöfen, wo man bei kümmerlichem Essen auf Steinböden schlief und von Ungeziefer zerfressen wurde, haben sich der Arbeiterschaft eingeprägt. Hinzu kommt das Scheitern der andalusischen Sozialbewegung, die sich um das Ziel der „,reparto“, der kollektiven Enteignung der Latifundien zentriert. Heute wird die Idee der reparto durch die Forderung nach Industrialisierung des Umlandes überlagert. ,,Die senoritos scheffeln Millionen und lassen sie nutzlos auf der Bank verkommen. Baute man Fabriken auf dem Land, brauchten wir nicht zu emigrieren, wir würden im pueblo bleiben." Die Landarbeiter wissen aber auch, daß diese Perspektive, illusionär ist, solange das kapitalistische Regime in Spanien weiter besteht.

Fabriken auf dem Land versprechen ständige Arbeit, ausreichenden Lohn und ermöglichen ein Verbleiben im Ort. Diese Hoffnungen beherrschen die andalusischen Arbeiter so sehr, daß sie die Fabrikarbeit gegen ihre eigenen Erfahrungen idealisieren. Viele Emigranten haben die Auslandsarbeit vorzeitig abgebrochen, weil sie mit den Einschränkungen der Bewegungsfreiheit, der despotischen Befehlsstruktur, der Asozialität der Tätigkeit - alle Faktoren konstrastieren stark mit ländlichen Arbeitsformen in Andalusien - nicht zurecht kamen. Einige Arbeiter erklärten, Magenbeschwerden, durch die Gasdämpfe in der Fabrik verursacht, hätten den vorzeitigen Abbruch erzwungen. „In der Fabrik ist man mit 40 Jahren ein alter Mann“, meinte 
ein ehemaliger Emigrant, jetzt Vorarbeiter auf einem Gut. Von 56 Arbeitern, mit denen wir in einem Dorf über konkrete Rückkehranlässe reden konnten, stellten ,zu niedriger Lohn" und „Wirtschaftskrise" nicht eingerechnet - 15 eindeutig negative Erfahrungen mit der Industriearbeit in den Vordergrund, wobei vor allem Auseinandersetzungen mit den Meistern, Somatisierung von Arbeitsentfremdung in $\mathrm{Ma}$ genkrankheiten und das traumatische Erlebnis der Größe und sozialen Unübersichtlichkeit einer Fabrik dominierten.

Kritische Äußerungen über Fabrikarbeit fielen aber nur in vertraulchen Gesprächen und selten mit dem Tenor ,das Land ist besser", die öffentlich geführten Unterhaltungen folgen fast immer dem Topos ,das Land ist härter als die Fabrik. dort verdient man mehr und muß dabei weniger arbeiten". Unter dem Gesichtspunkt der zu erwartenden Arbeitstätigkeit sehen die Andalusier also keinen Grund, nicht in die Großstadt abzuwandern.

\section{Bindung an das Dorfleben}

Offenbar spielen in der Entscheidung, provisorisch im Ausland zu arbeiten, um später weiter im Heimatort leben zu können, Bindungen an die sozialen Verkehrsformen im pueblo eine nicht unbeträchtliche Rolle. Viele Emigranten bestätigten das in ihren Äußerungen, wenn sie sagen, daß sie lieber das Opfer vorübergehender Trennung von Familie und Freunden in Kauf nehmen, als für immer den pueblo zu verlassen. ,,Hier führte ich ein ruhiges Leben, woanders finde ich das nicht", ist eine häufige Antwort. (Was mit ,ruhig" gemeint ist, werden wir noch sehen). Ihre vom Kapitalismus erzeugte Armut stellt die Arbeiter vor die paradoxe Situation, Jahre getrennt von der Familie verbringen zu müssen, um vielleicht - diese Hoffnung ist keinesfalls gesichert - den Rest des Lebens im pueblo wohnen zu können. Diese Orientierung am ländlichen pueblo beschränkt sich ziemlich eindeutig nicht auf die Familienbeziehungen. Dann wäre es folgerichtiger, mit der Familie innerhalb Spaniens auszuwandern und wenn notwendig, nur solange ins Ausland zu gehen, bis das Geld für den Eintritt in eine Stadtwohnung zusammengespart ist. Das aber ist, soweit die Arbeitsmöglichkeiten im Ortsumkreis das noch zulassen, gerade nicht die Absicht der meisten ländlichen Arbeitsemigranten, jedenfalls nicht in den Dörfern der Provinz Cadiz.

Im folgenden werden wir die Identifikation der andalusischen Arbeiter mit den sozialen Verkehrsformen im pueblo deutlich machen, indem wir ihre Wahrnehmung und Beurteilung des sozialen Alltagslebens in spätkapitalistischen Großstädten, vor allem Westdeutschland, darstellen. Einschränkend sei vorweggeschickt, daß die Reintegration zurückkehrender. Emigranten in das soziale Leben des pueblo auch dann häufig zu Schwierigkeiten führt, wenn die Erfahrungen des Auslands die Identifikation mit dem Heimatort noch verstärken. Ohne diese Schwierigkeiten an dieser Stelle näher zu schildern, sei doch festzuhalten, daß die praktischen Bindungen an das Dorfleben durch den lebensgeschichtlichen Bruch der vorübergehenden Abwanderung stark gefährdet sind. Zum Teil drückt sich das in schweren Identitätskrisen zurückgekehrter Emigranten aus. 
Ebensowenig behaupten wir, daß die Sozialbeziehungen im pueblo von Auflösungsprozessen verschiedener Art, zum Teil durch die Emigranten selbst verursacht, unberührt bleiben.

So hat natürlich die massive Abwanderung aus dem einen Ort, die binnen eines Jahrzehnts $75 \%$ der Bevölkerung erfaßte, auf die dörfliche Gemeinschaft tiefgreifende Auswirkungen. Dort wurde denn auch beständig darauf hingewiesen, daß es früher, als noch alle Nachbarn zusammenlebten, viel mehr alegria (Freude) und cachondeo (Scherzgespräche) gegeben habe - beides Begriffe, mit denen Andalusier die intensive Alltagskommunikation und die Möglichkeit, darin als Individuum und Kollektiv aufzugehen, umschreiben. Dennoch hatte sich gerade in diesem pueblo, der fast nur von Arbeiterfamilien und sehr kleinen Bauern bewohnt wird, das ausgedehnte Gemeinschaftsleben nicht völlig aufgelöst.

Zerstörende Wirkungen auf das Ortsleben hat die Ausbreitung der Massenmedien in andalusischen pueblos, ebenso wie der Fußballfanatismus vieler Männer, der nach Auffassung kritischer Arbeiter kompensatorische Funktion hat, weil er die Leute von ihren wirklichen Problemen ablenkt, und zum zweiten die Direktheit der alltäglichen Sozialbeziehungen bedroht. Ein kritischer Arbeiteremigrant: ,Der Fußball ist eine ziemlich politische Sache. Die Regierung macht viel Propaganda damit, seit 6 - 7 Jahren denken viele nur noch an Fußball und vergessen alle ihre Probleme dabei. Die Leute werden richtig verrückt, ieder hat seinen Lieblingsverein und dann ist $\mathrm{ihm}$ das wichtigste in seinem Leben, daß der Verein gewinnt. In den Kneipen ist das manchmal mit dem Gerede über den Fußball nicht mehr auszuhalten. Ich gehe deshalb oft gar nicht mehr rein. Mir reichts. Ich falle auf diesen Trick Francos nicht rein". Seinen Einfluß hat der Fußball über das Fernsehen gewinnen können, der heute in sehr vielen Arbeiterfamilien zu finden ist. Die negativen Auswirkungen des TV auf die gemeinschaftlichen Alltagsbeziehungen sind allerdings nicht eindeutig. Abgesehen davon, daß der Apparat oft nur als audo-visuelle Reizkulisse am Rande intensiver und direkter Kommunikation läuft, findet man im andalusischen Volk das abgeschlossene Familienfernsehen noch relativ selten - sehr zum Leidwesen örtlicher Priester, die im Sinn der herrschenden Ideologie die Familienbindungen stärken und die kommunalen Alltagsbeziehungen schwächen wollen. Die beliebten Wildwestfilme sehen die Männer in den Bars gemeinsam an, wie sich anläßlich von Filmen, die auf das Interesse der Frauen stoßen, oft Nachbarinnen in einem Haus versammeln.

Die herrschende Bewußtseinsindustrie kann vor allem dort auflösend auf die Gemeinschaft der Volksklasse wirken, wo sie auf Unterdrückungsmechanismen in dieser Gemeinschaft und damit auf emanzipatorische Grenzen stößt. Das trifft insbesondere für die Unterdrückung der Frau und generell für die sexuelle Unterdrükkung zu. Sie verknüpft sich bei vielen Jugendlichen mit projektiven Erwartungshaltungen an die angeblich freiere Großstadt. So begründeten manche Mädchen ihren Wunsch, in eine Stadt zu ziehen, mit dem unmißverständlichen Hinweis: ,Dort finde ich Arbeit und Vergnügen“. Im pueblo sind sie an den elterlichen Haushalt gebunden und ihr Verkehr mit jungen Männern wird durch die Ortsöffentlichkeit streng kontrolliert, wenngleich sehr viel schwächer als noch vor 20 Jahren. Hinzu kommt für die Mädchen, daß sie nur selten - und dann im Familienverband - ins Ausland 
gehen können. Da viele der unverheirateten Männer dort arbeiten, müssen sie befürchten, keinen ,novio“ (Verlobten) zu finden und unverheiratet zu bleiben. Ein großer Teil versucht daher als Dienstmädchen, Küchenhilfe, Zimmermädchen o.a. in die Stadt zu kommen, womit in der Regel die endgültige Abwanderung aus dem pueblo eingeleitet ist. Manche zurückkommenden jungen Männer gehen dann, wenn sie keine „novia“ mehr finden, einen ähnlichen Weg.

Wir verzichten auf eine genauere Analyse der angedeuteten Auflösungserscheinungen im Dorfzusammenhang der arbeitenden Bewohner, um genauer herauszuarbeiten, inwiefern die Orientierung an dörflichen Verkehrsformen ein Element der Kapitalismuskritik von Arbeitern ländlicher Herkunft ist. Um Mißverständnisse vorzubeugen: Wir meinen nicht, daß die Kritik an Verkehrsformen ausschließlich bestimmend noch zentral für das Kapitalismus-Verständnis der emigierten Arbeiter ist. Die Ablehnung bezieht sich natülich in erster Linie auf die Ausbeutung, die erzwungene "Brachlegung" der Arbeitskraft und die vielen unmenschlichen Auswirkungen der Profitwirtschaft, die etwa dazu zwingt, den Lebensunterhalt durch Arbeit in fremden Ländern suchen zu müssen. Auch zielen die Emigranten, mit ihrer Verarbeitung lebensgeschichtlicher Erfahrungen im Ausland, nicht bewußt gegen den Kapitalismus - jedenfalls nicht in ihrer überwiegenden Mehrheit - sondern greifen großstädtische Verkehrsformen auf einer zunächst klassenneutralen und vorpolitischen Ebene an. Im Lichte der Überlegungen, die Abschnitt I. skizziert hat, meine ich aber, daß die Erfahrungen sozialer Entfremdung und der Rückbezug auf ein stark gemeinschaftliches Dorfleben ein wichtiges Ferment in einer proletarischen Bewegung und Gegenkultur sein können, die über den Produktionsprozeß hinaus weitere Aspekte gesellschaftlicher WirkJichkeit umgreift.

Die Arbeiteröffentlichkeit im pueblo neigt deutlich dazu, das Ortsleben in Absetzung von der Stadt zu idealisieren. Dabei unterscheidet man nicht prinzipiell zwischen einer spanischen und einer ausländischen Großstadt. Viele Arbeiter sehen die Erfahrungen ihrer Emigrationszeit als Extremfall der Umstände, die sie etwa in Barcelona zu erwarten hätten. Allerdings räumen sie ein, daß die Sprachschwierigkeiten im Ausland und die Trennung von der Familie spezifische Probleme der Emigration sind.

Dabei fällt auf, daß aus der Darstellung des Stadtlebens in „Alemania“ - auf die Erfahrungen in diesem Land wird sich die Untersuchung beschränken - die persönlichen Entsagungs-, Krisen- und Entfremdungs-Erlebnisse ausgespart bleiben. Danach befragt, biegen die Emigranten entweder ab oder formalisieren das Gespräch etwa durch folgendes Spiel: Man trägt mechanisch irgendwelche Begriffe des Deutschen vor, an die man sich erinnert - besonders beliebt sind Zahlenangaben und zeitliche Periodisierung - und erkundigt sich nach der Bedeutung beliebiger spanischer Wörter im Deutschen.

Dieses erfolgreichere Ablenkungsmanöver gibt dennoch indirekt Aufschluß über Schwierigkeiten der Emigranten mit sozialen Verkehrsregeln im Ausland: Das Sprachverhalten in andalusischen pueblos fällt durch seine ausgebildete extraverbale Symbolik und eine betonte Kommunalisierung der Sprechakte auf. Es war nicht möglich, sich ohne ständige Beachtung von Gestik und Mimik in die Sprache der Ortsbe- 
wohner hineinzufinden. Die Bedeutung der extraverbalen Symbolik ließ sich besonders auffällig an der Kommunikation mit Taubstummen im pueblo beobachten, mit denen ausgedehnte gestische Unterhaltungen geführt wurden' wie überhaupt Taubstumme, körperlich und geistig Verkrüppelte nichtsozial stigmatisiert und ausgeschlossen werden, sondern über eine offene Anerkennung ihres Gebrechens in das soziale Leben einbezogen werden. Einige Rückkehrer stellten ihre Kritik an sozialen Verkehrsformen der ausländischen Großstadt vor allem in mimischen Nachahmen dar. Wie sehr das Sprachhandeln in der Spachwahrnehmung der Andalusier eingeht, mag das Verständnis der deutschen Wendung ,,komm zi, komm za is in einem Ort verdeutlichen. Allgemein bekannt, wurde sie einhellig mit ,klauen "übersetzt, weil eben die Handbewegung, mit der ein Deutscher sie zu begleiten pflegt, dort das Zeichen für „Diebstahl" ist.

Die nicht-verbale Symbolik dient vor allem der Herstellung und Aufrechterhaltung der sozialen Beziehung im Gespräch. Wenn wir nicht Gestik, Geschichtssprache und Tonfall unserer Sprecher mitmachten, versandete die Unterhaltung sehr schnell. Man schien den Eindruck zu gewinnen, wir seien an einer Fortführung des Gesprächs nicht sonderlich interessiert. Gestik, ständige Modulation der Lautstärke und singender Sprechduktus bekunden das Engagement an einer Kommunikation, während die Landbewohner uns sozial vertraute Normalformen eines Gesprächs als stillschweigende Aufkündigung der kommunikativen Beziehung deuten.

Die Feststellungen zur Sprechweise der andalusischen Arbeiterschaft legen nahe, Sprachprobleme der Arbeitsemigranten aus ihren Schwierigkeiten mit den kommunikativen Normalformen im Ausland zu erklären. So beherrschten die meisten Emigranten auch dann kaum die deutsche Sprache, wenn sie über Jahre in Deutschland gearbeitet hatten. Die Aussprache der wenigen deutschen Worte, die sie kannten, war ihnen oft nicht geläufig, die Worte wurden fragmentarisch, ohne Kenntnis von Regeln der Satzbildung, aneinandergereiht. Dabei korrelierten insgesamt die Sprachkenntnisse nur schwach mit der Dauer des Auslandsaufenthalts (42).

42 Daß die Sprachprobleme ausiändischer Arbeiter vor allem eine Frage der sozialen Verhaltensregeln im Ausland sind, und die schlechten Sprachkenntnise eine Folge verweigerter Kommunikation, wird von spanischen Arbeitern in Westdeutschland und Westberlin offen zugegeben. Dabei verbindet sich die Erfahrung mangelnder Sprachorientierung mit der Erfahrung sozialer Diskrimination. Die vielfache Zurïck weisung der Gastarbeiter durch ihre deutschen Kollegen führt oft dazu, daß selbst klassenbewußte Arbeiter einen scharfen Trennungsstrich zwischen ihrer Nation und den Deutschen, incl. der Arbeiterschaft, ziehen. Damit endet - dies ist kein Allgemeinurteil - der Rassismus vieler deutscher Arbeiter in einer umgekehrten Abgrenzung auch linksgerichteter ausländischer Arbeiter, für die internationale Solidarität nach ihren Lebenserfahrungen zum Abstraktum und vorläufig durch überwiegende Orientierung auf eine soziale Umwälzung im eigenen Herkunftsland verdrängt wird. Wir zitieren dazu aus einem Gespräch mit einem älteren spanischen Arbeiter, das wir nach vorheriger Absprache eigens zum Komplex "Sprachprobleme“ führten:

„,Ob ich viel Gelegenheit habe, Deutsch zu sprechen? Aber nein, denn die Deutschen sind einfach widerlich, ,ihre Herzen sind mit Nägeln durchbohrt'. Mit einem Ausländer reden sie nicht. Daß jemand ihre Sprache nicht beherrscht, fällt ihnen zur Last. Sie zucken dann mit den Schultern und erwidern: ,nicht verstehn“. Sie geben sich überhaupt keine Mühe, einem zu helfen, wenn man in ihrer Sprache nicht zurechtkommt. 
Daß sie mit der Verständigung im fremden Land nicht zurechtgekommen seien, gestanden manche Emigranten jedoch nicht ein. Sie waren, vor allem anderen Arbeitern im Ort gegenüber, bemüht, sich als Kenner der deutschen Sprache herauszustreichen. Dieses Verhalten verweist auf eine weitere Eigenheit, neben der Erfahrungsverdrängung, die an der Verarbeitung der Auslandserfahrungen durch manche Emigranten auffällt: Sie spielen gern den großen Mann, der sich überall und immer zurechtfand, der von den deutschen Kollegen voll anerkannt war und sie zu Freunden hatte, während sie umgekehrt die Diskrimination auf die Türken in Alemania projizierten, die allgemein als Menschen mit verwilderten Sitten und als Messerstecher gelten; und sie erwiesen dem machismo der Männeröffentlichkeit ihre Reverenz, indem sie von Abenteuern mit einer Unmenge ausländischer Frauen berichten.

Diese Aufschneidereien, die unter Rückkehrern iedoch nicht der Regelfall sind, machen ungewollt Identitätskrisen deutlich, die der Auslandsaufenthalt bei vielen Arbeitern auslöst. Sich-persönlich-herausstreichen verletzt nämlich das ausgeprägt vorhandene Gleichheitsbewußtsein im sozialen Verkehr und kollidiert mit dem Verbot gegenseitiger Konkurrenz. Obwohl diese Emigranten offensichtlich die persönliche Anerkennung wenigstens im pueblo wiedergewinnen wollten, die ihnen durch ihre allseitige Diskriminierung im Ausland versagt blieb, isolieren sie sich, wenngleich begrenzt, gerade durch ihr Aufschneiden von anderen Arbeitern. Sie werden oft verspottet, oder man übergeht ihre Protzerei mit Schweigen. Übrigens bekundet sich

10 Jahre arbeite ich in derselben Fabrik. Aber die Deutschen reden nur unter sich, nicht mit mir. Bei der Arbeit braucht man nicht viel reden, da genügt es, wenn der Vorarbeiter auf einem Zettel mitteilt, was ich an Material brauche. Und an der Maschine kenne ich mich selber am besten aus. Seit Jahren arbeite ich mit zwei Deutschen, die nicht einmal in den Pausen mit mir reden. Nie sind wir nach der Arbeit ein Bier trinken gegangen (was mindestens im ländlichen Spanien allgemeiner Brauch unter Arbeitskollegen ist), jeder geht seine Wege.

Die Deutschen reden nicht mit uns, weil sie uns nicht im Land wollen, am liebsten würden sie uns herausjagen. Sie sind Nazis, Faschisten. Und sie bekämpfen den Kommunismus, ich dürfte bei der Arbeit nicht sagen, daß ich einer bin. Die Leute sind verrückt, sie haben ein Brett vor dem Kopf, sie sind betrunken gemacht durch die Lügen der Presse.

Die deutschen Arbeiter profitieren von uns. Sie tun so, als ob wir ihnen die Arbeitsplätze rauben, in Wirklichkeit geht es ihnen besser durch uns. Sie haben die besseren Jobs und nutzen das aus. Sie wollen sich zu Königen machen und über uns herrschen. Mein Vorarbeiter z. B. ist ein Arbeiter wie ich, aber er plustert sich auf und tut nichts. Ohne die Ausländer müßte er so arbeiten wie ich jetzt.

Mit den Wohnungsnachbarn führe ich keine Gespräche. Wir grüßen uns, mehr nicht. Jeder verschwindet in seiner Wohnung, eingeladen in ihre haben sie mich in den 8 Jahren nie. Von den wenigen Wortwechseln lernt man nie Deutsch. Noch schlimmer ist es auf der Straße. Wenn ich nach dem Weg frage, bekomme ich höchstens zur Antwort ,nicht verstehn", und schon gehen die Leute weiter. Auch in den Kneipen ist es nichts. Mich redet niemand an, und da ich selber schwer etwas sagen kann, bleibe ich für mich.“

Ein Andalusier, in dessen Fabrik die meisten Deutschen als Meister angestellt sind, begründete seine geringen Kenntnisse damit, daß ihn die Sprache nicht interessiert. Würde er sie beherrschen, geriete er sofort in Streit mitden Deutschen, denn er lehnt sie ab, weil sie ihn diskriminieren. Da sei es schon besser und sicherer, sich überhaupt nicht um die fremde Sprache zu kümmern. 
eine bleibende Bindung auch dieser Emigranten an den dörflichen Egalitarismus darin, daß sie ihre Ersparnisse nicht zur demonstrativen Abgrenzung des Lebensstils gegen die anderen Arbeiterfamilien einsetzen. Konträr dazu fällt bei manchen anderen Emigranten, Rückkehrern und Urlaubern, ein soziales Verblassen auf. In den Gesprächsgruppen der Straßen und Schenken stehen sie häufig als schweigende Zuhörer am Rande, den größten Teil ihrer freien Tage verbringen sie im Familienhaus, das ein Arbeiter sonst nur zum Schlafen und Essen betritt.

Aufschneiderei, soziale Randstellung und schwere Persönlichkeitskrisen findet man vor allem unter Emigranten, die sehr lange Zeit (mehr als 5, 6 Jahre) im Ausland waren und unter Urlaubern, die oft deutliche Schwierigkeiten zeigen, sich im kommunikativem Verkehr zurechtzufinden. Die Mehrzahl der Emigranten, insbesondere wenn sie schon länger zuriickgekehrt sind, unterscheidet sich jedoch in Lebensstil und Sozialverhalten nicht sichtbar von den zurückgebliebenen Arbeitern. Das wäre auch widersinnig, da mindestens die Hälfte der Proletarier und Kleinstbauern irgendwann im Ausland gearbeitet hat. Eher fällt auf, daß sich viele der ,unauffälligen“ Rückkehrer besonders betont mit dem pueblo und seinen sozialen Verkehrsformen identifizieren.

Die schweren Identitätskrisen vieler Emigranten werden zum Teil aus traumatischen Sozialerfahrungen verständlich, die sich durch Abweisung und Absonderung vom sozialen Leben im fremden Land noch verschärfen. Die herrschende Psychatrie hat das sehroberflächlich und mißverständlich mit dem sog. ,Entwurzelungssyndrom“ oder der „Heimwehreaktion" diagnostiziert, die man vor allem bei Gastarbeitern ländlicher Herkunft findet. Es handelt sich um depressive Zustände, geäußert in der Wahrnehmung körperlichen Zerfalls und körperlicher Krankheiten, vor allem der Verdauungs- und Sexualorgane. Diese „leibnahe Depression“ verbindet sich häufig mit einem Gefühl der Auflösung als Person. „Mir ist als sei ich ein Anderer, ich bin verändert, die Leute schauen mich an und merken es" (ein Süditaliener - nach Laffranchini in Praxis 54, 1965). „Das Leben verläßt mich, ich fühle kein Leben mehr in mir. Die Kraft verläßt den Körper. Der Körper ist so schwer, daß ich ihn keine hundert Meter tragen kann. Ich habe kein Vertrauen mehr zu meinem Körper." (Ein Süditaliener - nach Poeck, Dt. Medizinische Wochenschrift, Jg. 87, H. 28, 1962)

Wir haben schon darauf hingewiesen, daß die Lebensformen der Volksklassen in andalusischen pueblos - und hierin dürften sie sich von einem süditalienischen, anatolischen oder mazedonischen Dorft nicht unterscheiden - eine Anerkennung der besonderen Persönlichkeit eines Menschen zuläßt, ohne dadurch den engen sozialen Zusammenhalt aufzulösen und die Norm gegenseitiger Gleichheit zu verletzen. Ersichtlich im Gegensatz zur Ermöglichung stark personengebundener Ich-Identität stehen die mehr statusorientierten Sozialbeziehungen in spätkapitalistischen Großstädten. Verbunden mit einer größeren Distanz im sozialen Verkehr, wird hier die Person mehr nach allgemeinen sozialen Merkmalen eingeschätzt, wobei diese Merkmale auch die Erwartungen an das soziale Handeln der Personen bestimmen. Obwohl eine vollständige Durchsetzung der ,Status-Identität" der Aufhebung menschlicher Sozialbeziehungen gleichkäme, gilt doch, daß sie Flexibilität und Personalismus des sozialen Verkehrs stark überlagert. 
Die Arbeitsemigranten aus andalusischen pueblos erfahren vor dem Hintergrund ihrer gewohnten Verkehrsformen die Statusidentität der Großstadt als soziale Entfremdung. Eine Standardbemerkung, mit der sie den Unterschied zum Leben im Heimatort verdeutlichen ist: ,hier kennt jeder jeden, dort kennt niemand den anderen". Diese Feststellung bezieht sich auch auf die Arbeitsverhältnisse in der Fabrik, die im Gegensatz zur Landarbeit jede Kommunikation blockieren und außerdem für die Emigranten keinen nur einigermaßen überschaubaren und geglückten sozialen $\mathrm{Zu}$ sammenhang bilden. Da die Emigranten meistens ihre Familie zurücklassen, können sie der Anonymisierung nur schwer über die Fortsetzung von Primärgruppenbeziehungen gegensteuern. Hinzukommt die Abweisung durch Einheimische aufgrund des sozialen Abstraktums ,Arbeiter aus einem anderen Land“.

Die Bedrohung der persönlichen Identität läßt sich auch nicht über Beziehungen innerhalb der eigenen Nationalität neutralisieren. Das Arbeiterwohnheim etwa, in dem sich über $50 \%$ der andalusischen Arbeiter in der BRD konzentrieren, erlaubt wegen seines rigiden Überwachungssystems und die erzwungene Kollektivität des Wohnens in überbelegten Zimmern keine Wiederherstellung der aus dem Herkunftsgebiet vertrauten Verkehrsformen. Bei aller Reserve, die gegenüber der standardisierten Umfrage von Maria Borris zur Situation ausländischer Arbeiter in Frankfurt (Ausländische Arbeiter in einer Großstadt, 1974) angebracht ist, stellt sie diesen Aspekt doch deutlich heraus: Die allgemeine Kritik am Wohnheim zentriert sich um die Leitmotive: „Das Wohnheim ist ein Gefängnis, ein KZ“", ,es leben zu viele Menschen auf einem Raum, die sich in alles einmischen": ,man hat dort kein Privatleben" (43) Die Überwachung des Alltagslebens, soweit es a-politische Züge hat, kontrastiert deutlich mit den Verhältnissen in südspanischen Orten. Aus dem engen sozialen Zusammenhang der Männeröffentlichkeit im pueblo sind mit Essen, Waschen und Schlafen gerade die - der Familie vorbehaltenen - Bereiche ausgespart, auf die sich der Verkehr der Emigranten im Wohnheim zwangsweise konzentriert. Nach Auskunft einiger Emigranten in Südspanien vermeidet man es denn auch, im Wohnheim mit Nachbarn des eigenen Orts zusammenzuleben. Das führe zu Streit und Prügeleien, wobei man sich vor Augen halten muß, daß physische Aggressionshandlungen im Alltag der kleinen Orte heute eine Schande für die gesamte Familie der Akteure sind

$43 \quad$ Ein Beispiel für die erzwungene Kollektivität des Arbeiterwohnheims sind in Deutschland die Kasernen der Opel-Werke, deren Wohn-,,Qualität" eher über dem Durchschnitt liegen dürfte. (Opel hatte in der Frovinz Cadiz einen Anwerbeschwerpunkt). Im Wohnheim von Rüsselsheim, Sommer 1972, hatte jedes Zimmer vier Betten, bei einer Raumgröße von im Schnitt 16 qm. Für je 26 Personen stand eine Dusche zur Verfügung, je 70 Personen teilten sich 12 Herdflammen in der Küche. Häufig waren die Bewohner eines Zimmers in verschiedene Schichten eingeteilt und störten sich daher ständig in ihrem Tages- und SchlafRhythmus. (nach Guillermo Diaz Plaja, La Condicion Emigrante, Madrid 1974).

Die Bezeichnung des Wohnheims als KZ ist unter spanischen Arbeitern allgemein geläufig. Sie verweist darauf, daß die Arbeiter zusammengepfercht leben und von der „A Außenwelt “ abgeschlossen werden. (Viele Wohnheime darf man nur mit besonderer Erlaubnis und zu besonderen Besuchszeiten betreten, davon abgesehen, daß dem anderen Geschlecht der Zutritt völlig verwehrt ist.) Schließlich auf die despotische Gewalt, mit der die ,Heimleiter" in das Alltagsleben der Emigranten eingreifen. Für Gastarbeiter in Wohnheimen ist die despotische Kontrolle des Kapitals nicht einmal im Reproduktionsbereich aufgehoben. 
und dementsprechend selten vorkommen.

Auf die Anonymisierung sozialer Beziehungen in der ausländischen Großstadt reagieren die Arbeiter vom Land üblicherweise so, daß sie möglichst jeden sozialen Verkehr in der Fremde meiden. Das soll am Alltag einiger andalusischer Arbeitsemigranten in einem Westberliner Wohnheim verdeutlicht werden. Das Wohnheim befand sich auf dem Gelände der Fabrik, in der die Arbeiter ein Jahr lang Beschäftigung fanden. Obwohl ihnen die Öde des Hauses und die ständigen Kontrollen durch den Aufseher verhaßt waren, verbrachten die Südspanier fast ihre gesamte Freizeit in den Zimmern oder im Tagesraum; nur gruppenweise besuchten sie gelegentlich und für kurze Zeit die nächstliegende Kneipe. Einziger regelmäßiger Kontakt zur deutschen Außenwelt war der Einkauf; notwendige Gänge zur Krankenkasse, dem Arbeitsamt oder der Polizeistation wurden unter Angst und in extremer Verunsicherung unternommen. Häufig bat man uns hier um Begleitung. Selbst das in spanischen Ortschaften gepflegte ,paseo", ein zielloser gemeinsamer Bummel in den Straßen, vermied man. Dazu fehlte in der fremden Stadt der soziale Rahmen, die Menge der Umherspazierenden, die wechselnden Unterhaltungen, diegegenseitigen Zurufe. Ihre Zurückgezogenheit begründeten die Arbeiter mit dem schlechten Wetter, dem Lärm in den Straßen, die gleichzeitig leer an Menschen sind, den hohen Vergnügungspreisen, den fehlenden Sprachkenntnissen und der sozialen Distanz der Einheimischen (44).

Die konsequente Vermeidung jedes sozialen Verkehrs in der fremden Stadt erklärt sich sicher zum Teil aus der Extremsituation des Auslandsaufenthalts. Am Beispiel des damals 28jährigen Jose M. läßt sich aber klarmachen, daß sie auch eine generelle Ablehnung städtischer Verkehrsformen zum Ausdruck bringt. Jose stammt aus einer Landarbeiterfamilie aus Südostspanien, die nach Madrid zog, als er 17 Jahre alt war. Bis zu seinem Arbeitsvertrag in Westberlin war er als Bauarbeiter in Madrid und im katalanischen Küstengebiet tätig. Wie viele Abwanderer vom Lande zog er

$44 \quad$ In Wetzlar hat eine Gruppe spanischer Arbeiter, die nicht in Wohnheimen leben muß, die Verhältnisse in drei Wohnheimen der Umgebung untersucht und veröffentlicht. Diese Untersuchung ist zugleich Anklage wie Aufruf an die spanischen Emigranten zu Solidarität und gegenseitiger Hilfe. Sie stellt die zum Teil vollständige Abgeschlossenheit der Bewohner, selbst von der spanischen Kolonie außerhalb des Wohnheims, deutlich heraus. „Es gab viele, die während vieler Jahre nichts anderes gesehen hatten als die Arbeit, den Schlafraum, die Arbeit, den Schlafraum ...". Für dieses Vergnügen zahlen sie pro Bett, in Schlafhallen von 5- 6 Personen durchschnittlich, um 90 DM. $97 \%$ haben keine Freundin, also keine Möglichkeit, ein einigermaßen normales sexuelles Leben zu führen. Und wie soll man mit einem Mädchen schlafen, wenn 3 Männer dabei zuschauen? Nur $12 \%$ haben in ihren Zimmern jemals Besuch empfangen, die nicht ihre Arbeitskollegen sind - bei einer durchschnittlichen Aufenthaltsdauer von $31 / 2$ Jahren! Die Beschäftigung in der freien Zeit beschränkt sich, neben essen, auf Fernsehen, das man nicht versteht, Bier trinken, Karten spielen, Lesen.

Die Arbeiter ziehen folgendes Resultat ihrer Untersuchung: ,all das macht die Situation ziemlich klar.: Die Wohnbedingungen sind schlimmer als in Gefängnissen und eines Menschen unwürdig. Das überrascht aber nicht weiter, da im Kapitalismus nicht auf den Menschen, sondern auf das Geld geschaut wird, und mit den Gastarbeitern verdient man eine Menge. Wir sind für die Deutschen in jeder Hinsicht ein Geschäft, wir sind die modernen Sklaven."

(aus: impulso. Revista libertaria No. 11, Mai 1974, Wetzlar, Silhöferstr. 7) 
sich ein Magengeschwür zu. Hier verschlimmerte es sich binnen weniger Monate so, daß er operiert werden mußte. Jose wirkt depressiv, er spricht müde und schleppend und im Gegensatz zu südspanischen Gepflogenheiten ohne Gebärden und mit monotoner Stimme. Als er nach seiner Magenoperation über Wochen krank geschrieben war, blieb er, den Einkauf ausgenommen, immer im Heim, obwohl er gleichzeitig über Kopfschmerzen durch die schlechte Zimmerluft klagte. Auch den Jahresurlaub verbrachte er durchgehend im Heim. Jose versicherte immer, für ihn sei es gleichgültig, ob er in Madrid oder in Deutschland lebt. Die großen Städte bieten nirgendwo ein annehmbares Leben. Statt zurïck nach Madrid, ginge er lieber in eine kleine deutsche Ortschaft, die nach seiner Auffassung mehr dem Leben im pueblo gleicht. In Madrid hat er keine Freunde - um in einer Stadt einen Freund zu finden, müsse man wenigstens 20 Tage suchen. Auch die Feste sind in den Städten ohne Reiz; in seinem Heimatort dagegen würde man die Feste mit viel alegria und Gesang verbringen, sich mit Familie, Freunden und Nachbarn vereinigen.

Durch die Abwanderung vom Dorf ist für Jose jeder soziale Lebenszusammenhang, in und mit dem er sich identifizieren kann, zerstört. Seine Freunde hat er verloren, mit den Eltem versteht er sich nicht mehr, eine Freundin findet er nicht und das anonyme Leben der Städte ödet ihn an. Unter diesen Umständen ist es ihm gleichgültig, ob er in den Häuserschluchten eines der Vororte von Madrid oder einem eingezäunten Fabrikgelände in Westberlin lebt. Die Emigration in das fremde Land ist nur die konsequente Fortsetzung der ökonomisch erzwungenen Abwanderung vom pueblo, die den entscheidenden Bruch in seinem Leben markiert.

\section{Großstadtkritik und dörfliche Gemeinschaft}

Trotz der Verdrängung der Emigrationserfahrungen in der Ortsöffentlichkeit kristallisieren Gespräche allgemein gebräuchliche Schlüsselbegriffe heraus, nach denen die Emigranten ihr kritisches Verständnis des Stadtlebens organisieren. Es sind dies: „Lärm" und „Streit", beides kontrastiert zur „Ruhe“ des pueblo, das Bild von den geschlossenen Türen der Stadthäuser, im Unterschied zu den offenen Türen im Ort, das Leben auf den Straßen, den Kneipen und den öffentlichen Verkehrsmitteln, die Gemeinsamkeit (union) und Gleichheit (igualdad) des Zusammenlebens im pueblo, der man die Trennung der Menschen in den Städten entgegensetzt. Die Erfahrungen im Ausland umreißt weiter der Hinweis auf die dort herrschende Kälte, wie sich auch bestimmte Außerungen über das Kneipenleben auf das Ausland beziehen. Das Bild vom kalten, regnerischen Wetter, seltener das vom abstoßenden Kneipenleben, findet ${ }^{\circ}$ gelegentlich auch für die nordspanischen Industriezentren Anwendung. Manchmal wird auch die schlechte Luft und das ubelriechende Trinkwasser der Stadt der guten Landluft und dem frischen Wasser der Brunnen entgegengesetzt - dieser Symbolik bedienen sich vorwiegend ältere Leute, die nie im Ausland und selten in einer Großstadt waren.

Mit Ausnahme der „union“ und der ,igualdad“, die jedoch im Klassenbewußtsein der Landarbeiter, Kleinbauem, Pächter, Handwerker und Händler Andalusiens 
eine lebendige Tradition haben, beziehen sich die als Gegensatzpaar gegliederten Schlüsselbegriffe alle auf sinnlich greifbare Merkmale von Dorf-undStadtle ben. Gleichzeitig symbolisieren die sprachlichen Darstellungen allgemeine begriffliche Bedeutungen, die weit über die unmittelbar angesprochenen Erfahrungsgehalte hinausreichen. Diese Art der Wirklichkeits deutung kennzeichnet durchweg die geistige Auseinandersetzung der arbeitenden Ortsbewohner mit ihrer gesellschaftlichen Situation. Die sprachliche Darstellung bestimmter sozialer Umstände muß sinnlich faßbar sein, ohne doch in ihrer Bedeutung auf den evozierten Erfahrungsgehalt beschränkt zu bleiben. Die ständige Sicherung des Erfahrungsbezuges sozialer Deutungsmuster hat, im Unterschied zur Sprechweise intellektualisierter Schichten, den Vorzug, an eine intersubjektive Erfahrungswelt anzuknüpfen und so eher zu kollektiv anerkannten Deutungen der sozialen Wirklichkeit zu gelangen. Die erwähnten Schlüsselbegriffe formulieren denn auch ein allgemeines Bewußtsein des pueblo über Dorf- und Stadtleben.

Aber auch ein Nachteil dieser Verständigungsweise liegt auf der Hand: Sie begünstigt eine Beschränkung der Deutungsmuster auf sinnlich Faßbares und erspart eine explizite Darstellung der allgemeinen Zusammenhänge oder Strukturen, auf welche die Begriffe anspielen. Es war darum in Gesprächen über Dorf- und Stadtleben sehr schwierig, eine Erläu terung der Schlüsselbegriffe und -wendungen über die evozierten Erfahrungsgehalte hinaus zu erhalten, über die eine Einigung schnell erzielt werden konnte. Die folgende Betrachtung der Schlüsselbegriffe soll derartige Erläuterungen nachträglich rekonstnuieren.

Die ,sinnliche Abstraktion“ wird besonders deutlich in der Darstellung von Sozialerfahrungen durch atmosphärische Bilder. „Dort ist es immer kalt", ,es regnet viel“", ,die Sonne scheintnicht", ,,die Luft in den Städten und den Fabriken ist schlecht", „das Wasser ist ungesund" - das sind ständig wiederkehrende Außerungen der Emigranten über das Leben im Ausland. Sie erläuterten die Unerträglichkeit des dortigen Lebens, oft werden sie als Gründe einer vorzeitigen Rückkehr angeführt. Es würde der Mitteilungsabsicht der Emigranten widersprechen, nähme man die atmosphärischen Bilder nur für Symbolisierungen von Sozialerfahrungen. Vielmehr neigen viele Arbeiter dazu, die Konnotation solcher Äußerungen auf den angeschnittenen sinnlichen Gehalt zu beschränken. Das zeigt aber mehr ihre Schwierigkeiten an, die Auslandserfahrungen abstrakt zu explizieren. Manchen Arbeitern gelingt es, ihre Sozialerfahrungen durch weitere Entfaltung der sinnlichen Bilder darzustellen. Bezeichnend dafür ist die folgende an das Klimabild anknüpfende Aussage zur deutschen Lebensweise:

„Das Wetter dort ist schlecht, es regnet viel und es wird früh Nacht; selbst die Tage sind dunkel, denn der Himmel ist fast immer bedeckt. Die Dunkelheit macht die Menschen traurig und bedrückt, und daher kommt es, daß man in Alemania so wenig alegria trifft. Das ist wie mit den Vögeln: Scheint die Sonne, dann singen sie und flattern herum, kommen aber Wolken und Regen dann bleiben sie still und verkriechen sich."

Hier wird die Spontaneität und Entfaltung sozialer Beziehungen - ein abstrakter Sachverhalt - an sinnlichen Erfahrungen nicht nur dargelegt, sondern zugleich in seiner Zwangsläufigkeit einsichtig gemacht.

Die Beziehung atmosphärischer Bilder auf Sozialerfahnungen in den Städten 
wurde direkter am Schlüsselbegriff des ,Lärms ${ }^{6}$ hergestellt, dem man die Ruhe des Dorfes entgegensetzt. Er bezieht sich zunächst auf den Lärm des motorisierten Verkehrs in den Städten. Doch ist weniger die Erfahrung größerer Lautstärke entscheidend - mit den spielenden Kindern und den lauten Unterhaltungen geht es auf den Gassen und Gemeinschaftshöfen andalusischer Orte keineswegs immer ruhiger zu. Gemeint ist vielmehr die Unüberschaubarkeit des Verkehrs an Autos und Menschen in den Städten. Der Emigrant kann die Vielzahl der Ereignisse in der Stadt nicht überschauen und sieht sich ständig von unvorhersehbaren Vorfällen bedroht - als Beispiel werden meist Verkehrsunfälle angeführt. Das Bild vom Lärm komprimiert die Hilflosigkeit, Verunsicherung, den Orientierungsverlust und eine diffuse Furcht derEmigranten vor einem unübersehbaren Geflecht von Personen, Sachen, Ereignissen, mit dem sie das städtische Straßenleben konfrontiert. Sie deutet auf die weitere Erfahrung hin, daß die äußeren Umstände eine soziale Verständigung auf den Straßen der Stadt blockieren. Ein Emigrant verglich die Menschenmengen der Großstadt mit einem diffusen Bienenschwarm. „Auf den Straßen surren die Leute aneinander vorbei. Wenn sie sprechen, so gedämpft und unverständlich für uns, hört es sich an wie das Summen von Bienen." Die Diffusität und Vielfalt des sozialen Verkehrs negiert gerade die Aufnahme sozialer Beziehungen, wie sie in den Straßen des pueblo üblich und vertraut ist. Darum widerspricht es der Lärm-Metapher nicht, wenn Emigranten die Verödung des Lebens im Ausland betonen. Die Städte dort werden oft als tot bezeichnet. Niemand singt auf den Straßen, es gibt keine lauten Zurufe, keine spielenden Kinder und keine Schenken - oder jedenfalls strahlt das Leben in der Schenke nicht auf die Straße aus. ,Wenn die Menschen von der Arbeit kommen, verschwinden sie sofort in ihren Häusern" Dieses triste Leben kontrastiert so ziemlich in allen Punkten mit dem Alltag im pueblo und erst recht mit seinen Festen, wenn sich alle Bewohner auf den Straßen vereinigen.

Bevor wir auf diesen Aspekt der Kritik am Stadtleben näher eingehen, bedarf der Gegenbegriff der ,tranquilidad“, der Ruhe, einer Erläuterung. Mit ihm umreißen die Bewohner am häufigsten die Vorzüge des pueblo. Viele Emigranten begründeten durch Hinweis auf die tranquilidad des Ortes ihre Entscheidung, provisorisch im Ausland zu arbeiten und die Trennung von der Familie vorübergehend in Kauf zu nehmen, als für immer in eine spanische Großstadt abzuwandern und so jede feste Bindung an den Heimatort zu verlieren.

Unter der Ruhe des pueblo versteht man vor allem seine soziale Überschaubarkeit. Hier kennt jeder jeden, man übersieht alles, was sich im Ort so tut, man kennt sich in den sozialen Gepflogenheiten aus. Ein ehemaliger Emigrant, der jetzt wie viele Rückkehrer die Vorzüge des Dorflebens ganz besonders herausstreicht, erklärte die „tranquilidad“" wie folgt: „Hier kenn ich mich überall aus. Wenn ich durch die Straßen gehe, werde ich nicht durch unvorhersehbare Ereignisse überrascht. Es kann mich nicht plötzlich ein Auto überfahren und auch sonst kann ich ganz beruhigt sein: Es gibt hier weder Diebstahl noch sonstige böse Taten." Diese Vertrautheit des sozialen Verkehrs bindet man nicht an die Tatsache, daß man im Ort geboren und aufgewachsen ist; vielmehr vertritt man die Auffassung, daß sie in den großen Städten wegen der Bewohner, der Wohnweise in Hochhäusern, der Funktionalisierung der 
Straße für den motorisierten Verkehr prinzipiell nicht erreichbar ist.

Entsprechend verweist der Begriff „tranquilidad" auch auf die Zusammengehörigkeit der Bewohner des pueblo, und er wird darum gelegentlich durch Hinweis auf die hier übliche union oder die Wendung ,Wir sind hier eine Familie " bzw. ,wir leben sehr familiär" erläutert. Damit spielt man - neben dem ausgebildeten überfamiliären Gemeinschaftsleben auf den Straßen, in den Bars, den Läden und Häusern auf Verpflichtungen gegenseitiger Hilfe unter den Arbeiterfamilien an, die den pueb1o im engeren Sinn bilden. Obwohl sich das taditionelle System der Nachbarschaftshilfe in vielfacher Hinsicht gelockert hat, hat es doch in einigen Bereichen bleibende Geltung. Als Beispiele seien die Stellung der Alten, die Hausnachbarschaft, das Verhältnis Kleinhändler-Arbeiterfamilien und die Totenzeremonie ange führt.

Für die Versorgung und Pflege der alten Menschen im Ort sind durchweg die Familienangehörigen zuständig. Wie die Unterhaltssicherung durch arbeitsfähige Burschen, die oft für Jahre ins Ausland gehen, ist diese Verpflichtung eine sehr strenge Regel. Ortsbewohner von R. konnten nur eine Ausnahme nennen. Die Einhaltung der Regel wird vom gesamten pueblo ïberwacht, wer seine alten Eltern nicht versorgt, muß mit informellen sozialen Sanktionen rechnen. Familienangehörige ferneren Verwand tschaftsgrades - wie Neffen und Nichten - sind für die Verpflegung kinderloser Alter zuständig, allerdings nicht verpflichtet, sie in ihrem Haus aufzunehmen, sie $\mathrm{zu}$ waschen und $\mathrm{zu}$ pflegen. In dieser Hinsicht muß sich ein kinderloser Alter selbst zurechtfinden, teilweise endet das - und das markiert eine Grenze der gegenwärtigen Dorfsolidarität - mit seiner Internierung in ein Altersheim, dessen Verhältnisse man allgemein mit einem Gefängnis vergleicht. Alten, die keine Familienangehörigen im Ort haben, wird von den Nachbarn geholfen. Man gibt ihnen, wenn sie nichts haben, zu essen und schafft minimale Voraussetzungen dafür, daß sie sich, wie es im pueblo heißt, , das Leben suchen können“. Juan Vecerra und seine Frau befanden sich in dieser Situation. Die Nachbarn vermachten ihnen eine Strohhütte zum Wohnen, einige Möbel und einen Esel, mit dem der Mann durch autonome Landarbeit, wie Kohlebrennen und Wildfrüchte sammeln, seinen Unterhalt sichern kann.

Neben der allgemeinen Nachbarschaftshilfe im pueblo gibt es auch die Hausnachbarschaft im engeren Sinn. Man trifft sich abends vor dem Haus, erzählt und diskutiert, bewacht die Kinder. Häufige Besuche und vielerleit Gesten der Hilfe und der Freundschaft sind wesentlich, die Nachbarschaft wäre ungenïgend, würde man sich nur ,guten Tag" sagen und sich nach dem Befinden des anderen im Vorbeigehen erkundigen. Man kann den Nachbarn Werkzeug ausleihen, Wasser holen, wenn er einen Brunnen hat und ihm Lebensmittel zum aufbewahren geben, wenn er einen Kïhlschrank hat. Ist einer krank, wird er besucht; und ist einer alt und ohne Verwandte, dann sorgen die Nachbarn für das Nötigste. Die wenigen aus dem Dorf, die ein Auto haben, übernehmen fuir andere die Erledigungen in der Stadt. Auch in Notfällen kann man auf die Nachbarn zählen: Als Dolores sich entschloß, nach Deutschland zu fahren, weil sie von ihrem Mann, der dort arbeitet, schon seit mehreren Monaten keine Post mehr bekommen hatte und auf einen Telefonanruf hin die Nachricht erhielt, er habe einen Unfall gehabt, da war ihre Nachbarin sofort bereit, ihre fünf Kinder in der Zwischenzeit bei sich aufzunehmen und zu versorgen. 
In den arbeitslosen Monaten sind viele Familien darauf angewiesen, ihren täglichen Lebensunterhalt durch Verschuldung an die Dorfläden zu beschaffen. Solange dem Ladenbesitzer nicht selber das Geld zur Beschaffung der Waren ausgegangen ist, muß er das Anschreiben gestatten - es sei denn, er riskiert einen Boykott durch andere Familien und in besseren Zeiten. Die Schulden werden in der Regel von den Verdiensten der nächsten Arbeitsperioden zurickgezahlt. Nicht alle Familien sind aber dazu imstande. In diesem Fall verbietet es die dörfliche Sozialmoral, daß der Händler durch eine Anrufung des staatlichen Gerichts die Schulden einzutreiben versucht. Die Schulden gelten als verfallen. Die Sanktion der Arbeiterfamilien gegen einen solchen Versuch wäre ein Boykott des Ladens. Auch wenn die Familie zahlungskräftig ist und dennoch ihre Schulden nicht begleicht, ist der Weg zum Gericht ausgeschlossen. In diesem Fall erzwingen aber die informellen sozialen Sanktionen des pueblo, daß der Händler das ausstehende Geld bekommt.

Wenn jemand im Ort stirbt, so ist es Brauch, daß sich Familie und Freunde im Haus des Verstorbenen versammeln, um gemeinsam die Totenwache zu halten. Dem heute noch verbal vertretenen Ideal nach sollte, jedenfalls in kleineren Orten, diese Versammlung von allen Bewohnern besucht werden, um die Lücke zu schließen, die der Verstorbene in den pueblo gerissen hat. Diese sehr wörtlich zu nehmende Idee des Zusammenschlusses liegt auch der Beerdigungszeremonie am folgenden Tag zugrunde, wenn die Frauen im Haus des Toten bleiben, während die Männer den Leichenzug zur Kirche bilden. Die Randstellung des religiösen Aktes wird daran deutlich, daß die meisten Männer, um die Totenmesse zu meiden, außerhalb der Kirche warten, aber nachdem der Tote wieder hinausgetragen wurde, alle den engsten männlichen Angehörigen die Hand drücken. Anschließend begleiten die Männer des Ortes den oder die Verstorbene zum Friedhof.

Wir sehen also: die Emigranten spielen soziale Überschaubarkeit, Gemeinschaftsleben und nachbarschaftliche Gegenseitigkeit im pueblo gegen die sozialen Verkehrsformen der großen Städte aus. „Ruhe“ hat aber für sie auch die Bedeutung ,friedlicher Harmonie" und wird insofern Raub, Laster und Untaten allgemein in den Städten entgegengesetzt. Als Erklärung verweist man auf die Möglichkeiten informeller sozialer Kontrolle im Ort: Während in der großen Stadt, wo niemand den anderen kennt, ein Gauner leicht untertauchen kann, überwachen die Leute im pueblo gegenseitig ihre Handlungen und beugen so Raub und Diebstahl vor. Manche Emigranten beriefen sich auf häufige Raubüberfälle und Prügeleien in großen Städten, wenn sie ihr zurückgezogenes Leben in ausländischen Wohnheimen rechtfertigen wollten. Andere münzten das Thema „pelea" in eine Kritik an der Gleichgiltigkeit der Stadtbewohner gegenüber Geschlagenen, Hilflosen und Verletzten um. Sie bezogen sich dabei ausschließlich auf Westeuropa. Ihre Kritik zielte weniger gegen die Tatsache alltäglicher Gewalttätigkeit, sondern darauf, daß sich niemand spontan in der Verteidigung Unterlegener und der Hilfe Verletzter engagiert.

Doch ist das Bild vom lasterhaften und gewalttätigen Stadtleben für sich kein bemerkenswerter topos; auffällig war aber, daß man Streit und Gewalttaten als häufige Vorkommnisse auch vieler größerer Nachbarorte nannte, und gelegentlich darauf 
verwies, daß es „früher“, vor Jahren, im eigenen pueblo viel Streit gegeben habe. In der Erläuterung der zuletzt genannten Aussage war man betont reserviert, einige meinten in gezielter Unbestimmtheit, damals hätten die Leute im Ort - lebensgeschichtlich ihre Väter, wenn nicht gar sie selbst - wenig „Kultur “" gehabt - „tener cultura“ bezieht sich nach einer der gebräuchlichen Bedeutungen auf Lebensformen der herrschenden Klasse. Ähnlich erklärte man die Gewalt in anderen pueblos durch die dort ansässigen vielen Zigeuner - sie bilden in Andalusien eine auch von den Arbeitern diskriminierte Minorität, andererseits gelten sie als die geschworenen Feinde der allgemein gehaßten ,guardia civil“", der bewaffneten Polizei im Ort. Schließlich schrieb man die Gewalttaten in deutschen Großstädten gern den Türken zu, deren Verhalten man in auffälliger Analogie zu den einheimischen Zigeunern und den brutalen Marokkanergarden im faschistischen Heer 1936 deutete.

Die Tatsache, daß im Gegensatzpaar pelea-tranquilidad verdrängte Erfahrungen aus dem eigenen Lebenszusammenhang auf die Großstadt projiziert werden, gibt Anlaß, politische Implikationen der öffentlichen Selbstdeutung des Dorflebens zu erwägen. Die Mehrzahl der von uns besuchten Orte waren vor 1936 Zentren der Sozialbewegung in Andalusien. Der Faschismus hat diese Sozialbewegung und ihre entwickelte politische Öffentlichkeit gründlich zerschlagen. Obwohl die Klassenantagonismen für das Bewußtsein der Arbeiter kaum an Schärfe verloren haben und in indirekten Wendungen auch häufig angedeutet werden, sind offene Gespräche über gesellschaftspolitische Themen im pueblo wegen des hohen Risikos streng tabuisiert. Dabei wird „Politik“ im allgemeinen Sprachgebrauch mit Kritik am System der Klassenherrschaft und seinem politischen Überbau, manchmal direkt mit „kommunistischerEinstellung“" gleichgesetzt. Daß eine politische Diskussion in eine Richtung gegen die herrschende Klasse geht, ist fuir die andalusische Arbeiterschaft quasi eine grammatische Regel. Die proletarische Öffentlichkeit, nicht allerdings vertrauliche Gespräche unter guten Freunden, war noch 1975 im pueblo vollständig entpolitisert. Nicht die Übernahme integrativer Ideologien, sondern die Verbannung politischer Themen aus der öffentlichen Kommunikation ist das Kennzeichen dieser Entpolitisierung. Vor allem jüngere Arbeiter haben heute, wie ein Emigrant es nannte, in politischer Hinsicht eine „leere Mentalität" (45).

Das Bild der „Ruhe“ spielt somit auch auf die blutige Befriedung durch den Faschismus an. Traditionell sahen sich die Landarbeitersiedlungen nicht als friedlich,

45 Aufschlußreich sind dazu die Beobachtungen des Sozialisten Manuel Cortes, der 1969 mit einem veränderten Dorfleben konfrontiert wird, nachdem er 30 Jahre im Versteck zugebracht hat: ,Mehr als alles andere hat mich die Jugend hier verblïfft . . . Als erstes fiel mir auf, daß sie über nicht s anderes Bescheid wissen als darüber, wie man sich amüsiert. Sie denken über nichts anderes nach, weder über die Regierung, die Nation noch die Belange des Dorfes. Wenn ich zu ihnen spreche, stehen sie da und starren mich mit offenem Mund an, als sei ich irgendein Wundertier aus der Vergangenheit. . . . Sie sind völlig ingnorant und en tpolitisiert. " (Aus R. Frazer, Im Versteck, S. 246/47)

Der Ort Mijas ist allerdings nicht verallgemeinerbar, da er in der Touristenzone liegt.

Auch muß hervorgehoben werden, daß die jungen Arbeiter wenig vom historischen Trauma ihrer Väter belastet sind. Das zeigt sich an der enormen Mobilisierung gerade junger Arbeiter in Klassenaktionen und ihren schnellen politischen Lemprozessen, wie wir sie seit Francos Tod erleben. 
was schon der Ausdruck ,hacerse pueblo“, „sich zum pueblo machen“ belegt, der in der Selbstinterpretation von lokalen Volksaufstän den gebräuchlich war. Die heutige, in der Dorföffentlichkeit bekundete, Anerkennung der Ruhe im Sinn von „Befriedung " setzt aber, der wirklichen Interessenlage der Arbeiter entsprechend, eine projektive Phantasietätigkeit frei, die die latente Tendenz zur gewaltsamen Aktion auf andere Orte und Regionen verlagert, sowie auf Randgruppen wie Zigeuner, und im Ausland, Türken, um so gleichzeitig der öffentlichen Verurteilung der Gewalt Genüge zu tun. Die Umsetzung der latenten Gewalttätigkeit in projektive Phantasie erklärt wohl auch das große Interesse, das speziell Wildwestfilme im Ort finden. In eine ähnliche Richtung weist das strenge Verbot von Karnevalsfesten im pueblo: Es sei damit zu rechnen, daß manche die Maskerade dazu benutzten, unerkannt einen reichen Kapitalisten umzulegen - so wurde das Verbot von einigen Arbeitern erklärt.

Kehren wir zum Schlüsselbegriff „tranquilidad“ zurück, soweit er sich auf Gemeinsamkeit und Nachbarschaftlichkeit der Verkehrsformen bezieht. Ihre Kritik am Stadtleben stellen die Emigranten vor allem an drei Lebensbereichen dar, deren Trennung in der Stadt und deren Zusammenhang im pueblo sie betonen: Die Straße, das Haus und die Kneipe (bar). Eine stehende Wendung ist, daß die Türen in der Stadt immer verschlossen sind, wogegen sie im pueblo immer offenstehen. Diese erfahrungsmäßig direkt einlösbare Feststellung verweist auf eine weitreichende Differenz der sozialen Lebensweise, die man abstrakt mit dem Gegensatz von zunehmender Privatisierung der Kleinfamilien im Spätkapitalismus und den intensiven Nachbarschaftsbeziehungen der Volksklassen mediterraner Agrostädte und Dörfer umreißen kann. Eine verschlossene Tür im pueblo bedeutet: „,niemand ist da“ oder ,,man schläft“. Bis in die späte Nacht stehen darum die Türen offen und das bedeutet: ,jedermann kann das Haus betreten". Die Anwesenheit von Verwandten, Nachbarn und Freunden im Haus ist daher eine selbstverständliche Gewohnheit. Umgekehrt zeigt die offene Tür an, daß die anwesenden Bewohner die Beziehung zum Gemeinschaftsleben auf der Straße nicht unterbrochen haben, jederzeit bereit sind hinauszugehen, nach den neuesten Ereignissen zu schauen und ein Schwätzchen mit den Nachbarn zu halten. Auch die Hausarbeit der Frau im pueblo vollzieht sich daher im ständigen sozialen Verkehr mit den Nachbarinnen. Das reicht vom morgendlichen Straßenfegen über den gemeinsamen Einkauf, zu dem sich die Frauen oft abzuholen pflegen, bis zur Waschtätigkeit, die traditionell an öffentlichen Waschplätzen stattfindet, aber selbst in Orten mit Wasserinstallation häufig auf Gemeinschaftshöfen der Landarbeitersiedlungen öffentlich vollzogen wird. Der familiäre Lebenszusammenhang ist, - das symbolisiert die offene Tür - mit den Nachbarschaftsbeziehungen eng verbunden.

Umgekehrt verweist das Bild der geschlossenen Tür auf die Trennung der beiden Lebensbereiche insbesondere in zentraleuropäischen Großstädten. „Man kann mit den Deutschen 10 Jahre lang im selben Haus wohnen, ohne daß sie guten Morgen und guten Abend sagen"; "nach der Arbeit verschwinden die Leute in ihren Häusern und ziehen die Tür hinter sich zu. Das Leben dort ist sehr traurig". Einige Arbeiter setzten die konkrete Darlegung der Kritik an sozialen Verkehrsformen fort, indem sie behaupteten, daß das ständige Leben hinter verschlossenen Türen gesund- 
heitsschädlich sei. In den abgedichteteten Wohnungen verbrauchen diese Menschen schnell die wenige Luft und stecken sich gegenseitig mit Krankheiten an. Indirekt verdeutlichen diese Emigranten die Enge und den Mief der kleinfamiliären Absonderung, wie die durch sie erzeugte soziale Verkrüppelung der Familienmitglieder.

Ein zweiter Bereich, der in der Kritik am Stadtleben ständige Erwähnung findet, sind die sozialen Verkehrsformen in den bars. Im pueblo bilden die bars, und bei gutem Wetter die zu ihnen gehörige Straßenecke, die sozialen Zentren der Männergesellschaft. Hier trifft man sich vor und nach der Arbeit, sowie an arbeitslosen Tagen, in „tertulias“, den jedermann offenen Gesprächsgruppen und zum Kartenoder Domino-Spiel. Obwohl die meisten Arbeiter trinken, besteht in den Schenken kein Konsumzwang, getrunken und gezahlt wird aber grundsätzlich gemeinsam. Sauberkeitsvorschriften und Einschränkungen der Lautstärke sind unbekannt. Die bars ermöglichen und garantieren in jeder Hinsicht eine entfal tete soziale Kommunikation.

Dem andalusischen Arbeiter stellen sich demgegenüber die Verkehrsregeln vornehmlich in deutschen bars - die Arbeiterkneipen spanischer Großstädte gleichen noch weitgehend dem dörflichen Typ - als Disziplinierung und Verfremdung sozialer Beziehungen dar. Negativ hervorgehoben werden vor allem der Konsum- und Sauberkeitszwang, die gedämpften Unterhaltungen, die Abgeschlossenheit der Gesprächsgruppen und die für einen Andalusier provokatorische Sitte, gesondert zu bestellen und zu bezahlen. Die bar ist kein Ort der sozialen Vereinigung, sondern nur eine weitere Einrichtung zur Separierung der Menschen in einer Großstadt; sie hebt die dortige Verkümmerung sozialer Beziehung nicht auf, sondernbestätigt sie neu. „Dort in der bar reden die Leute kaum miteinander. Sie sitzen allein vor der Theke, den Kopf auf die Ellenbogen gestützt und rauchen und trinken ein Bier nach dem anderen." Dem entspricht, daß andalusische Emigranten in Deutschland die bars entweder völlig meiden oder - seltener - nur für kurze Zeit betreten.

\section{Klassensolidarität und Klassenbewußtsein auf dem Land}

Auch wenn es mit den Emigranten gerade Arbeiter sind, die die dörflichen Sozialbeziehungen so sehr gegen die städtischen hervorheben, ist dieser Gegensatz doch dem Augenschein nach klassenneutral bestimmt. Tatsächlich spricht aber die Idealisierung des Dorflebens eine sozio-kulturelle Lebenseinheit der Arbeiterfamilien an. Auf die Doppelbedeutung des Wortes ,pueblo“ als sozialgeographische Siedlungseinheit und als Klassenbegriff haben wir schon hingewiesen. Welche Relevanz sie für den Vergleich städtỉscher mit ländlichen Verkehrsformen hat, wird an zwei zentralen Normen sozialen Zusammenlebens deutlich, die die andalusischen Arbeiter gern gegen großstädtische Verhältnisse vorbringen. Es handelt sich um die „union“, die Einheit, und die ,igualdad“, die Gleichheit der Ortsbewohner.

Der Begriff , union" wurde, soweit auf den sozialen Alltag im pueblo bezogen, als Parallelbegriff zur ,tranquilidad", der Ruhe, gebraucht. Auf ihn beriefen sich die Emigranten, wenn sie Zusammengehörigkeit und nachbarschaftliche Gegenseitigkeit im Ort herausstrichen. Die ,union“ ist aber nicht nur Basisregel im Alltagsleben, son- 
dern zugleich eine zentrale Norm der Klassensolidarität. Eindrucksvoll bekundeten das die Aktionen der andalusischen Sozialbewegung vor 1936, als ganze Orte, bis zu den Dienst- und Kindermädchen der Bourgeoisie, geschlossen in den Generalstreik traten, oder die Arbeiter das Angebot des Staatsapparats, einige durch Bauarbeiten über die Hungerjahre zu retten, ablehnten, weil nicht alle Arbeitslosen im Ort eingestellt wurden. Die zentrale Bedeutung der union in Klassenaktionen wird heute (Stand 1975) in Gesamtspanien an der Tatsache deutlich, daß eine geschlossene Streikfront in Betrieben vor allem dann zustande kommt, wenn sich die Aktionen gegen die Entlassung einiger politisch exponierter Kollegen richten. Das trifft etwa für den Streik bei SEAT, Barcelona $1971 \mathrm{zu}$, der die seitdem andauernden Aktionen in dieser Fabrik einleitete, ebenso für die „Sintermetal“" in El Valles bei Barcelona 1973, die 6000 Arbeiter von Bazan in El Ferrol 1972, deren Aktionen den Volksstreik in dieser Stadt einleiteten, oder den Streik der Textilfabrik Intelhorce in Malaga 1973. Die Beispiele ließen sich beliebig vermehren. Daß die union nicht nur die direkt Betroffenen, sondern die ganze ortsansässige Arbeiterschaft einschließlich ihrer Familien bis hin zum Kleinhandel und den Angestellten großer Geschäfte einschließt, zeigen die großen Stadtstreiks von El Ferrol (1972), Vigo (1972) und Pamplona (1973), Bajo Llobregat (1974) und Valladolid (1974/75). Die Menschen, die diese Streik- und Solidaritätsbewegungen tragen, sind zum größten Teil in ländlichen Gegenden aufgewachsen und während der letzten 15 Jahre mit der beschleunigten Industrialisierung (und der andauernden Auspowerung der Landgebiete) in die großen Städte gezogen.

Wir gehen auf den Zusammenhang von union und Klassenaktion in den großen Städten Spaniens nicht näher ein, sondern beschränken die Darstellung auf Landarbeiterstreiks in der Umgebung von Jerez de la Frontera, Provinz Cadiz, 1973 und 1974 (46):

In der Feldregion um Jerez sind 14.000 ha mit Weinreben bepflanzt. Weinbau ist kaum mechanisierbar, die Arbeiten werden daher in erster Linie von etwa 9.000 Spezialisten verrichtet, die in Jerez und umliegenden Landorten leben. Von ihnen haben nur etwa 600 eine feste Anstellung, diese "fijos" wohnen meist auf den großen Gutshöfen außerhalb der pueblos. Der Rest, weit mehr als $90 \%$, findet nur während der Saisonmonate Arbeit, vor allem wenn die Weinstöcke beschnitten werden müssen und zur Zeit der Emte. Sie arbeiten 6 bis selten 8 Monate im Jahr und da sie wie alle Gelegenheitsarbeiter kein Arbeitslosengeld erhalten, müssen sie vom Verdienst dieser Zeit auch die restlichen Monate leben. Die Spezialisten haben ihre Tätigkeit durch Praxis erlernt, „durch Zuschauen und Nachmachen", wie man es nennt, angelernt

$46 \quad$ Ich stïtze mich auf:

Gespräche und Informationen 1973 in Orten, die in unmittelbarer Nachbarschaft der "Mark von Jerez" liegen; auf Berichte der Comisiones Obreras dieser Region, die in Barcelona zu einer unveröffentlichten Broschüre zusammengestellt wurden; einige Korrespondentenberichte an die Zeitschrift der KP Spaniens "Mundo Obrero".

Wie die Norm der "union" die Arbeitsbeziehungen von Landarbeitern im einzelnen bestimmt, hat dargestellt: Juan Martinez Alier, Labourers and Landowners in Sou thern Spain, London 1971. Alier hat in einjähriger Feldforschung in der Feldregion Cordoba die Profitwirtschaft der Großgüter, Arbeitsformen und Klassenbewußtsein der Landarbeiter um 1965 untersucht. Seine ausgezeichnete Studie kann man jedem Interessierten empfehlen. 
werden sie hauptsächlich über Familienbeziehungen oder durch gute Freunde. Man sagt ihnen einen ausgeprägten Berufsstolz nach, der sich aber - wie wir sehen werden - nicht als Abgrenzung ,nach unten" manifestiert. So verrichten sie in der Regel neben ihrem Beruf keine andere ländliche Lohnarbeit, um anderen Arbeitern nicht lebensnotwendige Verdienstquellen zu rauben. Vor allem während der Ernte, aber auch bei anderen Arbeiten, werden die Spezialisten von einer unbestimmten Zahl ungelernter Arbeiter unterstïtzt, die einen geringeren Lohn erhalten. Diese Ungelernten werden in aller Regel aus denselben Orten wie die gelernten Weinarbeiter angeworben.

Die ,viticultores“, wie man die gelernten Weinarbeiter nennt, haben um Jerez eine lange Kampftradition. Die Erste Internationale in Sanlucar, einem wichtigen Ort in der Weinbauregion, setzte sich zur Zeit ihrer Gründung 1872 hauptsächlich aus ihnen zusammen. Mitglieder waren damals in den ersten Monaten 200 Weinarbeiter, 100 Landarbeiter, 29 Schuster und 6 Frauen. Sie organisierten eine zeitweilige proletarische Machtergreifung in Sanlucar (47), die in vieler Hinsicht eine Miniaturauflage der Pariser Kommune war und deren Charakter Engels grïndlich verkannte, als er sie als ferngesteuertes Werk der Bakunisten kritisierte. Zur Zeit der Republik waren so ziemlich alle viticultores in der Arbeiterbewegung organisiert (allein die Weinarbeiter-Sektion der C.N.T. in Jerez zählte 1.200 Mitglieder) (48), wenngleich gespalten zwischen Sozialisten und Anarchosyndikalisten (der Mehrheit). Dabei scheint es, daß die Linie der Spaltung mehr zwischen den pueblos als in ihnen verlief.

Im März 1959 haben die Tagelöhner des Weinbaus um Jerez ihren ersten grossen Streik nach dem Bürgerkrieg entfesselt. Seitdem haben sie beinahe jährlich die Arbeit niedergelegt und so erreicht, daß ihre Löhne heute deutlich über den durchschnittlichen Abfindungen an Weinarbeiter im spanischen Süden liegen (49). Arbeiterkommissionen haben sie früh hervorgebracht, ihre organisatorische Bedeutung in den Arbeitskämpfen kann kaum unterschätzt werden (50). „Wenn wir kämpfen so erklärte man im pueblo Trebujena - ist jeder Weinarbeiter in der Mark ein Mann der Comisiones Obreras. Darum gewinnen wir die Streiks" (51).

Die Bedeutung der ländlichen Klassensolidarität soll an einem Erntestreik der Weinarbeiter 1973 und zwei Arbeitskämpfen der folgenden Jahre erläutert werden. Im Erntestreik standen neben der Forderung nach besseren Arbeitsbedingungen

$47 \quad$ vgl. Anm. 32

48 Aus ,,La Voz del Campesino“", Jerez 1932

49 Der Basislohn für das Beschneiden der Rebe lag 1966 in der Provinz Cadiz bei 200 pts., in Granada und Malaga bei 175 pts., in Cordoba bei 100 pts. (Nach Estudio Socioeconomico de Andalucia, Madrid 1970, Bd. I., S. 44). 1975 erreichten die Erntelöhne im grossen Weinbaugebiet Montilla bei Cordoba nur 2/3 der Löhne von Jerez.

50 In einem Gespräch hat uns ein kommunistischer Arbeiter genauer geschildert, wie die Comisiones Obreras um Jerez Arbeitskämpfe und Volksbewegungen organisieren. Der Mann arbeitet in einer Weinkellerei und hatte längere Zeit wichtige Funktionen als oppositioneller Syndikatsvertreter inne.

Abgedruckt in: Gewerkschaftsbewegung in Spanien, ed. von H.-W. Franz/Santiago Tovar, Westberlin 1976

51 Nach der Monatszeitschrift „Gaceta de Derecho Social", Madrid, Jg. V, Nr. 60, Mai 1976 
(7- statt 8-std. Arbeitstag, Bezahlung der zum Teil langen Anfahrtwege durch die Unternehmer u.a.) Lohnerhöhungen im Vordergrund. Das vertikale Syndikat (den Vorsitz in der Weinbausektion hatte damals der Großkapitalist Domecq!) hatte eine Erhöhung von 12,7\% beschlossen, die Weinarbeiter forderten eine Lohnsteigerung von $60 \%$ (z. T. auch $80 \%$, die Informationen sind hier nicht eindeutig), sie begründeten das mit dem unmäßigen Preis- und damit Profitanstieg für die Weintraube binnen eines Jahres: „,Das vertikale Syndikat, das die Unternehmer in den Händen haben, ist wie immer dabei, uns zu betrügen. Sie glauben, daß wir der jämmerlichen Erhöhung um 12,7 \% zustimmen, während sie den Preis der Weintrauebe um $100 \%$ erhöhen". Auch hätte die verordnete Lohnerhöhung nicht einmal die gestiegenen Lebenshaltungskosten kompensiert.

Im Verlauf des Arbeitskampfes sollte den Spezialisten, jedenfalls für die Erntearbeiten, die Forderung fast vollständig zugestanden werden, indem man ihnen eine Prämie von $50 \%$ zusicherte, während man die Ungelernten weiter mit den läppischen $12 \%$,abspeisen wollte. Daraufhin setzten sie Spezialisten den Streik mit dem Ziel fort, gleichen Lohn für alle zu erreichen und forderten - in ihren pueblos weitgehend erfolgreich - auch die Ungelernten auf, sich am Streik weiter zu beteiligen. Sie organisierten also einen Streik in erster Linie für die Sache anderer Arbeiter - oder besser: für die gemeinsame union! Die Begrïndung dafür war zweifellos, daß während der Ente Spezialisten wie Ungelernte dieselbe Arbeit verrichten und daher von der Arbeitstätigkeit her (wohl aber vom Spaltungsinteresse der Unternehmer) kein Anlaß besteht, die einen schlechter zu entlohnen. Einschränkend muß man für diesen wie die folgenden Streiks hinzufigen, daß sie îur von den Gelegenheitsarbeitern im Weinbau getragen wurden. Die 600 Festangestellten, die fijos, schlossen sich nicht an, die es dennoch taten, wurden umgehend entlassen. Auf die wenigen fiios können die Kapitalisten wegen der um ein Vielfaches größeren Reservearmme besonders wirksame Pressionen ausüben, und da sie auf den Gutshöfen leben, sind die Möglichkeiten der sozialen Kontrolle durch die Arbeiteröffentlichkeit der Landorte stark eingeschränkt.

Der Erntestreik endete nach einmonatiger Dauer (!) mit einer Niederlage, da die Unternehmer erfolgreich Streikbrecher aus ferner gelegenen Orten - großenteils aus anderen Provinzen - anwarben, die fuir die Weinernte um Jerez nicht zuständig sind. Andererseits mußten sie den gelernten Weinarbeitern die Prämie von $50 \%$ für die nächste Arbeitsphase zugestehen, den Ungelernten dagegen nur $22 \%$. Die zweite Phase des Streiks Frühjahr 1974 wurde durch ein Betrugsmanöver der Unternehmer im Syndikat provoziert: im „convenio colectivo", dem koliektiven Lohnvertrag, war vereinbart, daß die Löhne zu Jahresbeginn nach dem gestiegenen Lebenshaltungsindex neu berechnet werden sollten. Die 12 \% ige Lohnerhöhung wollten nun die Unternehmer mit den im Herbst vereinbarten Prämien verrechnen, legale Proteste der Arbeiter blieben, wie nicht anders zu erwarten, ohne Erfolg. Daraufhin traten 6.000 Spezialisten im April 1974 in den Streik. Da das jetzt anstehende Beschneiden der Rebe ausschließlich gelernte Arbeiter erforderte, trugen sie den Streik allein, stellten aber gleichzeitig ihre Forderung, Prämie und Lohnerhöhung zu trennen, für die zukünftigen Tätigkeiten der Ungelernten mit. Da die Spezialistenarbeit nur schwer durch auswärtige Streikbrecher ersetzbar ist, kapitulierten dieses Mal die mittleren 
Weinbauem vorzeitig und boten „,ihren“ Arbeitem - etwa 1/3 der Streikenden Arbeit zum geforderten Lohn an. Alle Arbeiter wiesen das als Spaltungsversuch zurück. ,Viele der Streikenden hatten schon die geforderte Erhöhung in der Tasche, als sie sich der Aktion anschlossen. Einmütig entschied man sich, den Streik solange fortzusetzen, bis für alle Arbeiter das Ziel erreicht sei."Das einheitliche Auftreten brachte den Weinarbeitern nach 24 Tagen den vollständigen Sieg.

Als im Winter 1974/75 in der Gemarkung um Jerez die Kollektivverträge erneuert werden sollten, bereiteten die Weinarbeiter, gestützt auf ihre Comisiones Obreras, den Kampf in einer Mischung legaler und außerlegaler Aktivität vor. Sie mobilisierten, wie wohl auch in früheren Kämpfen, durch Versammlungen auf dem Land, den Ortsplätzen und Kneipen - also den natïrlichen Zentren der Arbeiteröffentlichkeit -, zu denen sich die Arbeiter aus jedem pueblo zusammenfanden. Teilweise organisierten sie auch Versammlungen in der Arbeitersektion des Zwangssyndikats, die natürlich nicht von der eingesetzten Leitung genehmigt waren. Auf diese Weise beschlossen sie ihre Lohnforderungen, die sie dem Zwangssyndikat durch gewählte Delegierte vorlegten. Sie liefen auf eine Erhöhung von $25 \%$ hinaus, für gelemte Tätigkeiten 913, für ungelernte 815 pts. Wieder akzeptierten die viticultores keine generellen Lohnunterschiede zwischen sich und den Ungelernten, sondern wollten nur nach Tätigkeitsarten differenzieren. Als die Unternehmer im Zwangssyndikat ihre Forderungen ablehnten, traten sie ab Mitte Dezember geschlossen in den Streik. Der beharrlichen union konnten sich dieses Mal die fijos nicht verschließen, trotz aller Pressionen schloß sich ein großer Teil von ihnen der Bewegung an. Auch auswärts angeheuerte Arbeiter kehrten, als sie von den Streikenden informiert wurden, in ihre Orte zurück. Als die Regierung zu sog. „kommunitären Arbeiten“ wie Straßenbau, Wegeverbesserung usw., die gelegentlich zur Überbrückung der arbeitslosen Monate eingerichtet werden, keinen der streikenden Weinarbeiter anstellen wollte, boykottierte zumindest ein Teil der anderen Arbeiter aus den betroffenen pueblos die Arbeiten. „Gegen diese Machenschaften gaben die Arbeiter die Parole des ,entweder alle, oder niemand" aus." Auch hier zeigt sich die Rolle der union im Arbeitskampf.

Die Unternehmer hatten dieses Mal zwar keine Streikbrecher und nur wenige fijos, wohl aber die Natur auf ihrer Seite. Wegen der anhaltenden Trockenheit konnten sie die anstehenden Arbeiten, das Beschneiden und Pfropfen, lange hinauszögern, während die viticultores kaum ökonomische Rücklagen haben. Sie mußte verstärkt auf den Brauch des Anschreibens in den Läden zurïckgreifen. Dieser Zwang wird mit Sicherheit die Solidarität innerhalb der örtlichen Volksklasse weiter verstärkt haben (52). Nach einem Bericht aus „Mundo Obrero“, Anfang März 1975, dauerte

52 Nach unseren Kenntnissen hängt das lange Durchhaltevermögen der Weinarbeiter wesentlich von der Unterstiitzung durch die kleinen Ortsläden ab. Hier zeigt sich, wie eine Regel der Nachbarschaftlichkeit im pueblo (das Anschreiben beim Kaufmann) direkte Funktionen im Klassenkampf erhält.

Wahrscheinlich aus diesem Grund versucht gegenwärtig die Provinzregierung, durch bevorzugte Ansiedlung von Supermärkten in der ,Mark von Jerez" die vielen kleinen Läden kaputtzumachen. In derselben Linie liegt das kürzlich verhängte Verbot an kleine Bauern, direkt im Ort ihre Produkte zu verkaufen (diese Information nach der Tageszeitschrift von Cadiz, Juni 1976 
die Streikbewegung schon über 40 Tage an! Über den Ausgang des heroischen Kampfes sind wir nichtinformiert. Wir wissen nur, daß bei den Wahlen von Arbeitervertretern zum Syndikat die Comisiones Obreras in den Landgebieten um Jerez, die mit der Strategie, die Zwangssyndikate von innen her zu zerstören, wieder Kandidaten aufgestellt hatten, im Juni 1975 einen großen Sieg errangen.

Man muß sich vor Augen halten, daß unter dem faschistischen Regime Streiks verboten sind. Streikende können mit Geldstrafen belegt und zu jahrelangem Gefängnis verurteilt werden. Die guardia civil bediente sich auch gegenüber den Weinarbeitern massiver Einschüchterungsmethoden. „Von Beginn an streiften sie in Zivil verkleidet umher (um zu spionieren), besetzten die Zugänge zu den Gütern und drohten allen Vorbeikommenden, sie einzusperren, wenn sie ihre Kollegen, die zur Arbeit gingen, zum Aufhören überreden wollten. In den bars und Plätzen des pueblo spionierten sie Gruppen nach, fragten überall ,wer redet von Streik“. Taten so, als ob sie Leute verhafteten, bedrohten sie und ließen sie nach 20,30 Metern wieder frei“. Trotz dieser Repressionen und ihrer ökonomischen Zwangslage streikten die viticultores auch für die Sache der Ungelernten in der eigenen Branche! Für diese ausgebildete Klassensolidarität spielt sicher das dichte Gemeinschaftsleben der arbeitenden Bevölkerung im pueblo eine nicht unerhebliche Rolle. Die anderen Arbeiter, für die man sich einsetzt, sind nicht Unbekannte, sondern Leute, mit denen man befreundet oder sogar verwandt ist. Die union der Landarbeiter hat $u$. a. diese reale Lebenseinheit der Arbeiter im pueblo zur Voraussetzung. Negativ wird das daran deutlich, daß die fijos, die eben nicht der direkten sozialen Kontrolle ihrer Klasse im Alltagsleben unterliegen, meist abseits blieben. Vor allem aber zeigt es sich an der Tatsache, daß die Streikbrecher, deren Einsatz den Arbeitskampf 1973 scheitern ließ, aus anderen pueblos kamen.

Wir hielten uns zur Zeit dieses Streiks in vier pueblos der weiteren Umgebung auf. Aus zwei dieser Orte übernahm ein Teil der Arbeiter die traurige Rolle des Streikbrechers. Natürlich konnten wir als Fremde kaum über die politisch brisante Angelegenheit des Streiks sprechen. Dennoch machen die wenigen Informationen aus der Sicht dieser Standorte indirekt die Wichtigkeit der union für die arbeitende Bevölkerung deutlich. Wir erläutern das an einem Streikbrecher-pueblo, den wir ,La Campinera" nennen.

Die Männer aus La Campinera sind für die Weinlese in den entfernter liegenden Anbaugebieten nicht zuständig. Dieses Jahr gelang es jedoch den Weinkapitalisten, ungefähr 100 Arbeiter, fast die Hälfte der damals Arbeitslosen, zum Streikbruch zu verdingen, während ein mindestens ebenso großer Teil der Arbeiterschaft aus La Campinera die Anwerbung verweigerte. Diese Spaltung des pueblo schlug sich jedoch in den alltäglichen Sozialbeziehungen nicht sichtbar nieder. Die Streikbrecher wurden nur in vertraulichen Gesprächen vorsichtig kritisiert, man brach aber nicht den sozialen Verkehr mit ihnen ab und mied in den bars jede Auseinandersetzung über das heikle Thema. Zum Teil erklärt sich das aus dem Politiktabu in öffentlichen Gesprächen, zum Teil machte das Verhalten der Arbeiter sowohl untereinander wie im Streik die Begrenzung der Arbeitersolidarität auf den Umkreis eines pueblo deutlich. 
In einer Sache waren sich aber in La Campinera die Streikbrecher und die Arbeiter, die den Streik indirekt unterstiitzten, einig: Sie bewunderten die Geschlossenheit, die ,union" des den Arbeitskampf führenden Ortes Sanlucar, wo alle Arbeiter am Streik teilnahmen. Mit Respekt berichtete man von den schweren Sanktionen gegen Streikbrecher in Sanlucar - ein Mann wurde getötet, andere krankenhausreif geschlagen. Die Arbeiter von Sanlucar galten durchweg als "sehr gute Leute", denn - so ein Streikbrecher (!) - ,sie handeln einig und geschlossen. Entweder verweigern sie sämtlich die Arbeit, oder sie gehen bis zu den Frauen und Kindern alle in die Ernte". In der Gemarkung dieses Ortes arbeitete denn auch kein Bewohner aus La Campinera, zum Teil wegen des großen Risikos verprügelt zu werden, zum Teil sicher, weil sie die union der Arbeiter dieses Orts respektierten. Entsprechend begründeten auch die Streikbrecher ihre Tätigkeit in der Gemarkung von Jerez: Sie bestritten, daß die Leute aus Jerez überhaupt in den Streik getreten waren. Tatsächlich war damals die dortige Arbeiterschaft in der Frage des Streiks gespalten: Ein Teil der verfiggbaren Ungelernten nahm an der Ernte teil, eine union des pueblo bestand nicht. Ein Streikbrecher aus La Campinera meinte dazu: „Der Streik ist nur von den Leuten aus Sanlucar gemacht worden. Daß Jerez, wie du meinst, teilgenommen hat, stimmt nicht. Denn ein Streik wird immer vom ganzen pueblo getragen."

Dieses Beispiel macht die Bedeutung der „union“, als Norm der Arbeitersolidarität, im pueblo klar und verweist gleichzeitig auf Tendenzen lokaler Beschränkung. Keineswegs alle Arbeiter im pueblo waren jedoch der Auffassung, daß die Einheit des Klassenhandelns sich auf die Bewohner eines pueblo reduziert. Das beweist die Vielzahl der Männer in La Campinera, die trotz Arbeitslosigkeit am Ernteeinsatz nicht teilnahmen. Ein Emigrant begründete das mit Hinweis auf die traditionelle Kampfparole „o todos, o ninguno", alle oder keiner, die er dieses Mal auf die Arbeiterschaft als Klasse, unabhängig von ihrer Ortszugehörigkeit, bezog.

Wie die union, bezieht sich auch die ,igualdad“ vorrangig auf die sozialen Verkehrsformen der Ortsbewohner und streicht ihren klassenspezifischen Charakter heraus. Die Gleichheit, die das Ortsleben auszeichnet, erläuterte man immer als eine der Lebensweise, etwa in der häufigen Wendung: ,wir sind alle gleich im Essen, Schlafen und Arbeiten." Über die Forderung, denen im pueblo zu helfen, die weniger haben als man selbst, bezog ein Arbeiter das Gleichheitsbewußtsein direkt auf die union im Ort. Auch im kommunikativen Verkehr wurde die Gleichheitsregel beachtet. Niemand, der nicht die kollektiven Verbindlichkeiten des Dorflebens verletzt, darf in Unterhaltungen ausgeschlossen werden und es gilt als verwerflich, wenn sich jemand auf Kosten der anderen hervortut. Ein Landarbeiter begründete seinen Abbruch jeder Beziehung zu einem anderen damit, daß dieser sich immer herauszustreichen versucht und er betonte, daß er damit die Gleichheitsregel verletzt: „alle, die auf dem Land arbeiten, sind in der gleichen Lage, und sie müssen sich darum wie Gleiche behandeln. "Diskussionsstrukturen, wie sie in intellektualisierten Verkehrskreisen die Regel sind, werden im pueblo als permanente Verletzung des Gleichheitsbewußtseins aufgefaßt.

Die Betonung der Gleichheit aller Ortsbewohner führt in ihrer wörtlichen Fas- 
sung zu einem expliziten Widerspruch. So lebt in einem Ort La Campanera ein steinreicher Familienklan, der zusammen über mehrere 1000 ha Land sowie über die einzige Bäckerei und das einträgliche Dorfkino verfügte. Außerdem gibt es einige Bauern, die gemessen an ihrem Besitz als „,señoritos" - die abfällige Bezeichnung für große Grundbesitzer - gelten, ein paar Kleinunternehmer, die über prosperierende Geschäfte, Baulager, Lastwagentransporte und Landmaschinenverleih reich geworden waren, ein Arzt, von dem man berichtete, daß er Millionen scheffelt und sich nur um die Reichen kümmert, schließlich wohłhabende Angehörige des Verwaltungsapparats, wie Bürgermeister und Lehrer. Mit dieser Tatsache konfrontiert, betonten die Landarbeiter und Emigranten, daß die Staatsbeamten, da sie von auswärts kommen, nicht zum pueblo gehören, und daß der reiche Familienklan erst vor einiger Zeit von seinen Landgütern in den Ort gezogen sei (vor dem Faschismus war ihm der Boden zu heiß). ,In Wahrheit leben in diesem pueblo nur Arbeiter und ihre Familien, und du siehst ja auch, daß sich in den bars nur Arbeiter vereinigen. Die Reichen kommen von auswärts und bilden ihren eigenen Kreis.“

Die andalusischen Arbeiter sehen die Gesellschaft dichtomisch in zwei Klassen gespalten. Die eine Klasse verfuigt über den Reichtum, hat das Bildungsprivileg und ihre Angehörigen brauchen nicht zu arbeiten. Die andere Klasse lebt in Armut, ist von der Bildung ausgeschlossen und verdient ihr Brot mit der Arbeit der Hände und dem Schweiß des Körpers. Arbeit und Armut der einen Klasse bedingen Reichtum und Faulheit der anderen. Die einen - das sind,wir, die Armen, die Ärbeiter", die anderen - das sind „sie, die Reichen, die Parasiten“. Zu welchem Lager etwa ein Händler, Kleinbauer, Handwerker oder Oberaufseher auf Landgehöften zählt, hängt von seiner praktischen Entscheidung im Klassenkonflikt ab.

Zum anderen Lager zählen vor allem die Kapitalisten. Man kann den latenten Klassenhaß gegen die señoritos nur schwer überschätzen, obwohl die Emigration die strikte Klassentrennung teilweise gelockert hat, da sie viele Arbeiter von der ökonomischen Macht der Agrarkapitalisten vorläufig unabhängig macht. Wenn aber Emigranten, was manchmal vorkommt, mit Söhnen der Reichen verkehren, werden sie von anderen Arbeitern kritisiert. „Früher haben die Reichen die Armen wie Hunde behandelt. Wenn man vor ihren Häusern um Brot bat, weil man hungert, haben sie einen verjagt. Wenn man mit einem gestohlenen Sack Erbsen erwischt wurde, haben sie einen verprügelt und schwer bestraft. Heute aber trinken die Emigranten (in Wirklichkeit sind es nur wenige), wenn sie im Urlaub sind, mit den Kapitalisten zusammen. Das ist schlimm. Die Armen sind schlechter als die Reichen, wenn sie mit diesen verkehren und vergessen, wie man sie früher erniedrigt hat."

Zur anderen Klasse zählen aber auch die intellektuellen Berufe wie Ärzte und Lehrer. Der Arzt hat meistens ein sehr schlechtes Ansehen im Ort. Er kommt meistens von auswärts und bereichert sich an den Krankheiten der Leute. Er bevorzugt die Reichen, die ihm viel Geld zahlen und vernachlässigt die armen Familien, die wenig geben können. Man weiß immer von Fällen zu berichten, wo der Arzt den Besuch bei einem Sterbenden verweigerte, weil seine Familie kein Geld hatte. In einem Ort hielt man uns vor, daß der Arzt, der vor Jahren mit einem Motorrad ins Dorf kam, jetzt einen Luxuswagen fährt, im vornehmsten Haus des Orts wohnt und den Bürger- 
meisterposten innehat; ..Alles hat er hier zusammengescheffelt".

Einen schlechten Ruf haben in der Regel auch die Lehrer. Man hält ihnen vor, den Schulunterricht zu vernachlässigen, wobei insgesamt ihre Tätigkeit nicht als Arbeit zählt. „Unterrichten - das ist keine Arbeit". Gelten ließ man noch das Schreiben, weil es mit den Händen verrichtet wird. Das tiefe Mißtrauen gegen intellektuelle Tätigkeit bekundete ein Alter, der nach längerer Überlegung zugestand, daß ein Lehrer, ,,wenn er mit dem Kopf denkt, sogar noch mehr arbeitet als etwa ein Bauer oder ein Maurer. Der Grund war das hohe Risiko, das er für seine geistige Gesundheit eingeht: „Denn wer mit dem Kopf denkt, überfordert seinen Verstand und wenn er das $\mathrm{zu}$ oft macht, wird er verrückt. Das ist genauso wie mit der Liebe: Wenn jemand eine Frau sehr stark liebt, muß er dauernd an sie denken und das macht ihn verrückt." Es sei angemerkt, daß die Zuordnung der Leute mit akademischer Ausbildung, ,la gente que tiene carrera", zum anderen Lager nicht objektivistisch verfestigt ist. Vielmehr hängt sie entscheidend vom Verhalten der Einzelnen ab. Ein Arzt, der sich nicht bereichert und um das Volk kümmert, ein Lehrer, der seine Ferien nicht verlängert, keine Extragelder kassiert und mit den Leuten im pueblo zusammenlebt - das sind hombres valientes, Menschen von Wert, sie gehören zu uns.

Insgesamt wird an Gleichheitsbewußtsein und Klassenbild die Tendenz deutlich, den örtlichen Lebenszusammenahng auf die ansässigen Arbeiterfamilien zu beschränken. Unter den zentralen Normen der union und der igualdad vereinigt der pueblo als sozialgeographische Einheit die Arbeiterfamilien, also den pueblo, als sozio-kulturelle Einheit der Volksklassen. Das gilt zwar nicht mehr als streng objektive Beschreibung, wohl aber bestimmt die Symmetrie von Ort und Volksklasse noch das Selbstständnis der ortsansässigen Arbeiter. Dabei werden die gemeinsamen Lebensbedingungen in den ausgebildeten Landarbeitersiedlungen explizit als proletarische Lage begriffen: „Wir hier haben alle kein Land, außer der Ecke im Friedhof, wir sind geschoren und müssen unser Leben suchen, als „eventuales “, Gelegenheitsarbeiter unsere Familien durchbringen -- oder eben emigrieren."

Allerdings leben in La Campinera, mehr noch in anderen andalusischen pueblos, einige kleine Bauern, Handwerker und Händler, die nicht- oder nur partiell auf gelegentliche Lohnarbeit oder gar Emigration angewiesen sind. Diese Schicht wird aber nicht aus dem sozialen Verkehr mit den rein proletarischen Familien ausgeschlossen, noch neigt sie zu einer Absonderung. Thre Ortszugehörigkeit wird durch den Arbeitsbegriff des pueblo, nach dem alle Bewohner durch manuelle Tätigkeit ihr Leben suchen müssen, gestützt und gerechtfertigt. Gemeinsamkeit und Gleichheit im sozialen Verkehr, sowie der Zwang zu arbeiten, sind die integrativen Kräfte, die im Selbstverständnis der Bewohner eine Spaltung in Arbeiterschaft und kleinbürgerliche Schichten ausschließen. Eine Klassengliederung, die nach dem Kriterium der Stellung zu den Produktionsmitteln vorgeht, widerspricht der realen Lebenseinheit der arbeitenden Bevölkerung im pueblo, die sich umgekehrt als klassenbewußte Gemeinschaft von den capitalistas, den als „Brotschlucker“ verspotteten Staatsbeamten sowie den Leuten mit ,carrera“", mit akademischer Ausbildung, eindeutig abgrenzt. Der proletarische Klassenbegriff wird, über das Thema der „Landlosigkeit", nur in solchen Gesprächskontexten vertreten, in denen eine Abgrenzung zu den in union und Gleich- 
heit einbezogenen kleinbürgerlichen Schichten ausgeschlossen ist.

Wir sehen also: Wenn die andalusischen Emigranten am Dorfleben die „Ruhe“, die ,union" und die Gleichheit der Bewohner hervorheben, so hat das wenig mit den Topoi bürgerlicher Kulturkritik zu tun, die sentimentale Sprüche über die verlorene Gemeinschaft des Landlebens klopft und die Anonymität der großen Städte beklagt. Vielmehr beziehen die Emigranten ihre Idealisierung des pueblos auf eine reale soziale Lebenseinheit der arbeitenden Bevölkerung in ihrer Heimat, und sie kritisieren zumindest tendenziell das westeuropäische Alltagsleben von diesem Standpunkt. Aus dem Blickwinkel der kapitalistischen Progression, die das Land zum Randgebiet der wenigen Industriezonen macht, seine Bewohner zur Abwanderung zwingt und die Landorte veröden läßt, sind ihre Vorstellungen rückwärtsgewandt und historisch überholt. Aus dem Blickwinkel einer revolutionären Neugestalltung gesellschaftlicher Verhältnisse und Beziehungen zielen ihre Vorstellungen zwar immer mehr in die Vergangenheit; die latente Idee, die sozialen Verkehrsformen ländlicher Volksklassen zu erhalten und wiederzubeleben, ist aber sicher nicht historisch überholt.

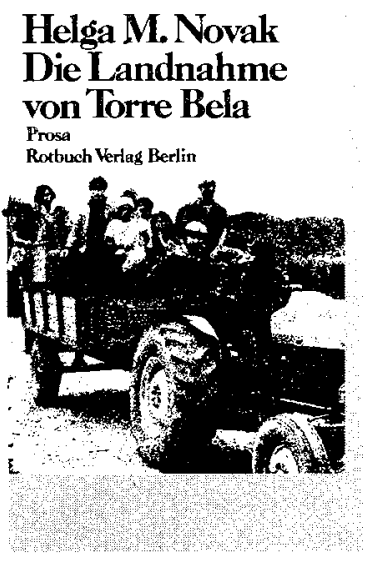

Rotbuch 153: Teil 1 dieses Rotbuchs analysiert die Wirtschaft und den Frankismus seit den vierziger Jahren. Teil 2 beschreibt die Entwicklung der Arbeiterkommissionen. Teil 3 beschäftigt sich mit der Kommunistischen Partei Spaniens. 160 Seiten. DM 8 (Abo 7)

Rotbuch 150: Bericht von Arbeit und Kampf auf Torre Bela, einem besetzten Landgut in Portugal. 72 Seiten. DM 7

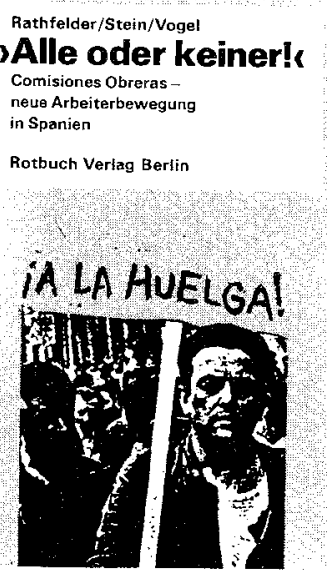

